\title{
INVESTIGACIONES ARQUEOLÓGICAS EN PACARÁN, VALLE MEDIO DEL RÍO CAÑETE: CURACAZGO DE RUNAGUANAC
}

\author{
Pieter VAN DALEN LUNA \\ UniversidAd NACIONAL MAYOR DE SAN MARCos \\ pvandalen2@hotmail.com
}

\section{RESUMEN}

Se presentan los resultados de las investigaciones arqueológicas desarrolladas en la localidad de Pacarán, valle medio del río Cañete. Como resultado de estas investigaciones se logró identificar sitios correspondientes a dos periodos de ocupación: Intermedio tardío representados por una entidad sociopolítica conocida como Runaguanac y el Tawantinsuyu.

Palabras Clave: arqueología, Cañete, valle medio, Runaguanac, Tawantinsuyu.

\section{Abstract}

The results of archaeological research conducted in the locality of Pacarán, half the Cañete River Valley are presented. As a result of these investigations was identified sites corresponding to two periods of occupation: Late Intermediate represented by a socio-political entity known as Runaguanac and Tawantinsuyu.

KEYworDS: Archeology, Cañete, middle valley, Runaguanac, Tawantinsuyu. 


\section{INTRODUCCIÓN}

El presente artículo está referido a los resultados del proyecto de investigación arqueológica de inventario, catastro y registro de los sitios arqueológicos del valle medio del río Cañete, jurisdicción del distrito de Pacarán, provincia de Cañete, departamento de Lima, proyecto auspiciado por la Municipalidad distrital de Pacarán y desarrollado el año 2006. Como resultado se obtuvo el registro de 38 sitios arqueológicos ubicados en ambas márgenes del río Cañete, muchos de los cuales presentan una compleja organización espacial y arquitectónica, pertenecientes en su totalidad al Intermedio Tardío y al Periodo Tawantinsuyu.

\section{LA CUENCA DEL RÍO CAÑETE}

La cuenca del río Cañete se encuentra ubicado en el extremo meridional del departamento de Lima y se constituye en la cuenca más extensa y más caudalosa del departamento. Presenta el mismo régimen que los otros ríos costeños, es caudaloso en verano y seco en invierno. El río Cañete tiene su origen en la laguna Ticllacocha, a $4600 \mathrm{msnm}$, recorriendo las provincias de Yauyos y Cañete, para desembocar al sur de la ciudad de San Vicente. La longitud del río Cañete, entre su nacimiento y su desembocadura es de aproximadamente 220 kilómetros, presentando una pendiente promedio de $2 \%$. Sin embargo, presenta sectores donde su pendiente es mucho más pronunciada, especialmente en la parte alta, llegando hasta el $8 \%$ en el tramo comprendido entre la localidad de Huancaya y la desembocadura del río Alis. A lo largo de su recorrido el río Cañete recibe el aporte de varios afluentes, entre los cuales cabe mencionar por la margen derecha los ríos Miraflores $\left(120 \mathrm{~km}^{2}\right)$, Yauyos $\left(102 \mathrm{~km}^{2}\right)$; la quebrada Huantulla de Carania $\left(54 \mathrm{~km}^{2}\right)$, Aucampi $\left(343 \mathrm{~km}^{2}\right)$ y por la margen izquierda los ríos Tomas $\left(450 \mathrm{~km}^{2}\right)$, Laraos $\left(182 \mathrm{~km}^{2}\right)$, Caccra $\left(635 \mathrm{~km}^{2}\right)$ y las quebradas de Tinco de Huantán $\left(424 \mathrm{~km}^{2}\right)$, Pampas $\left(133 \mathrm{~km}^{2}\right)$ y Tupe $\left(224 \mathrm{~km}^{2}\right)$, principalmente.

Las Formaciones ecológicas identificadas por la ONERN en la cuenca del río Cañete son:

1. Formación desierto subtropical: Topográficamente, esta formación presenta dos áreas bien definidas: una de ellas es la conformada por llanuras y colinas de relieve ondulado, dentro de la cual se encuentra el área agrícola del valle. La otra área, fuertemente accidentada es la conformada por las montañas que emergen aisladas dentro, de la formación, así como, también por las primeras estribaciones de la Cordillera.

2. Formación matorral desértico subtropical: Esta formación ecológica se extiende inmediatamente por encima del desierto subtropical, hasta los $2000 \mathrm{~m}$ aproximadamente. Su medio ambiente se caracteriza por presentar un clima de tipo árido y semicálido. Topográficamente, la formación presenta dos áreas bien diferenciables; una de menor extensión constituida por pequeñas terrazas al margen de las quebradas y por piedemonte, de suave inclinación, que son aprovechados por la agricultura. La otra es fuertemente accidentada y tiene mayor extensión, constituida por montañas con malezas poco densas.

3. Formación estepa espinosa montano bajo: Esta formación ecológica corresponde a la franja comprendida entre los 2000 y $3000 \mathrm{msnm}$. Su medio ambiente se caracteriza por presentar un clima de tipo semi árido y templado. De acuerdo a su topografía, esta formación muestra dos sectores bien diferenciables: uno constituido por las zonas agrícolas de quebradas y laderas, de relieve semi accidentado; y el otro conformado por montañas densas.

4. Formación estepa montano: Esta formación ecológica corresponde a la zona comprendida encima de la formación estepa montano bajo, está entre los 3000 y 3800 msnm. Su medio ambiente se caracteriza por presentar un clima de tipo subhúmedo y frío. De acuerdo a su topografía, esta formación muestra una configuración general montañosa accidentada, salpicada de áreas de suave pendiente que se encuentran principalmente en las faldas de los cerros y en las cercanías de las quebradas que llevan agua, de tal manera que en estas formaciones se puede hablar de dos sectores: áreas agrícolas 
de laderas y montañas húmedas. Dentro de este último sector, en los niveles superiores se encuentran dispersos algunos bosques residuales conformados por especies arbustivas y arbóreas.

6. Formación tundra pluvial alpino: Esta formación ecológica corresponde a la zona comprendida entre los 4800 y $5000 \mathrm{msnm}$, siendo por esto la zona de vida mas alta. La topografía es muy accidentada unida a las bajas temperaturas. Su medio ambiente se caracteriza por presentar un clima de tipo pluvial y gélido, es decir con abundantes precipitaciones. De acuerdo a su topografía, esta formación es muy accidentada

\section{UBICACIÓN Y MEDIO AMBIENTE DEL ÁREA DE ESTUDIO}

El área motivo del presente estudio se encuentra ubicado políticamente en el distrito de Pacarán, provincia de Cañete, región Lima; mientras que geográficamente se ubica en el valle medio del río Cañete (en ambas márgenes del mismo), uno de los ríos más amplios de la cuenca hidrográfica de la vertiente del Pacífico, en la costa central del Perú.

Este estudio tuvo como meta principal reconocer sistemáticamente el íntegro del patrimonio cultural que se emplaza dentro del referido distrito, bajo la modalidad de prospecciones arqueológicas sin excavación, explorando ambas márgenes de la cuenca y registrando metódicamente cada uno de los sitios arqueológicos identificados, obteniendo un catálogo o inventario detallado y completo que permitirá evaluar en diferentes niveles el potencial arqueológico, sirviendo de base a planes orientados al desarrollo socio-económico y científico de la región.

El río en esta zona, se orienta de noreste a suroeste. Los puntos extremos que delimitan el área de nuestro estudio son: entre la quebrada de Guagil (margen izquierda) y quebrada de Nigacho (margen derecha).

El área de nuestro estudio se caracteriza por presentar dos ecosistemas bien definidos: Uno conformado por el valle, de poco ancho, con una típica forma en "V", angosto y encajonado, con una vegetación arbustiva, arbórea y herbácea; y un ecosistema árido, conformado por los elevados cerros y las accidentadas quebradas que se unen al valle por ambas márgenes, donde predominan las formaciones vegetativas de tillandsiales y cactáceas, que crecen a expensas de la humedad.

\section{ANTECEDENTES DE ESTUdios ARQUEOLÓGICOS Y ETNOHISTÓRICOS}

Existen en verdad muy pocos antecedentes de estudios arqueológicos realizados en la zona de estudio, al igual como en la cuenca entera, siendo estos más escasos en la cuenca alta y en el valle medio. La teoría sustantiva arqueológica del valle medio del río Cañete se puede clasificar en las fuentes etnohistóricas y arqueológicas.

Los primeros autores en hacer referencia a los pueblos de la cuenca baja y media del río Cañete son los cronistas Pedro Cieza de León en sus obras El Señorío de Los Incas (1553) y Crónica del Perú (1553), así como el padre Bernabé Cobo en su obra Historia del Nuevo Mundo (1653), quienes relatan especialmente la resistencia del señorío Guarco sobre los Incas. Posteriormente Emilio Hart Terré (1933) hace una descripción del sitio de Incahuasi, describiendo sus principales sectores, pero de forma general. El padre Pedro Villar Córdova (1931-1982), analiza las características arqueológicas de la cuenca del río Cañete, tanto en la parte baja-media, como de los grupos yauyos de la cuenca alta.

Carlos Williams y Manuel Merino (1974) realizaron para el centro de investigación y restauración de bienes monumentales del Instituto Nacional de Cultura el "Inventario, Catastro y delimitación del patrimonio arqueológico del valle de Cañete", identificando un total de 163 sitios arqueológicos, que fueron clasificados en 18 categorías de sitios, según su función y dimensiones (complejo, centro cultural, centro poblado mayor, centro poblado menor, edificación aislada, cementerio, camino, canal, colcas, montículos, cuevas, sitios abiertos, campos de cultivo, andenes, terrazas, geoglifos, petrogli- 
fos, wankas), de los cuales 14 sitios pertenecen al distrito de Zúñiga, 24 a Pacarán y 45 a Lunahuaná, es decir al valle medio. Entre los sitios identificados figurán los de cerro Huanaco, Antahuaya, cerro Mal Paso, Guagil, Cantagallo, Incahuasi y Pueblo Viejo de Lunahuaná. Las descripciones son muy técnicas y tienden a la generalidad, no realizando interpretación cultural alguna.

Alberto Bueno Mendoza (1982) publica en la revista Espacio 12 el artículo "Cañete arqueológico: un futuro promisor", donde hace un bosquejo de la arqueología del valle bajo y medio, analizando los asentamientos Guarco e Inca, como cerro Azul (Guarco), centro ceremonial y de vivienda con conjunto de pirámides de perfiles escalonadas y cimas truncadas. La fortaleza de Ungará, un cerro fortificado con cinco murallas, con áreas de vivienda y depósitos. Incahuasi es otro sitio, compuesto por sus tres sectores: Arka, con sus residencias señoriales, plazas y mamacunas: El conjunto de las columnas o Incahuasi, de planta trapezoidal con un ushnu, depósitos con columnas, vivendas de vigilancia; y el sector monumental, con sus grandes depósitos articulados por pasadizos y patios y un gran "palacio residencial" con nichos y vanos altos trapezoidales. Bueno define durante el periodo Tawantinsuyu tres sitios importantes en la configuración política del valle: Incahuasi, como centro administrativo, Ungará como fortaleza militar y cerro Azul como lugar de culto y ceremonias.

John Hislop (1986) publica un trabajo titulado Incahuasi: el nuevo Cusco, en el cual clasifica el sitio en seis sectores, en base a la morfología de las mismas, dándole una connotación astronómica a la orientación de los mismos.

Entre las décadas de 1990 y la primera del siglo XXI los arqueólogos Gori Echevarría y Enrique Ruiz $(2003,2007)$ han realizado numerosas investigaciones sobre la ocupación Tawantinsuyu en los alrededores de Pacarán, describiendo importantes sitios como Guagil, San Marcos y Huaca Daris. En los últimos años un ex estudiante y hoy arqueólogo que participó con nosotros en el proyecto de catastro del 2006, ha realizado excavaciones en uno de estos sitios que presentamos, en el sitio cerro Guanaco II, constituido por un conjunto de colcas (Ramírez 2011, 2013). Cabe resaltar los trabajos desarrollados en la segunda mitad de la década pasada por la arqueóloga Vega-Centeno (2011), quien prospectó numerosos sitios tardíos del distrito de Pacarán.

\section{Sitios ARQUEOLÓGICOS IDENTIFICADOS}

Los sitios arqueológicos identificados durante el proceso de investigación son los siguientes:

\section{COMPLEJO ARQUEOLÓGICO GUAGIL}

Ubicación: Está conformado por un conjunto de edificios emplazados en la base del cono de deyección de la quebrada de Guagil, en la margen izquierda del río Cañete, a $3 \mathrm{~km}$ al este del pueblo de Pacarán. Se accede al sitio siguiendo la trayectoria del camino de herradura o rural que se dirige al este del pueblo de Pacarán, atravesando los campos de cultivo del sector de San Marcos hasta Guagil.

Descripción: El sitio está conformado por seis sectores, diferenciados espacialmente entre sí.

- Guagil "A": Este sector se ubica en las coordenadas UTM"1: 8575888 N, 0384191 E, a 724 m de altitud. Este conjunto se ubica en el lado oriental del cono de deyección de la quebrada de Guagil, sobre un terreno aluvial. La estructura tiene planta rectangular, orientando su eje mayor de este a oeste. Se ha edificado adaptando su diseño y disposición a la topografía del terreno mediante la construcción de una amplia terraza o plataforma de mampostería ordinaria de 50 $\mathrm{m}$ de largo y $30 \mathrm{~m}$ de ancho aproximadamente, nivelando el terreno natural de leve pendiente. Sobre esta superficie se edificó las estructuras.

1 Todos los puntos UTM consignados en el presente artículo se encuentran en sistema WGS-84. 
En el lado este, hay una extensa plaza delimitada por dos plataformas adosadas a los muros límites sur y oeste del mismo, y un grupo de ambientes de distinta configuración espacial en el lado oeste del monumento. Existe una banqueta en el lado norte de la plataforma de $1 \mathrm{~m}$ de ancho y 1,10 m de altura. La plaza tiene $35 \mathrm{~m}$ de largo y $25 \mathrm{~m}$ de ancho, orientada de este-oeste y ocupando casi las tres cuartas partes del área total que abarca el sector. Está delimitada, como ya señalamos, por dos plataformas dispuestas en los lados sur y oeste que miden 1,20 m de altura y $2 \mathrm{~m}$ de ancho como promedio; sobre ellas se han construido otras plataformas menores de aproximadamente $1 \mathrm{~m}$ por lado y 0,10 $\mathrm{m}$ de altura, establecidas en intervalos de 1,80 $\mathrm{m}$ a lo largo de ambos muros, a modo de bancas o pequeñas banquetas. Así mismo, dichos muros están decorados con una serie de hornacinas o nichos de planta rectangular y ligeramente trapezoidal emplazados sucesivamente.

En la parte central del extremo oeste de la plaza se ha edificado una plataforma de planta triangular con lados escalonados, rematando en un descanso o relleno al nivel de la plataforma. A 2 m aproximadamente al norte de dicha construcción se observa una rampa de $1 \mathrm{~m}$ de ancho y 3,50 m aproximadamente de largo, con un ligero talud orientado de oeste-este, que comunica ambos niveles arquitectónicos.

Muestras de remodelaciones son evidentes en el muro sur, donde se aprecia un acceso sellado con piedra careada que comunicaba directamente la plaza con el exterior del edificio, antes de la edificación de la plataforma que se alza por ese lado y que cubre parte del acceso.

En el lado oeste del sector se observan construcciones de planta rectangular dispuestas sucesivamente en un eje norte-sur. Hacia el lado norte se emplaza un recinto de regulares dimensiones a modo de kancha con acceso directo desde la plaza que, en parte, ha colapsado junto con el muro que lo delimitaba por el lado oeste. Este ambiente se comunica a través de un acceso indirecto con otro, localizado en la parte central de este sector, que se constituye de una plataforma de 0,90 $\mathrm{m}$ de ancho y 0,30 $\mathrm{m}$ de altura adosada al muro levantado en el lado sur de la plaza; el nivel inferior que abarca mayor espacio, está dividido transversalmente por tres muretes de $0,20 \mathrm{~m}$ de altura y $0,30 \mathrm{~m}$ de ancho como promedio, formando espacios rectangulares de función no definida.

El ambiente del extremo sur tiene planta rectangular orientada de este-oeste y acceso directo desde la plaza; se compone de dos habitaciones pequeñas, dispuestas en sentido longitudinal a su eje de orientación. Aquella ubicada en el lado este luce los muros decorados con hornacinas o nichos de planta rectangular y ligeramente trapezoidal, se comunica con el otro ambiente de características arquitectónicas simples por medio de un pasadizo de 1,80 m de longitud.
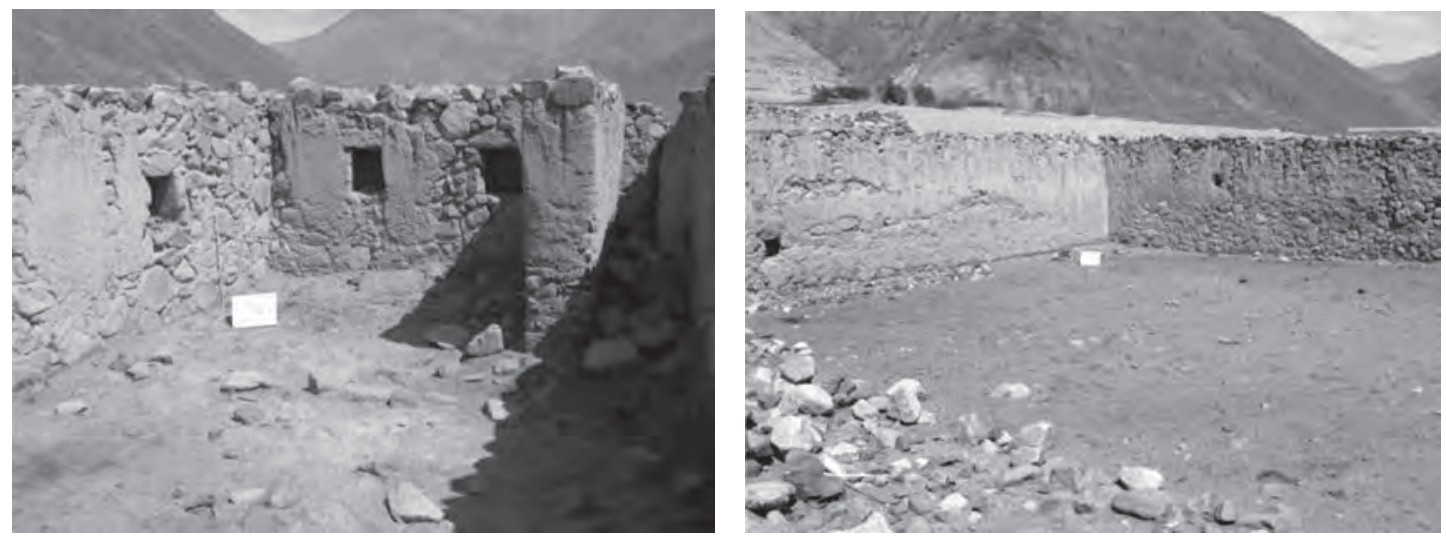

Figura 1. Izquierda: Vista de los muros con hornacinas, lado oeste de la estructura de Guagil "A". Derecha: Vista de la plaza, Guagil "A". 
La arquitectura del sector está conformada íntegramente por mampostería, con piedras ligeramente labradas, unidas entre sí con argamasa de barro. Los muros son dobles, conformado por dos estructuras verticales, con un relleno central de cascajo, piedra y tierra compactada a fin de brindarle mayor solidez, con algunas piedras grandes que cumplen la función de amarre. Los paramentos internos y externos están cubiertos con un revoque de barro de 0,03 $\mathrm{m}$ de grosor con rastros de pintura color rojo ocre.

- Guagil "B": Se ubica en el extremo suroriental de la quebrada de Guagil, hacia la ladera norte del cerro Guanaco. La ubicación UTM del punto medio del sector es: 8577700 N, 387567 E, y a $790 \mathrm{~m}$ de altitud. Está conformado por una estructura de planta en forma de "L" y de orientación este-oeste, dividida en tres secciones distribuidas siguiendo su mismo eje de orientación. Se encuentra emplazado sobre una amplia terraza o plataforma de mampostería ordinaria de $45 \mathrm{~m}$ de largo y $15 \mathrm{~m}$ de ancho aproximadamente que niveló el terreno natural de regular pendiente, dejando un zócalo de $1 \mathrm{~m}$ de ancho y 1,10 $\mathrm{m}$ de altura en el lado norte de la misma. El sector en general ha sido escenario de constantes remodelaciones arquitectónicas que se manifiestan en los diferentes espacios arquitectónicos que describiremos en sentido oeste-este.

El recinto ubicado al extremo oeste de la estructura posee planta cuadrangular y ocupa un área menor a comparación de los otros dos recintos (10 $\mathrm{m}$ por lado aproximadamente). Presenta una banqueta en el lado sur de $4 \mathrm{~m}$ de largo y 2,5 $\mathrm{m}$ de ancho promedio. En el lado oeste presenta un acceso con cuatro escalones que lo comunica con el exterior de la estructura. Del mismo modo, en el lado este se aprecia un acceso sellado durante una reorganización del espacio arquitectónico, que conducía con el segundo recinto en el centro del edificio.

El segundo recinto posee planta rectangular (15 $\mathrm{m}$ de largo y $8 \mathrm{~m}$ de ancho aproximadamente) y se compone de un espacio interno y una banqueta en su lado sur de $2 \mathrm{~m}$ de ancho y 0,55 $\mathrm{m}$ de altura. Este recinto se ubica a 1,50 m aproximadamente sobre el nivel de la superficie del ambiente anterior. Evidentemente, en un segundo momento constructivo, se cubrió el interior del recinto con una gruesa capa de tierra, piedras y cascajo hasta alcanzar la altura actual.

En el extremo este del sector se erige un amplio espacio de planta trapezoidal (18 $\mathrm{m}$ de largo y 8-12 m de ancho aproximadamente), articulado con el exterior por medio de dos corredores o pasadizos que se yuxtaponen entre sí y conectan con un vano de acceso en el lado norte del mismo, actualmente cubierto por un relleno similar al descrito para el segundo ambiente. En el extremo oriental de este recinto se edificó un pequeño recinto cerrado (a partir de división interna) cuya función no es clara.

Los muros son dobles con relleno central de tierra, cascajo y piedra, íntegramente de mampostería con argamasa de barro, sin revoque de barro. Los muros de contención de las terrazas o plataformas se han construido con mampostería simple o con una rústica capa de argamasa de barro y cascajo.

- Guagil "C": Se ubica en la parte media de la quebrada de Guagil, en las coordenadas UTM: 8577886 N, 387640 E y a 767 m de altitud, a 100 m al oeste de Guagil "A”. Este sector se orienta de oeste-este con una planta en forma de "L", conformada por dos unidades arquitectónicas aterrazadas, dispuestas en dos niveles hacia los lados norte y sur del mismo. Poseen planta rectangular y se yuxtaponen transversalmente a su eje de orientación mayor, dejando una especie de zócalo en el lado norte de la terraza inferior de $1 \mathrm{~m}$ de ancho y 1,10 $\mathrm{m}$ de altura con respecto al nivel de la superficie del terreno. Las dos estructuras se articulan a través de un acceso dispuesto de norte a sur, ubicado en el muro central que divide ambos espacios, conduciendo a una escalera de siete peldaños que descansa sobre una plataforma de 0,50 $\mathrm{m}$ de altura y 1,80 m de ancho que se adosa a la base del muro central. 
El recinto del lado norte del sector se orienta de este-oeste. Se compone de un espacio con una plataforma de 0,20 $\mathrm{m}$ de alto y 1,20 $\mathrm{m}$ de ancho adosada en el lado suroeste del recinto, así como pequeñas banquetas de $1 \mathrm{~m}$ de ancho y 0,10 $\mathrm{m}$ de altura, adosadas a la base de los cuatro muros que delimitan este recinto. En el lado sur se ubica el acceso principal del sector que deriva directamente a un camino reutilizado cuyo trazo es paralelo a su eje de orientación mayor y que también bordea el flanco sur de Guagil "A".

El segundo ambiente se localiza en el lado norte del sector, posee planta rectangular, su eje mayor se orienta de oeste-este y manifiesta un desnivel de $1,50 \mathrm{~m}$ con respecto a la superficie del ambiente anterior. Presenta un espacio mucho más amplio con una plataforma de $0,50 \mathrm{~m}$ de altura adosada al muro del lado sur, comunicándose entre sí a través de una escalera de cuatro peldaños, poco definidas, ubicada en su extremo este. Los muros norte, este y parcialmente el sur exhiben un conjunto de hornacinas de forma rectangular, otras ligeramente trapezoidales, cuyo promedio de altura es de 0,45 $\mathrm{m}$ y 0,38 $\mathrm{m}$ de ancho, dispuestas tanto en sentido longitudinal como alternado (zig-zag).

Los muros se han edificado íntegramente con mampostería careada, ligeramente labradas unidas con argamasa de barro, dispuesta en dos hileras con un relleno central de cascajo, piedra y tierra apisonada a fin de brindarle mayor solidez. Los paramentos internos y externos están cubiertos con un revoque de barro de 0,03 $\mathrm{m}$ de grosor con rastros de pintura color rojo ocre.

- Guagil D: Se ubica en el extremo noroeste del cono de deyección de la quebrada de Guagil, en las coordenadas UTM: 8577842 N, 0387465 E y a 759 m de altitud, a 100 m aproximadamente al oeste de Guagil C. Tiene forma alargada y se orienta de oeste a este. Está cortado en el lado noroeste por un canal moderno y por el avance de la frontera agrícola. A diferencia de las construcciones anteriores, Guagil D, se ha edificado sobre un terreno natural, cuya superficie es casi plana.

Este sector se compone de un conjunto de estructuras arquitectónicas de planta rectangular, y una plaza rectangular en el extremo oeste del conjunto, la cual está delimitada por una plataforma en el lado este de 0,65 $\mathrm{m}$ de alto y 3,50 $\mathrm{m}$ de ancho. Ambos espacios se articulan a través de una pequeña escalera casi colapsada de tres peldaños. Sobre la plataforma existe una pequeña construcción rectangular no definida a causa de su pésimo estado de conservación.

En la parte central se ubican un conjunto de recintos de acceso independiente y planta rectangular en regular estado de conservación. Uno en particular se localiza en el lado este, mide $3,20 \mathrm{~m}$ de largo y 1,80 $\mathrm{m}$ de ancho y su acceso se orienta al centro de la plaza. Los paramentos interiores están decorados con nichos de forma rectangular dispuestos sucesivamente, con una altura promedio de 0,50 $\mathrm{m}$ y $0,35-0,40 \mathrm{~m}$ de ancho. Frente a este recinto se ubica una
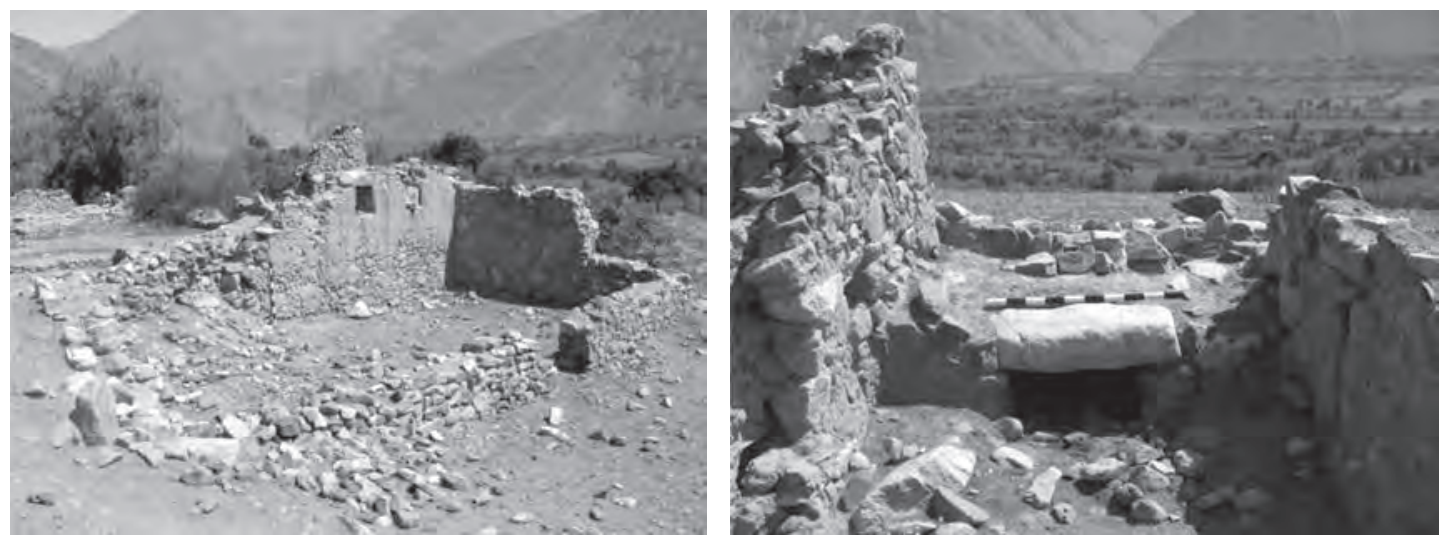

Figura 2. Izquierda: Vista de uno de los recintos destruidos de Guagil "D", nótese el nicho superior. Derecha: Vista del interior de otro recinto del mismo sector. 
pequeña habitación de 1,80 $\mathrm{m}$ de largo y 1,50 $\mathrm{m}$ de ancho, cuya particularidad es poseer dos grandes nichos edificados uno frente al otro, empleando en su construcción adobes paralelípedos unidos con argamasa. Uno de estos nichos mide casi $1 \mathrm{~m}$ de ancho. Este pequeño recinto está cubierto con un relleno de tierra, cascajo y piedras, dejando al descubierto solo la parte superior de ambos nichos.

En el extremo oeste del sector, las estructuras arquitectónicas han sido notablemente alteradas, siendo solo posible observar algunos tramos de un muro de contención que formaba una plataforma de baja altura y secciones de muros rodeados de cultivos, desmontados y casi al borde del colapso.

- Guagil “E”. Estructuras Arquitectónicas Menores: Entre los edificios de Guagil "C" y Guagil "D" se identificó una serie de pequeñas estructuras de planta cuadrangular de $2 \mathrm{~m}$ de lado aproximadamente, concentradas en dos grupos: uno hacia el extremo oeste, donde solo se definen un par de construcciones en pie, y otra, ubicada en el lado este, ocupando un espacio mayor, donde se aprecia un núcleo importante de edificaciones de este tipo. El punto medio de ubicación de estas estructuras está en las coordenadas UTM: 8577868 N, 0387527 E, a 766 m de altitud. Se han construido íntegramente con mampostería careada unida con argamasa de barro y cascajo dispuesta en doble hilera con relleno de piedra, tierra y cascajo en el interior, brindándole mayor solidez a los muros. La superficie de los paramentos no muestra rastros de revoque.

Materiales asociados: No se identificó material cultural asociado a ninguno de los sectores descritos para este complejo. Sin embargo, en el área denominada como estructuras menores de Guagil o Guagil "E”, identificamos dentro de un contexto disturbado (huaqueo) no definido una gran porción de una vasija de regulares dimensiones que posee base plana, cuerpo semiesférico y lados divergentes, correspondiente a un plato, cuya superficie exterior denota diseños pintados de líneas horizontales alternas de color marrón sobre un engobe de color crema, muy próximas a la boca. Se apreció que en su interior contenía, restos orgánicos vegetales como semillas de lúcuma, palta, pacae, restos de coca y maíz. Además, muy cerca de este hallazgo, observamos dispersos restos óseos animales de regular magnitud (camélidos), que podrían haber formado parte del mismo contexto. Asimismo, registramos restos de fragmentería cerámica pertenecientes a bordes de vasijas de grandes dimensiones (tinajas) y cántaros de bordes rectos o ligeramente evertidos con pasta color marrón claro-oscuro.

Asociación cronológica: En base al análisis arquitectónico y la cerámica observada en superficie, inferimos que este complejo pertenece al Intermedio Tardío, siendo reocupado hasta el Horizonte Tardío, con la intrusión de nuevos sectores de filiación Tawantinsuyu.

Estado de conservación: En líneas generales el Complejo Arqueológico de Guagil se encuentra en un estado de conservación de malo a regular. Todas las estructuras del complejo presentan colapso parcial de sus muros a causa principalmente del constante tránsito de personas, al pastoreo de ganado sobre las construcciones arqueológicas, las constantes excavaciones clandestinas (huaqueo) y la habilitación de muchos de los espacios como corrales y viviendas modernas. La plaza de Guagil "A" representa el rasgo arquitectónico más importante del edificio, pero se utiliza actualmente como cancha de minifútbol; incluso se ha instalado postes de madera a modo de arcos, uno de los cuales limita con la plataforma escalonada del lado oeste de la plaza.

\section{HUACA SAN MARCOS DE PACARÁN}

Ubicación: El sitio se encuentra ubicado en la margen izquierda del río Cañete, a un kilómetro aproximadamente al este del pueblo de Pacarán, en el paraje de San Marcos, adyacente al camino que se dirige a Guagil; sobre el piso del valle, rodeado de campos de cultivo. Se ubica en las coor- 
denadas UTM: 8577792 N, 0386463 E y a 750 m de altitud. Se accede al sitio siguiendo la trayectoria del camino que se dirige al este del pueblo de Pacarán.

Descripción: Este sitio manifiesta características monumentales. Está conformado por un edificio de planta en forma de "L", orientado de este a oeste, cuyo interior se divide en seis secciones, donde destacan las construcciones abiertas o plazas de planta rectangular con plataformas adosadas a uno o más muros que delimitan estos ambientes. Complementando estos espacios arquitectónicos se han edificado algunos recintos siempre apostados a los extremos norte o sur de cada sector.

En la sección este se identificó una amplia plaza con una plataforma en el lado sur, la cual, a su vez, se adosa a una construcción que exhibe un acceso sellado con adobes, orientado hacia la plaza. En su interior alberga dos ambientes regulares, de gran tamaño, de planta rectangular, sin cubiertas o techumbre, con muros que presentan nichos, que evidentemente se empleaba como un espacio de carácter sacro. Estos ambientes solo pueden ser observados desde la parte superior de esta construcción, a la cual se accede a través de una rampa ubicada hacia el lado oriental de la plataforma.

Las secciones ubicadas en la parte central del conjunto se definen solo en parte, considerando el grado de destrucción causada por el desmonte de los muros de piedra y adobes para construir edificaciones modernas, así como la remoción de tierras que constituía la superficie del asentamiento, actualmente habilitada como campos de cultivo de viña.

En el extremo oeste se puede identificar construcciones que siguen el patrón sugerido anteriormente, es decir una pequeña plaza con plataformas adosadas y algunos ambientes apostados hacia los extremos norte y sur del edificio. Sin embargo, cabe indicar que existe una práctica constante de cubrir las estructuras arquitectónicas de carácter habitacional, cuyos muros, generalmente, lucen decorados con nichos de planta trapezoidal y rectangular pintadas de color rojo ocre, con un relleno de piedras, tierra y cascajo que alcanza la cabecera de los muros. Para comunicarse con estas superficies se disponen escalones empleando piedras planas de regular tamaño. En algunos casos se reedifica sobre estas superficies muros decorados con nichos. Cabe anotar que también se emplean como medios de comunicación la parte superior de los muros a manera de caminos epimurales que han sido reforzados con una franja de mampostería que excede el grosor del muro (a modo de alero) evitando el desgaste de la superficie del muro.

Los muros están elaborados a base de una técnica mixta que combina muros de mampostería de piedra unida con argamasa de barro, muros dobles con un relleno central de tierra, cascajo y piedra compactada, con revoque de barro que cubre los paramentos de los muros; y muros de adobes paralelípedos de 0,40-0,45 $\mathrm{m}$ de largo y 0,28-0,30 $\mathrm{m}$ de ancho, muros dobles, con los elementos
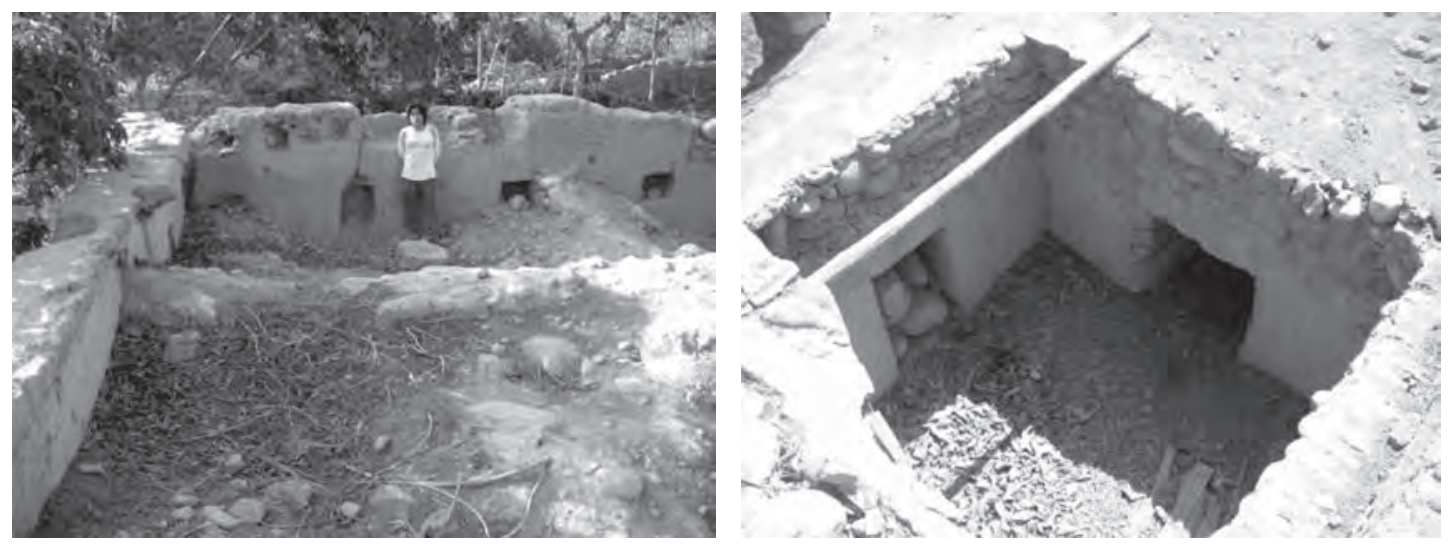

Figura 3. Izquierda: Vista de las construcciones superiores en Huaca San Marcos de Pacarán. Derecha: Vista de un recinto Tawantinsuyu, desde arriba. 

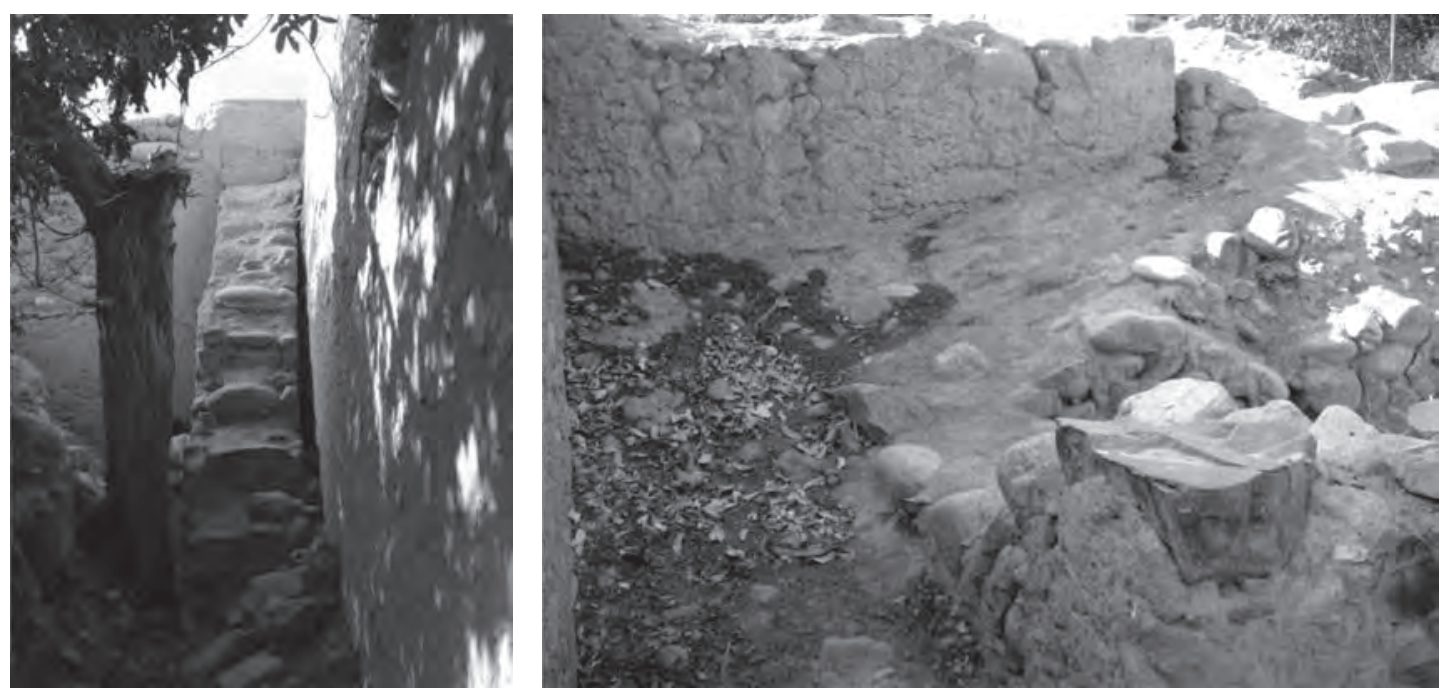

Figura 4. Izquierda: Vista de una escalera lateral que comunica con los niveles superiores, Huaca San Marcos de Pacarán. Derecha: Vista de la parte superior del mismo sitio.

alternados a tizón y soga, cuyos paramentos, también, se cubren con un revoque de barro de regular grosor. Ambos tipos se superponen indistintamente y alternadamente.

Los muros exteriores alcanzan $5 \mathrm{~m}$ de altura y 0,80-0,90 $\mathrm{m}$ de grosor. Los muros del interior son un poco más delgados, pero, los rangos de medida generalmente son muy similares.

Materiales asociados: No se identificó ningún tipo de material cultural, dado que los espacios interiores del monumento han sido removidos y habilitados como campos de cultivo de viña.

Estado de conservación: El sitio en general se encuentra en regular estado de conservación. Muchos muros presentan un colapso parcial, erosión basal y superficial, desmontaje de las estructuras arquitectónicas, el adosamiento de elementos arquitectónicos modernos y la remoción de tierras. Actualmente el sitio tiene una propietaria que lo dispone como área de cultivo, evitando el ingreso a cualquier tipo personas, incluyendo a aquellas que arriban al sitio con propósitos científicos. Recomendamos el saneamiento legal adecuado, supervisando su inscripción en registros públicos y acelerando su declaración como parte del patrimonio cultural de la Nación.

\section{HUACA DARIS, FORTALEZA DE PACARÁN O MARCA PAQARÁN}

Ubicación: Se ubica al noreste del pueblo de Pacarán, en el sector denominado San Marcos, margen izquierda del río Cañete, sobre el piso del valle, circunscrito por campos de cultivo, en las coordenadas UTM: 8577812 N, 0386068 E y a 736 m de altitud. Se accede al sitio siguiendo $800 \mathrm{~m}$ aproximadamente por el camino al este del pueblo de Pacarán, desviándose hacia el norte por un pequeño sendero que flanquea los campos de cultivo de la Sra. Daris.

Descripción: Huaca Daris se asienta en el medio del valle, rodeado por campos de cultivo. Presenta planta rectangular y su eje mayor está orientado de este a oeste. Este sitio, de características monumentales, se compone esencialmente de un complejo de patios, pequeñas plazas con plataformas adosadas y un área donde se concentra regular cantidad de ambientes, posteriormente, cubiertos por un relleno de piedra, tierra y cascajo. Estos espacios se distribuyen en dos áreas o sectores específicos (oriental y occidental), divididos por un muro de $0,80 \mathrm{~m}$ de grosor orientado en sentido transversal al eje mayor y articulados a través de un vano de acceso, casi colapsado. 
En el sector oriental se encuentra una extensa plaza, ocupando casi el 60\% del área total de este sector; y un patio hacia el lado norte. La primera posee planta rectangular, orientada de norte a sur. Exhibe dos plataformas adosadas al sur y este de la plaza, comunicándose con ellas por medio de una rampa, poco definida a causa de la remoción de tierra. El muro sur y parte del muro oeste están decorados por una serie de nichos de forma rectangular o ligeramente trapezoidal dispuestas en sentido longitudinal al eje de los muros. Se comunica con un recinto en el extremo norte por medio de un vano de acceso. Esta tiene forma rectangular, orientada de este a oeste y cercada con muros altos que alcanzan hasta los $4 \mathrm{~m}$ de altura.

En el sector occidental existen dos pequeñas plazas ubicadas en los extremos norte y sur del mismo, constituidas por plataformas adosadas a la base de los muros que alcanzan hasta 0,25 $\mathrm{m}$ de altura. Los muros están decorados con nichos de forma rectangular y trapezoidal; en el caso de aquellos del extremo norte del sector, se han edificado adosando un muro allanado de ventanas a otro que cubre la abertura de uno de los lados. Las plazas se comunican entre si por medio de un pasadizo de 4,80 $\mathrm{m}$ de largo. En el centro del sector se erige un grupo de recintos de planta rectangular, cuyos muros están decorados con nichos de planta trapezoidal y pintura color rojoocre, comunicados por accesos de forma trapezoidal de una jamba que han sido cubiertos por un relleno de piedra, tierra y cascajo hasta formar una plataforma de $3 \mathrm{~m}$ aproximadamente de altura que se comunicaba con el nivel inferior por medio de una escalera muy sólida construida con piedras de cara plana en el lado sur del sector.

Los muros se han edificado, principalmente, en base a mampostería levemente labrada, unida con argamasa de barro. Se trata de muros dobles. Sus paramentos están recubiertos por un revoque de barro de 0,02 $\mathrm{m}$ de grosor con rastros de pintura color rojo-ocre. También, en menor proporción, se ha utilizado adobes paralelepípedos de 0,38-40 $\mathrm{m}$ de largo, 0,28 $\mathrm{m}$ de ancho y 0,15 $\mathrm{m}$ de alto.

Materiales asociados: Solo se identificó algunos pocos fragmentos de cerámica diagnostica poco significativos, dispuestas en la superficie del relleno disturbado que cubre parte de las estructuras arquitectónicas del sector occidental.

Asociación cronológica: El sitio pertenece al Intermedio Tardío, con ocupación hasta el Horizonte Tardío.

Estado de conservación: El sitio se encuentra en regular estado de conservación. Los muros presentan una fuerte erosión basal debido a las filtraciones de agua y humedad que proviene de los campos de cultivo adyacentes al sitio, causando el colapso parcial de los muros perimétricos. La erosión superficial también es causada por las precipitaciones pluviales y el contacto físico natural. Se nota la remoción de la superficie original de los diferentes recintos arquitectónicos con el propósito de habilitar áreas de cultivo de alfalfa. Todos los sectores están cubiertos por
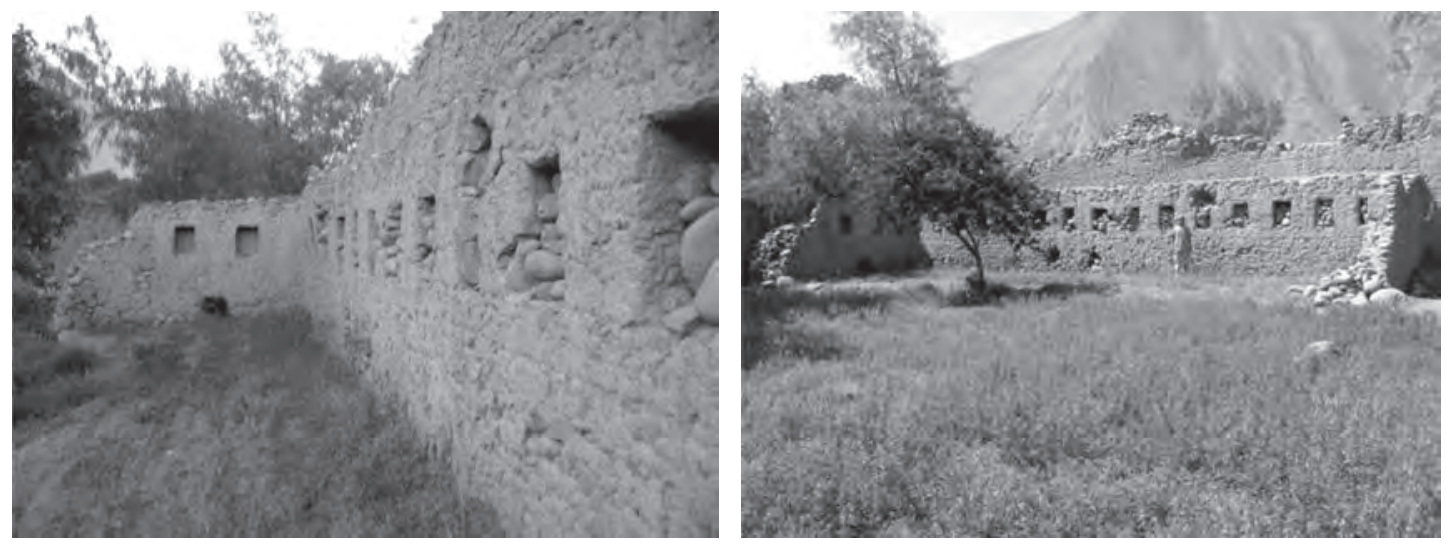

Figura 5. Izquierda y derecha: Vista del detalle de los muros con nichos, Huaca Daris. 
vegetación arbustiva y arbórea, siendo los espacios mas afectados la plaza del sector oriental y las plazas norte y sur del sector occidental del sitio.

\section{PETROGLIFOS DE SAN MARCOS}

Ubicación: Se encuentra ubicado, en parte sobre el lecho del río Cañete, y en parte sobre campos agrícolas, en el sector de San Marcos, a $150 \mathrm{~m}$ al noreste de huaca Daris. Se hallan dispersos en la margen izquierda del río Cañete. No existe un camino preciso que conduzca hasta este sitio, pero se accede bordeando el río Cañete en un trayecto de $300 \mathrm{~m}$ aproximadamente en dirección este, desde el puente Pacarán hasta identificar ciertas concentraciones de cantos rodados de gran magnitud.

Descripción: Sobre una extensión de 600 m en línea recta, paralelo al río Cañete, se emplazan un grupo disperso de cantos rodados de gran tamaño, dispersos en toda el área; cuyas superficies se han empleado para plasmar motivos de género diverso, sobre una capa de pintura color rojo-ocre previamente fijada. En cuatro de ellos ha sido posible identificar diseños de carácter antropomorfo, zoomorfo, naturalista, geométrico, etc., modelados en las superficies empleando diferentes técnicas de impresión. Algunos diseños se han logrado a través de incisiones o acanaladuras en la piedra; otros se han obtenido utilizando moldes que se han adherido a la superficie antes de ser cubiertas por la pintura color rojo ocre que decora todas las superficies de las piedras. Todos estos motivos se disponen irregularmente sobre las superficies de los cantos rodados, sin un patrón definido que pueda ser establecido en base al análisis del tipo de diseño y la técnica de impresión. Entre los motivos figuran principalmente: camélidos, soles, serpientes, plantas, entre otros.

Cuadro 1: Motivos y ubicación de los petroglifos de San Marcos.

\begin{tabular}{|c|c|c|c|l|}
\hline \multirow{2}{*}{$\begin{array}{c}\text { No. DE } \\
\text { PETROGLIFO }\end{array}$} & \multicolumn{3}{|c|}{ UBICACIÓN UTM } & \multirow{2}{*}{ MOTIVOS } \\
\cline { 2 - 4 } & N & E & ALTITUD & \\
\hline 01 & 8578086 & 386086 & 720 & Zoomorfos, antropomorfos y no definidos. \\
\hline 02 & 8578014 & 385997 & 731 & Zoomorfos \\
\hline 03 & 5878072 & 385992 & 729 & Zoomorfos, naturalistas, antropomorfos \\
\hline 04 & 8578010 & 385951 & 728 & Zoomorfos, no definidos. \\
\hline
\end{tabular}

Materiales asociados: No se encontró ningún tipo de material cultural asociado.

Asociación cultural: No definido.

Estado de conservación: Malo. Algunos de los cantos rodados han sido removidos de su posición original, con el propósito de ampliar los campos agrícolas que se aproximan al río Cañete, produciendo la erosión de las superficies decoradas. Las superficies de los cantos rodados decorados, muestran rastros de exfoliación en grado avanzado, afectando su estructura interna y siendo propenso al colapso de una parte significativa del mismo. Del mismo modo, la pintura que cubre las superficies se ha desgastado y corren el riesgo de desaparecer. Se ha repintado con tiza los trazos
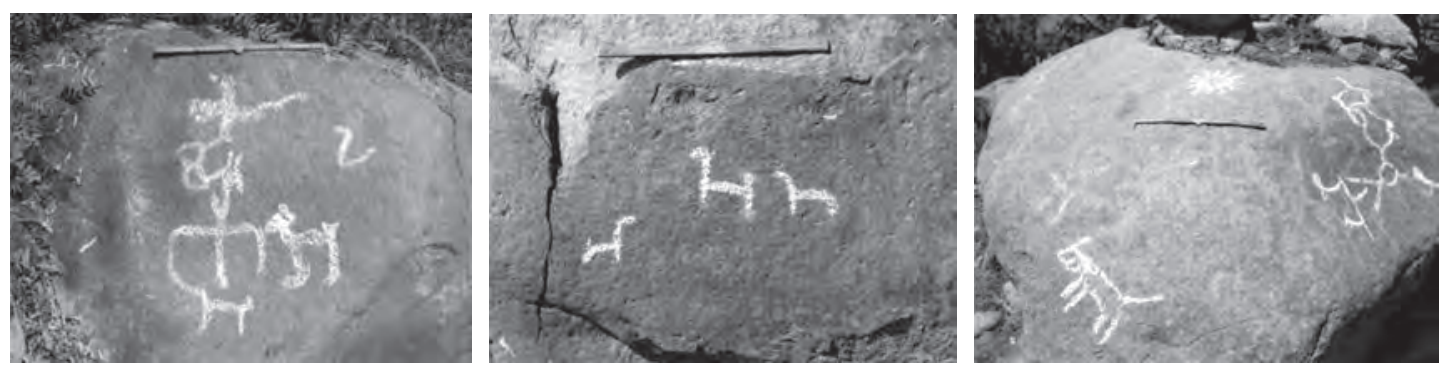

Figura 6. Vista panorámica de tres petroglifos, 
correspondientes a los motivos, a fin de hacerlos evidentes, contribuyendo a acelerar la erosión superficial de los cantos rodados.

\section{CERRO GUANACO I-A}

Ubicación: Se ubica en el flanco noroeste del cerro Guanaco, a $500 \mathrm{~m}$ al suroeste de la quebrada de Guagil y en un tramo aproximado de 300 m, en la división del canal de San Marcos, siguiendo en dirección sureste, en la margen izquierda del río Cañete. La ubicación UTM del sitio es: 8577838 N, 0386980 E y a 750 m de altitud.

Descripción: Se compone de un muro aislado orientado en el eje noroeste a sureste, emplazado en la ladera de regular pendiente del cerro Guanaco, a $20 \mathrm{~m}$ aproximadamente al sur del desvío de la divisoria de aguas del canal San Marcos y próximo a los campos de cultivo. El muro mide $14 \mathrm{~m}$ de largo, 0,60 m de ancho y 0,50 $\mathrm{m}$ de altura promedio. Está construido completamente con mampostería ordinaria unida con argamasa de barro y cascajo, dispuesta en doble hilera con relleno intermedio de piedras, cascajo y tierra apisonada.

Materiales asociados: No se identificó material cultural alguno sobre la superficie del terreno.

Asociación cultural: Intermedio Tardío.

Estado de conservación: El muro se encuentra en regular estado.

\section{CERRO GUANACO I-B}

Ubicación: Se encuentra ubicado en una ladera de regular pendiente en el lado noroeste del cerro Guanaco, en las coordenadas UTM: 8577750 N, 0386980 E y a 750 m de altitud, en la margen izquierda del río Cañete.

Descripción: Pequeño recinto aislado de aproximadamente un metro por lado, posee planta rectangular. Los muros de este pequeño recinto alcanzan casi el metro de altura y están construidos con piedras canteadas unidas con argamasa de barro dispuestas en el muro en una hilera simple, cuyo paramento está cubierto por un revoque de barro muy erosionado sin rastros de pintura.

Materiales asociados: Asociado a este recinto se observa una regular cantidad de restos óseos humanos esparcidos sobre la superficie; como secciones de cráneo, algunos huesos largos, etc. Por asociación con los restos óseos esta estructura tendría un carácter funerario.

Asociación cultural: Intermedio Tardío.

Estado de conservación: El sitio se encuentra en regular estado.

\section{CERRO GUANACO I-C}

Ubicación: El sitio se encuentra ubicado en la ladera noroeste del cerro Guanaco, en la margen izquierda del río Cañete, junto al límite de las zonas de cultivo. Su ubicación UTM es: 8577686 N, 0386802, y a $752 \mathrm{~m}$ de altitud.

Descripción: Está conformado por un muro aislado orientado en el eje noroeste a sureste, construido con mampostería con argamasa, rematando en dos hileras horizontales de adobes paralelepípedos dispuestos en soga de 0,40 $\mathrm{m}$ de largo, 0,20 $\mathrm{m}$ de ancho y 0,15 $\mathrm{m}$ de alto como medidas promedio. El muro alcanza la altura de 0,70 $\mathrm{m}$ y 0,55 $\mathrm{m}$ de ancho. Este elemento estaría asociado a los dos sitios anteriores por hallarse a poca distancia entre sí.

Materiales culturales asociados: No hemos observado material cultural asociado.

Asociación cultural: Intermedio Tardío.

Estado de conservación: El sitio se encuentra en regular estado. 


\section{CERRO GUANACO II}

Ubicación: El sitio se ubica en la parte media de la ladera noroeste del cerro Guanaco, en el sector conocido como San Marcos, a un kilómetro aproximadamente al sureste del pueblo de Pacarán, en la margen izquierda del río Cañete. La ubicación UTM es: 8577588 N, 0386517 E y a 766 m de altitud. Se accede al sitio siguiendo el trayecto hacia el suroeste de un sendero que bordea el flanco noroeste del cerro Guanaco, paralelo a una derivación del canal San Marcos.

Descripción: Este sitio posee forma alargada orientada de este a oeste, presenta regular concentración de estructuras arquitectónicas de planta cuadrangular, semisubterráneas, adaptadas a la topografía del terreno mediante la construcción de una amplia terraza sobre una franja estrecha de la ladera suroeste del cerro Guanaco. Estas construcciones miden $3 \mathrm{~m}$ por lado como promedio y se disponen en dos hileras alternas hasta copar el ancho total del área con una profundidad de 1,80 m. Se han construido íntegramente en base mampostería careada unida con argamasa de barro y cascajo. Los paramentos interiores y exteriores exhiben una cubierta de barro de 0,02 $\mathrm{m}$ de grosor, enlucida y pintada de color rojo. La cabecera de los muros está reforzada con una hilera más de mampuestos o piedras que forman un alero o cornisa en la cima, con el fin de brindarle solidez y evitar el desgaste debido al continuo tránsito de personas sobre su superficie en momentos de funcionamiento. Probablemente, estas edificaciones, funcionaron como depósitos para almacenar productos agrícolas $u$ otro tipo de bienes relacionados.

Materiales asociados: No se registró ningún tipo de material cultural dada su ausencia en toda el área del sitio.

Estado de conservación: El sitio se encuentra en mal estado. Se aprecia el colapso parcial de los muros perimetrales, así como el desgaste o erosión de la superficie de los muros debido a las inestables condiciones ambientales (humedad y temperatura). El acarreo masivo de material aluvial sobre las estructuras arquitectónicas provenientes de la cima del cerro Guanaco, ha cubierto parte de las construcciones y empujando las fuerzas hacia la depresión del lado oeste.

\section{CERRO GUANACO III}

Ubicación: El sitio se ubica en la parte media de la ladera noroeste del cerro Guanaco, sobre una explanada natural muy angosta, a $300 \mathrm{~m}$ al suroeste del sitio cerro Guanaco II, en el sector de San Marcos, margen izquierda del río Cañete. La ubicación UTM del sitio es: 8577548 N, 0386241 E y a $760 \mathrm{~m}$ de altitud. Se accede al sitio siguiendo el trayecto hacia el suroeste del mismo sendero que bordea la acequia derivada del canal de San Marcos desde cerro guanaco II.

Descripción: Este sitio posee forma alargada, orientado de noreste a suroeste. Se constituye de una serie de recintos de planta cuadrangular de $3 \mathrm{~m}$ aproximadamente por lado, distribuidos
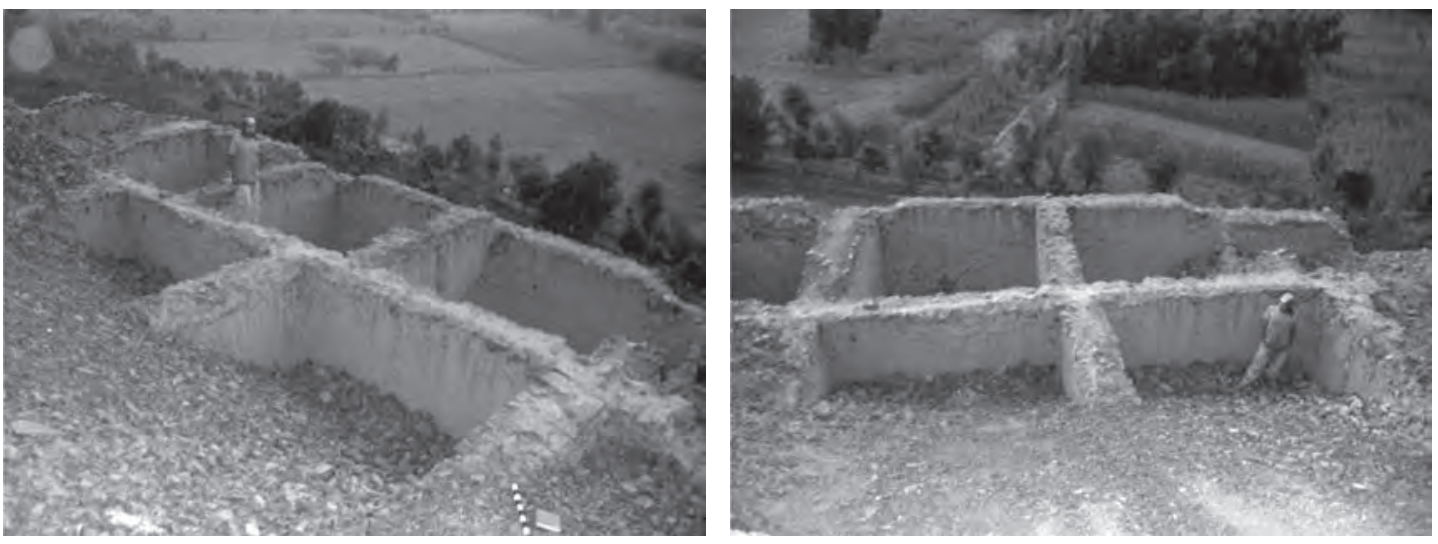

Figura 7. Vista panorámica en dos vistas de las estructuras de Cerro Guanaco II. 
sucesivamente en sentido longitudinal al perfil del cerro y edificados sobre un terreno previamente nivelado. Los muros alcanzan 0,50 $\mathrm{m}$ de ancho y 1,80 $\mathrm{m}$ de profundidad, edificados en base a mampostería careada unida con argamasa de barro y cascajo, con restos de revoque de barro sobre la superficie de los paramentos exteriores e interiores. En general, presenta características técnicas y espaciales similares a cerro Guanaco II. Sin embargo, en esta área se han construido, adicionalmente, un grupo de terrazas dispuestas en la parte superior e inferior de las edificaciones detalladas previamente. Algunas de ellas alojan pequeñas estructuras subterráneas de planta semicircular y de sección troncocónica, probablemente de carácter funerario, cubiertas, en parte, por lajas o piedras planas.

Materiales asociados: Se registró algunos restos de cerámica fragmentada no diagnóstica dispersas sobre la superficie del terreno.

Asociación cultural: Intermedio Tardío-Horizonte Tardío.

Estado de conservación: Malo. Presenta colapso parcial de los muros causado principalmente por factores naturales.

\section{CERRO GUANACO IV}

Ubicación: El sitio se ubica sobre una pequeña terraza aluvial en la base de la ladera noroeste del cerro Guanaco, sobre un lecho aluvial adyacente a los campos de cultivo, a $100 \mathrm{~m}$ aproximadamente del sitio cerro Guanaco II, en la margen izquierda del río Cañete, en las coordenadas UTM: 8577430 N, 0386397 E a $758 \mathrm{~m}$ de altitud. Se accede siguiendo la trayectoria hacia el suroeste del sendero que flanquea la base de la ladera oeste del cerro Guanaco desde el sitio cerro Guanaco III.

Descripción: cerro Guanaco IV se encuentra en muy mal estado de conservación siendo muy difícil definir espacios arquitectónicos o identificar algún tipo de patrón de asentamiento de
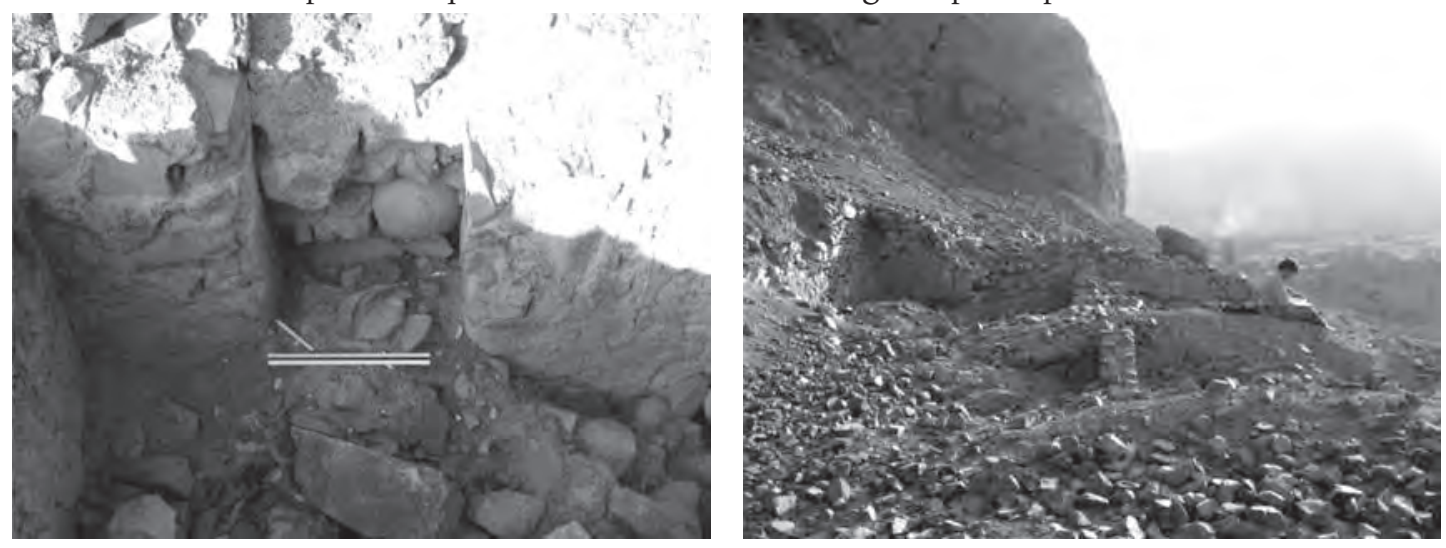

Figura 8. Izquierda: Detalle constructivo Cerro Guanaco III. Derecha: Vista panorámica Cerro Guanaco III.

manera coherente. Solo se observa un conjunto de estructuras arquitectónicas dispuesta de forma irregular sobre el terreno, separadas por un muro de 7,80 m de largo construido con mampostería careada unida con argamasa de barro, dispuestos en dos hileras rellenados con tierra y cascajo apisonado, rematando con dos hileras de adobes paralelepípedos de 0,38 $\mathrm{m}$ de largo, 0,22 $\mathrm{m}$ de ancho y 0,12 $\mathrm{m}$ de alto. En el lado noreste del sitio se han construido una serie de estructuras arquitectónicas subterráneas de planta rectangular, de carácter funerario, construidas con mampostería careada, levemente labrada, unida con argamasa de barro y cascajo, sin rastros de revoque.

Materiales asociados: Se ha identificado algunos restos de cerámica fragmentada perteneciente a bordes de ollas y cantaros. 
Asociación cronológica: Intermedio Tardío-Horizonte Tardío.

Estado de conservación: Pésimo. Se aprecia intensas excavaciones clandestinas o huaqueo que han permitido el colapso casi total de los muros que constituían las diferentes estructuras arquitectónicas del sitio.

\section{CERRO GUANACO V}

Ubicación: Se ubica sobre la ladera noroeste del cerro Guanaco, en un tramo aproximado de 200 $\mathrm{m}$., iniciándose a $250 \mathrm{~m}$. aproximadamente del sitio cerro Guanaco IV, en el sector del anexo de Romaní, en la margen izquierda del río Cañete. Se accede al sitio siguiendo el sendero que bordea el flanco noroeste del cerro Guanaco, paralelo a una acequia que se deriva del canal de San Marcos. El sitio se ubica entre las coordenadas UTM: $8577368 \mathrm{~N}$ y $0386229 \mathrm{E}$.

Descripción: El sitio se constituye de un conjunto de terrazas distribuidas en un tramo aproximado de $200 \mathrm{~m}$ a lo largo de la ladera noroeste del cerro Guanaco, con intervalos de $20 \mathrm{~m}$ a $30 \mathrm{~m}$ formando cuatro grupos de mayor concentración de este tipo de estructuras arquitectónicas en zonas donde la pendiente se torna mucho mas abrupta, revelando el propósito fundamental de su edificación: contener en gran parte el deposito de material aluvial acarreado desde la cima del cerro sobre los terrenos agrícolas y canal de regadío. Muchas de estas terrazas han sido reconstruidas, y en algunos tramos, se han edificado recientemente nuevas terrazas, a fin de reemplazar a aquellas que se encuentran totalmente cubiertas por material aluvial. El primer tramo del sitio esta conformado por un pequeño grupo de edificaciones de planta cuadrangular muy deterioradas, ubicadas sobre una pendiente pronunciada de la ladera del cerro. Probablemente cumplió la función de área de almacenaje o depósito. En otros tramos, algunas terrazas alojan una pequeña construcción subterránea de planta semicircular (0,50 m diámetro mayor y 0,30 m diámetro menor y $0,10-0,15 \mathrm{~m}$ de profundidad) muy alteradas, de carácter funerario. Todas las construcciones se han edificado en base a mampostería ordinaria unida con argamasa de barro sin revoque sobre el paramento exterior de la empalizada que constituye el muro de contención. Sus medidas son muy variables; sin embargo, suelen variar en un rango de 1,50-2,50 $\mathrm{m}$ de largo y 0,80-1,20 $\mathrm{m}$ de ancho y $0,50 \mathrm{~m}$ de altura promedio.

Materiales asociados: No se identificó ningún tipo de material asociado sobre la superficie del terreno.

Asociación cronológica: Intermedio Tardío.

Estado de conservación: Malo.

\section{CERRO GUANACO VI}

Ubicación: Se ubica sobre una terraza aluvial de regular pendiente, en la base de la pronunciada ladera noroeste del cerro Guanaco, en el sector que comprende el anexo de Romaní, adyacente a los campos de cultivo y a $600 \mathrm{~m}$ aproximadamente al oeste del conjunto de terrazas de cerro Guanaco V, en la margen izquierda del río Cañete. Se localiza en las coordenadas UTM: 8576870 $\mathrm{N}, 385489 \mathrm{E}$ y a $772 \mathrm{~m}$ de altitud. Se accede siguiendo hacia el oeste la trayectoria del sendero que franquea la ladera noroeste del cerro Guanaco desde el sitio arqueológico anterior.

Descripción: Este sitio, dadas las características topográficas del terreno, se ha edificado sobre un sistema de terrazas, elaboradas previamente a la construcción de los muros u otro tipo de elementos constructivos primarios y secundarios, con el propósito de habilitar un área adecuada para su levantamiento. En la parte alta, en una zona de fuerte pendiente se identificó una pequeña concentración de estructuras arquitectónicas muy erosionadas y debilitadas por el constante acarreo de material aluvial de la parte alta del cerro Guanaco, mitigadas, en parte, por la construcción de algunas pequeñas terrazas en la parte mas alta del sitio, empleando piedras de cerro 
aparejadas irregularmente y unidas con argamasa de cascajo y barro (mampostería ordinaria). En la parte media, delimita por un lado con la ladera fuertemente pronunciada del cerro, se ha construido un conjunto de estructuras arquitectónicas de planta cuadrangular ( $3 \mathrm{~m}$. por lado aproximadamente), sin accesos, dispuestos en sentido longitudinal al perfil del cerro. El interior de los muros de algunos recintos se ha decorado con nichos u hornacinas de planta rectangular y de lados ligeramente convergentes (forma trapezoidal). Adosado paralelamente al muro de contención del extremo oeste se ha diseñado una construcción de forma escalonada, aprovechando las características morfológicas de los adobes. Probablemente, esta zona se manejó como área de depósitos o colcas.

En la parte baja del sitio se apreció un extenso patio aterrazado de $20 \mathrm{~m}$. de largo y $8 \mathrm{~m}$. de ancho promedio, con una construcción de forma irregular, no definida debido a su lamentable estado de conservación, en la parte central.

Las estructuras arquitectónicas se han edificado utilizando mampostería careada, unida con argamasa de barro dispuestas en dos hileras con un boquete en el centro cubierto con un relleno de piedras, cascajo y tierra apisonada; y adobes paralelepípedos unidos con argamasa de barro y cascajo, dispuestos en soga. Los paramentos muestran un grueso revoque de barro sin rastros de pintura.

Materiales asociados: No se identifico material cultural asociado.

Asociación cronológica: Intermedio Tardío-Horizonte Tardío.

Estado de conservación: Malo. Se aprecia el colapso parcial de los muros interiores y exteriores del área empleada como depósitos o colcas, a causa de la agregación de factores naturales, principalmente las condiciones inestables de humedad y temperatura; así como los factores culturales, claramente tangibles en los pozos producto de excavaciones clandestinas (huaqueo) y el tránsito constante de ganado caprino y ovino sobre las estructuras arquitectónicas. Se nota también la continua erosión de la superficie de los muros y el "enterramiento" parcial de algunas secciones del sitio, específicamente las más próximas a los farallones del cerro, debido al constante acarreo de material aluvial proveniente de la cima del mismo.

\section{CERRO GUANACO VII}

Ubicación: El sitio se ubica sobre una pequeña terraza entrecortada en la escarpada pendiente de uno de los contrafuertes del cerro Guanaco, en el lado noroeste, en la margen izquierda del río Cañete. Se accede continuando el recorrido hacia el suroeste del sendero que flanquea la base de la ladera noroeste del cerro Guanaco, tomando una pequeña ruta de fuerte talud hacia la parte media del cerro. La ubicación UTM del sitio es: 8576662 N, 0385379 E y a 755 m de altitud.

Descripción: Este sitio está conformado por un pequeño conjunto de recintos de planta rectangular erigidas sobre dos niveles de terrazas, mejorando las abruptas condiciones del terreno. Dichas construcciones miden aproximadamente $2 \mathrm{~m}$ por lado, estando el paramento interior de uno de ellos decorado con tres nichos de planta rectangular. A la base del muro de contención de la terraza superior se adosa una pequeña construcción delimitada por pequeños muros de contención que se proyectan hasta un aparente pasadizo que recorre longitudinalmente el sitio. En la parte baja, donde la pendiente adquiere mayor talud, se han alzado algunos recintos aterrazados cuya planta se adaptó a la topografía del terreno. A diferencia de los muros de otros sitios, los muros que se han levantado en cerro Guanaco VII poseen un ancho de 0,30 m, construidos en base a mampostería careada unida con argamasa de barro y cascajo, dispuesta en dos hileras simples con una abertura central muy estrecha rellenada con tierra y cascajo bien apisonado. Algunos muros se han construido, en parte, con adobes paralelípedos de 0,38 $\mathrm{m}$ de largo, 0,15 $\mathrm{m}$ de ancho y $0,10 \mathrm{~m}$ de ancho como promedio, sobrepuestos a los muros de 
mampostería. Los paramentos de ambos tipos de muros presentan rastros de revoque de barro sin enlucido o pintura.

Materiales asociados: Se ha identificado algunos restos de cerámica fragmentada, con una pasta de $3 \mathrm{~cm}$ de grosor, principalmente derivadas de tinajas o vasijas de gran tamaño. La pasta varía del color naranja a marrón claro en los fragmentos delgados, con inclusiones de piedra y arena de acuerdo al grosor de la pasta.

Asociación cronológica: Intermedio Tardío-Horizonte Tardío.

Estado de conservación: Malo. El sitio se encuentra en pésimas condiciones. Presenta el colapso parcial de muros y basamentos (muros de contención), erosión superficial de los paramentos que han deteriorado la cubierta de barro que los protegía, perforaciones en la superficie y en algunos muros de contención producto de excavaciones clandestinas (huaqueo), afectando la estructura interna o núcleo de las construcciones. Una parte del sitio está cubierto de material aluvial acarreado de la cima del cerro y que se deposita naturalmente en esta zona.

\section{CERRO GUANACO VIII}

Ubicación: El sitio se ubica sobre una ladera de regular pendiente, en el lado noroeste del cerro Guanaco, a $400 \mathrm{~m}$ aproximadamente del sitio arqueológico cerro Guanaco VII, en los terrenos del anexo de Romaní, en la margen izquierda del río Cañete. Se accede al sitio siguiendo hacia el suroeste la trayectoria del sendero ubicado en la base del flanco noroeste del cerro Guanaco, paralelo al canal de regadío que resulta del canal matriz San Marcos en la zona de Guagil, desde el sitio arqueológico anterior. Se localiza en los puntos UTM: 8576440 N, 385178 E y a 732 m de altitud.

Descripción: Este sitio está conformado por un conjunto de pequeños recintos subterráneos aterrazados, que se suceden en un radio aproximadamente de $15 \mathrm{~m}$ a la redonda desde la parte central. Están construidos íntegramente a base de mampostería careada unida con argamasa de barro y cascajo, recubiertos por un revoque de barro de $0,5 \mathrm{~cm}$ de grosor, sin rastros de pintura o enlucido. Estos recintos poseen planta semicircular y sección troncocónica, orientados de norte a sur. Su boca mide 0,60 m de diámetro y 1,10 m de altura promedio. Delimitando el sitio por el lado suroeste se erige un muro construido con mampostería careada unida con argamasa de barro y cascajo, dispuesta en dos hileras con una depresión central rellenada con tierra y cascajo bien apisonado, alcanzando un ancho de 0,60 m, 1,00 m.de altura y $16 \mathrm{~m}$ de ancho.

Evidentemente, dada su configuración arquitectónica, en este sitio se llevaron a cabo actividades de carácter eminentemente funerario.

Materiales Asociados: No se identificó material cultural asociado alguno.

Asociación cronología: Intermedio Tardío.

Estado de conservación: Muy malo. Se aprecia principalmente, excavaciones clandestinas que han provocado el colapso de muchas de las estructuras y terrazas que componen el sitio.

\section{CERRO GUANACO IX}

Ubicación: El sitio se ubica sobre una ladera de regular pendiente, en la ladera noroeste del cerro Guanaco, a $150 \mathrm{~m}$ aproximadamente del sitio arqueológico cerro Guanaco VIII. En los terrenos del anexo de Romaní, margen izquierda del río Cañete, adyacente a una pequeña ocupación moderna. Se accede al sitio siguiendo hacia el suroeste la trayectoria del sendero ubicado en la base del flanco noroeste del cerro Guanaco, paralelo al canal de regadío que resulta del canal matriz San Marcos en la zona de Guagil, desde el sitio arqueológico anterior.

Descripción: Este sitio se compone de un conjunto de construcciones de planta cuadrangular, muy deterioradas, cuyos lados miden $2,50 \mathrm{~m}$, construidos íntegramente en base a mampostería 
careada unida con argamasa de barro y cascajo, recubiertos por un revoque de barro de 0,5 cm de grosor, sin rastros de pintura o enlucido. Se disponen sobre una plataforma de regulares dimensiones que nivela el terreno de regular pendiente y se orienta de este a oeste. Asociado a este grupo de construcciones se observa una gran cantidad de pequeñas terrazas edificadas con mampostería ordinaria unida con argamasa de barro que se distribuyen en un tramo aproximado de $100 \mathrm{~m}$ al este y $50 \mathrm{~m}$ al oeste, cuyo propósito fundamental fue contener sobre su superficie cierta parte del material aluvial acarreado desde la cima del cerro.

Material asociado: No se identificó material cultural asociado, dada la gran alteración del terreno.

Asociación cronológica: Intermedio Tardío.

Estado de conservación: Pésimo. Muchos de los muros que definen las edificaciones han colapsado a causa de actividad humana reciente en el sector. Una ocupación moderna ubicada en el lado este tangibiliza este hecho, pues, ocupan parte de las estructuras arqueológicas y las han habilitado como viviendas y corrales de ganado.

\section{CERRO GUANACO $X$}

Ubicación: El sitio se ubica en un terreno de pendiente regular de la ladera noroeste del cerro Guanaco, sobre los terrenos del anexo de Romaní, margen izquierda, a $100 \mathrm{~m}$ aproximadamente de la última concentración de terrazas del sitio cerro Guanaco IX. Se accede siguiendo hacia el suroeste la trayectoria del sendero ubicado en la base del flanco noroeste del cerro Guanaco, paralelo al canal de regadío, desde el sitio anterior. Se ubica en las coordenadas UTM: 8575940 N, $0384484 \mathrm{E}$ y a $737 \mathrm{~m}$ de altitud.

Descripción: Este sitio se compone de un conjunto de estructuras arquitectónicas aterrazadas orientadas de este a oeste y dispuestas en sentido longitudinal a la pendiente del cerro. Poseen planta cuadrangular (2,80 m por lado como promedio) y está desnivelada 1,50 m aproximadamente con respecto a la superficie del terreno. Se han construido con mampostería careada unida con argamasa de barro rellenada con tierra y cascajo apisonado, alcanzando un ancho de 0,60 $\mathrm{m}$ promedio. Los paramentos están cubiertos con revoque de barro, ligeramente erosionado sin rastros de pintura. Se disponen sucesivamente en dos niveles de terrazas, siendo la inferior la más afectada por las constantes intervenciones clandestinas. Estas estructuras cumplían la función de depósitos.

Materiales asociados: Se ha identificado algunos fragmentos de cerámica diagnóstica, principalmente bordes de cantaros o jarras, de lados evertidos y labio biselado, de lados convexos y labios redondeados o biselados, la pasta varía del color marrón claro a marrón oscuro, principalmente derivados de jarras o cántaros. Algunos fragmentos de bordes de mayor grosor, manifiestan rasgos idénticos a los ya registrados en otros sitios arqueológicos; es decir, pasta color naranja a marrón oscuro de lados divergentes y borde redondeado y cuerpo de forma ovoide.

Asociación cronológica: Intermedio Tardío-Horizonte Tardío.

Estado de conservación: Malo. El sitio evidencia el colapso parcial de los muros externos debido a perforaciones en la base causadas por excavaciones clandestinas (huaqueo), así como la erosión superficial del paramento de los muros causado por acarreo de material de naturaleza aluvial.

\section{CERRO GUANACO XI}

Ubicación: El sitio se ubica en la base de un farallón de la ladera noroeste del cerro Guanaco, sobre un depósito de material aluvial acarreado de la cima del cerro (lecho aluvial), a $100 \mathrm{~m}$ aproximadamente al suroeste del sitio arqueológico cerro Guanaco X. Dentro de los límites del 
anexo Romaní, en la margen izquierda del río Cañete. Se accede al sitio siguiendo un sendero muy accidentado hacia el suroeste, practicado sobre la ladera noroeste del cerro Guanaco, desde el sitio cerro Guanaco XI. La localización UTM del sitio es: 8575938 N, 0384453 E y a 735 m de altitud.

Descripción: El sitio se compone de una serie de estructuras arquitectónicas de planta cuadrangular dispuestas en sentido longitudinal a ladera del cerro (este-oeste). Sus características morfológicas y espaciales son similares a las descritas para el sitio anterior. Es decir, constituyen espacios de 2,80-3 m por lado sin accesos, construidos en base a mampostería de piedra careada unida con argamasa de barro, rellenada con tierra y cascajo apisonado, brindándole mayor solidez al muro y alcanzando un ancho de $0,55 \mathrm{~m}$ de ancho. Sus paramentos están cubiertos con un revoque de barro de 0,02 $\mathrm{m}$ de grosor. Presentan 1,60 m aproximadamente de desnivel con respecto a la superficie natural del terreno. De manera similar al sitio anterior, se empleó como un área de depósitos.

Materiales asociados: Fue posible identificar algunos restos de cerámica fragmentada diagnóstica, específicamente, bordes de vasijas de gran magnitud que probablemente se destinaron a almacenar agua o algún tipo de producto agrícola (granos). Estos bordes presentan lados divergentes y labios redondeados; algunas asas cintadas pertenecientes a ollas o algún tipo de recipiente de tamaño regular. Las pastas son de color marrón oscuro y contienen inclusiones de piedra, arena y cuarzo.

Asociación cronológica: Intermedio Tardío-Horizonte Tardío.

Estado de conservación: Malo. Los muros evidencian erosión basal y superficial a causa de factores ambientales, así como el desfasamiento y colapso parcial de muros externos por causas ambientales.

\section{CERRO GUANACO XII}

Ubicación: El sitio se ubica sobre el piso del valle, rodeado de campos de cultivo y adyacente a las estribaciones del cerro Guanaco, a 500 m aproximadamente de cerro Guanaco XI. No existe un acceso formalmente establecido al sitio, atravesando en dirección noroeste-sureste desde el sitio anterior los campos de cultivo, que se proyectan hasta la base del cerro Guanaco impidiendo el transito sobre sus faldas debido a la fuerte pendiente que se forma. Se localiza en los puntos UTM: 8575888 N, 0384191 E y a 724 m de altitud, en la margen izquierda del río Cañete.

Descripción: Este sitio se emplaza sobre un terreno de regular pendiente, dada su proximidad a las estribaciones rocosas del cerro Guanaco, totalmente habilitado como terrenos de cultivo, incluyendo el interior de los distintos espacios arquitectónicos que forman este sitio arqueológico que en conjunto, adopta forma alargada y orientación este-oeste. Se compone de una serie de recintos aterrazados y patios cercados a manera de canchas, establecidos sobre una superficie regular, que se distribuyen en un eje este-oeste. En el extremo este se localiza un pequeño grupo de ambientes de trazo recto edificados sobre una ancha terraza, comunicados entre si a través de accesos de lados rectos o pasadizos. Un ambiente en particular evidencia remodelaciones arquitectónicas, dado que después de un primer uso se rellenó el interior con tierra, piedras y cascajo hasta nivelarse con la cabecera de los muros, consolidándose como un montículo de estructura sólida. El sello del acceso con mampostería careada y el empleo de adobes como material constructivo en reemplazo de los mampuestos, comúnmente utilizados en edificaciones de la zona, apoyan esta aseveración, representando la mejor prueba de dicho proceso de remodelación arquitectónica. Algunos muros exhiben nichos de planta casi cuadrangular ( 0,30 x 0,27 m) como decoración. Empotrado en el piso, muy próximo a un acceso, se registró una vasija (tinaja) de regulares dimensiones, cuyo diámetro alcanza $1,20 \mathrm{~m}$ y una altura de 0,80 $\mathrm{m}$ aproximadamente de pasta gruesa y color naranja. En los alrededores se observa pequeñas estructuras muy dañadas 

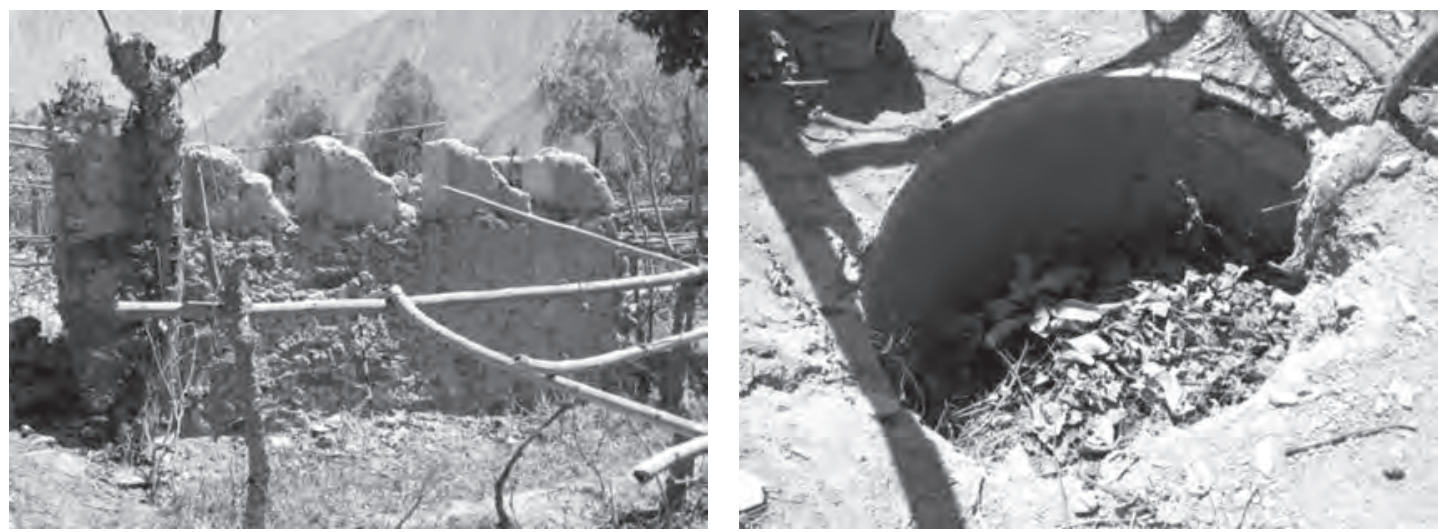

Figura 9. Izquierda: Vista del estado de conservación del sitio de Cerro Guanaco XII. Derecha: Vista de una vasija grande empotrada en el suelo.

y poco definidas.

En el extremo oeste se identificó dos patios de planta rectangular, cercadas por muros que alcanzan, en algunos casos, $3 \mathrm{~m}$ de altura, dispuestas sucesivamente en un eje este-oeste. En el interior de uno de estos patios se observa una afloración rocosa de regulares dimensiones que definitivamente reserva un carácter naturalmente simbólico. La parte superior de los muros que delimitan y dividen ambos espacios arquitectónicos se han decorado con diseños escalonados empleando adobes como elemento constructivo básico. En unos casos solamente se delineó un motivo escalonado contrapuesto dividido por una línea incisa y, en otros casos, se completó un diseño escultórico en forma de escalera aprovechando los lados planos de los adobes.

Se ha empleado técnica mixta en la edificación de las distintas estructuras arquitectónicas, por un lado se utilizó como material constructivo mampostería careada (aparejo regular) unida con argamasa de barro y cascajo, dispuestas en doble hilera con un relleno de piedra, cascajo y barro en el interior a fin de adquirir consistencia y solidez, por otro lado, se usó adobes paralelepípedos dispuestos a tizón unidos con argamasa de barro y cascajo. Indistintamente del material constructivo empleado, los paramentos de los muros se cubrieron con revoque de barro de 0,02 $\mathrm{m}$ de grosor y con rastros de pintura color rojo ocre. Es evidente que las construcciones de adobe se superponen a las de mampostería y, en ciertos casos, se reconstruyó usando el mismo tipo de material constructivo.

Materiales asociados: No se identificó restos de material cultural asociado sobre la superficie del terreno debido a la fuerte alteración que se produjo al habilitar los espacios interiores como áreas de cultivo, salvo la vasija descrita líneas arriba.

Asociación cronológica: Intermedio Tardío-Horizonte Tardío.

Estado de conservación: Malo. Se aprecia el colapso parcial y fuerte erosión basal de los muros que constituyen las diversas estructuras arquitectónicas del sitio cerro Guanaco XII, debido a la fuerte humedad del terreno y las intensas actividades agrícolas orientadas al cultivo de viña. Muchos muros han sido destruidos con el propósito de ganar mayor cantidad de tierras agrícolas.

\section{CERRO GUANACO XIII}

Ubicación: Este sitio se ubica en la quebrada de Guanaco, ocupando principalmente las estribaciones rocosas irregulares de las márgenes norte y sur que encierran el cono de deyección de la quebrada, adyacentes a los Cerros Guanaco y Mal Paso respectivamente, en la margen izquierda del río Cañete. Se accede al sitio atravesando los campos de cultivo desde la carretera Lunahuaná- 
Pacarán hacia el Asentamiento Humano Guanaco emplazado en la base del cono de deyección de la quebrada de Guanaco.

Descripción: El sitio está conformado por tres sectores:

- Sector "A": Se localiza sobre una pendiente regularmente pronunciada del cerro Guanaco, en el margen norte de la quebrada de Guanaco, en las coordenadas UTM: 8575510 N, 0383934 E a $721 \mathrm{~m}$ de altitud. Adquiere forma irregular y se orienta de este a oeste. Comprende un conjunto de estructuras arquitectónicas aterrazadas dispuestas sucesivamente desde la base de esta sección del cerro, muy cerca a los campos de cultivo y a la acequia derivada del canal de San Marcos, hasta la cima del mismo.

Se identificó distintos tipos de arquitectura que cumplían roles específicos. En la sección más alta del cerro se erige una construcción de $20 \mathrm{~m}$ de largo aproximadamente, de planta rectangular constituida por un serie de ambientes de pequeñas dimensiones y planta principalmente cuadrangular (4-3 m por lado), dispuestos en un eje este-oeste y sin accesos que comuniquen estos espacios. Evidentemente dada su configuración morfológica se empleó como espacios para almacenar cierto tipo de bienes, probablemente, de naturaleza agrícola como granos, dada la existencia de restos de cerámica fragmentada de pasta gruesa perteneciente a vasijas de considerables dimensiones.

En la parte media y baja del sitio se concentran un grupo de estructuras arquitectónicas de planta cuadrangular y rectangular de dimensiones regulares sin accesos desde el exterior; algunas de ellas divididas en ambientes menores con los muros decorados con hornacinas de planta rectangular y levemente trapezoidal mostrando restos de la cubierta de lajas que cubría esos ambientes formando cámaras de evidente función funeraria muy alteradas. En otros casos, se exhiben estructuras subterráneas alojadas en el interior de terrazas con una pequeña ventana cuadrada en el muro de contención, también alteradas por excavaciones clandestinas realizadas en años anteriores.

Se han edificado íntegramente en base a mampostería de piedra canteada (aparejo regular) unida con argamasa de barro y cascajo dispuesta en dos hileras con un relleno en el centro de cascajo, piedra y tierra apisonada, brindándole solidez al muro. Los paramentos externos e internos conservan gran parte del revoque de barro e incluso, parte del enlucido de barro color beige que cubre el interior de los muros y hornacinas o nichos de las cámaras funerarias. Los muros mejor conservados alcanzan los 2,20 m de altura y 0,70 $\mathrm{m}$ de ancho.

- Sector "B": Este sector se localiza al SE del sector anterior, en las coordenadas UTM: 8575448 N, 0383911 E y a $721 \mathrm{~m}$ de altitud; ocupando una prolongación rocosa de forma alargada y de baja altura del cerro Guanaco hacia el centro del cono de deyección de la quebrada de Guanaco. Se compone de estructuras arquitectónicas aterrazadas de planta rectangular y cuadrangular bastante similares morfológicamente y funcionalmente a las erigidas en el sector "A", las que a diferencia se encuentran muy seriamente dañadas por la reutilización de muchos de sus ambientes como depósitos de paja y restos secos de cultivos de maíz (chala) usados como alimento de ganado, y otros, como corrales de ganado, principalmente caprino. Están edificadas íntegramente a base a mampostería de piedra careada (aparejo regular) unida con argamasa de barro y cascajo dispuestas en dos hileras con un relleno en el centro de cascajo, piedra y tierra apisonada, brindándole solidez al muro. Los paramentos externos e internos conservan gran parte del revoque de barro

- Sector "C": Este sector se localiza al SE del sector B, sobre una amplia terraza natural de la margen sur de la quebrada Guanaco, en las coordenadas UTM: 8575282 N, 0383914 E y a 751 m de altitud. Posee forma irregular y se orienta de norte a sur. Se compone de un gran conjunto de estructuras arquitectónicas subterráneas de planta cuadrangular, rectangular y semicircular, de tamaños muy variados distribuidos sobre un área considerablemente extensa, penetrando, 

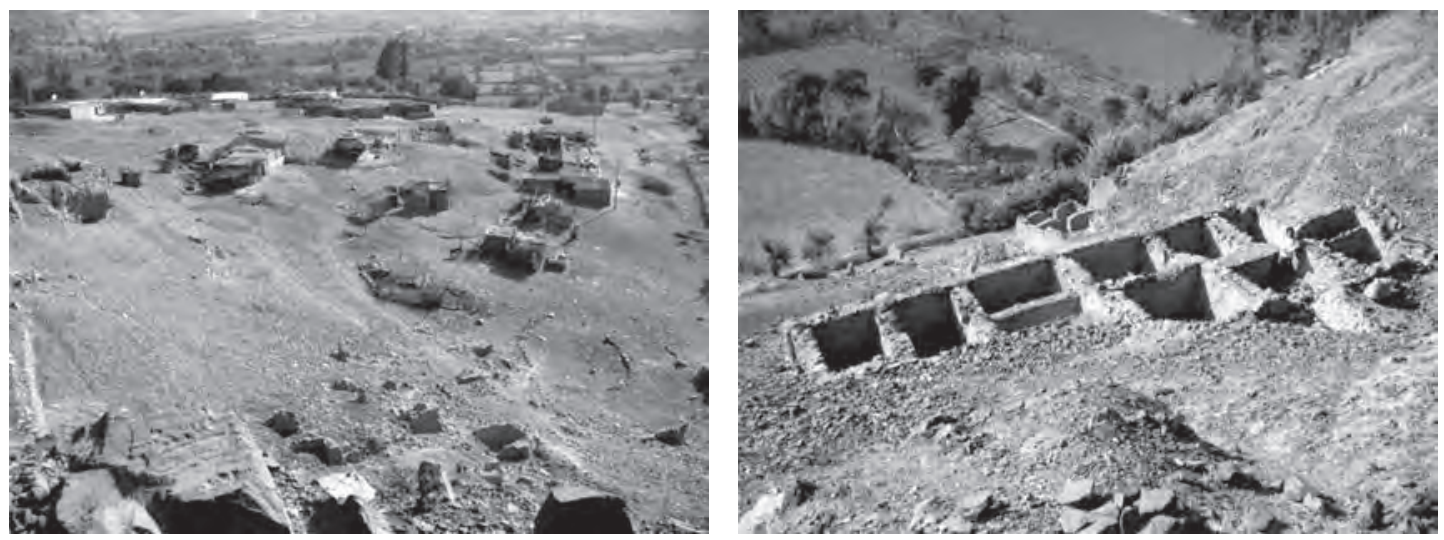

Figura 10. Izquierda: Vista panorámica del sitio de Cerro Guanaco XIII. Derecha: Vista del sector A de Cerro Guanaco XIII.

incluso, en las pequeñas quebradas que se forman en sentido transversal a la orientación de la quebrada Guanaco. Se distribuyen sucesivamente y de modo regular, adaptándose al contexto topográfico del terreno donde se asienta. Indudablemente, este tipo de estructuras cumplían funciones estrictamente funerarias. Dada la magnitud del espacio abarcado por algunas de ellas afirmamos el carácter múltiple de tales construcciones. Estas estructuras se han edificado en base a mampostería careada (aparejo regular), unida con argamasa de barro y cascajo. Los paramentos exhiben restos de revoque de barro muy erosionado sin rastros de pintura. Alcanzan una profundidad promedio de $1,20 \mathrm{~m}$.

Materiales asociados: En los sectores "A" y "B" se identificó bajos niveles de concentración de restos fragmentados de cerámica diagnóstica, constituidos por bordes fragmentados de cerámica llana pertenecientes a vasijas de magnitud regular como tinajas, empleadas principalmente para almacenaje y depósito de recursos comestibles. Solo se identificó un fragmento de cerámica con decoración pictórica en bandas alternadas de color marrón y negro. En el sector "C" se identificó la mayor concentración diagnóstica de material cultural para la margen izquierda de esta sección del valle. Proviene de restos asociados a contextos funerarios muy disturbados y dispersos en cantidades sorprendentes sobre la superficie del terreno. Gran parte consiste en restos de cerámica fragmentada pertenecientes a vasijas de formas no domesticas de pasta fina color naranja, con la superficie exterior pintada en base a diseños escalonados, cuadrangulares, etc. en color naranja, rojo, marrón. Así mismo, registramos algunos fragmentos de cerámicas de pasta muy fina de color gris fabricada en atmósfera reducida con una superficie de color negro bruñido. En el interior de una estructura se observó una concha Spondylus que formó parte del ajuar funerario del individuo o individuos inhumados por los huaqueros. También, se identificó una alta cantidad de restos cerámicos fragmentados pertenecientes a vasijas de formas domesticas sin decoración exterior ya identificadas y descritas para sitios anteriores. Asociados al material cerámico se observó una vasta concentración de restos óseos humanos de individuos de diversas edades (en base a la observación del tamaño del cráneo) dispersos sobre todo el ámbito del terreno que ocupa el sector "C".

Estado de conservación: Malo. El sitio evidencia el colapso parcial de muros y estructuras arquitectónicas secundarias por el continuo transito de personas y ganado sobre la superficie del sitio, produciendo desgaste en la cabecera y base de los muros. También se aprecia la erosión superficial producto de las inestables condiciones atmosféricas (principalmente lluvias). Las excavaciones clandestinas han destruido la totalidad de los contextos funerarios inhumados en todos los sectores del sitio. 


\section{CERRO MAL PASO I}

Ubicación: El sitio se ubica en la ladera noroeste del cerro Mal Paso, a $500 \mathrm{~m}$ aproximadamente al suroeste de la quebrada de Guanaco y del sitio arqueológico cerro Guanaco XIII, casi en línea recta con el puente de Antahuaya y dentro de los límites del anexo de Romaní, en la margen izquierda del río Cañete, en las coordenadas UTM: 8574918 N, 0383530 E y a 718 m de altitud. Se accede al sitio siguiendo el sendero que bordea la parte baja del flanco NW del cerro Mal Paso, paralelo al canal de regadío, desde la quebrada de Guanaco.

Descripción: Este sitio se ubica sobre una ladera de pendiente regular, alterada por una especie de "relleno" cubierto de material de naturaleza aluvial, sobre el cual se ha edificado un conjunto de estructuras arquitectónicas aterrazadas de planta cuadrangular, distribuidas a lo largo de la pendiente (este-oeste), adaptando su diseño a la topografía del terreno. Se distinguen aproximadamente diez unidades arquitectónicas sin acceso entre sí, con un desnivel promedio de 1,60 $m$ con respecto a la superficie del terreno. Se ha edificado en base a mampostería careada unida con argamasa de barro y cascajo (consistente), rellenando el interior con piedra y cascajo a fin de brindarle mayor estabilidad y solidez, alcanzando un ancho promedio de 0,55 $\mathrm{m}$ en los muros exteriores. La cabecera del muro ha sido reforzada con una hilera de mampostería ordinaria dejando una especie de alero que sobrepasa el nivel de la superficie del muro, con el indudable propósito de evitar la erosión debido al continuo transito de personas sobre su superficie. El paramento de los muros está recubierto con revoque de barro con ciertos rastros de pintura color rojo ocre. Este tipo de estructuras arquitectónicas, probablemente, funcionaron como establecimientos donde se realizaron actividades de aprovisionamiento o almacenamiento de cierto tipo de productos.

En la parte superior del sitio se identificó una serie de estructuras subterráneas aterrazadas de planta semicircular y sección troncocónica, dispuestas irregularmente sobre la ladera del cerro, mide $0,90 \mathrm{~m}$ de diámetro de boca y $1 \mathrm{~m}$ de profundidad. Se han construido con mampostería careada unida con argamasa de barro, con indicios de revoque muy erosionado que cubrió el paramento visible. Evidentemente, esta sección del sitio funcionó como área de carácter exclusivamente funerario, como se manifiesta en los elementos culturales asociados y los rasgos arquitectónicos propios.

Materiales asociados: Sobre la superficie del sitio se registró restos de cerámica fragmentada, presentando rasgos particulares ligados al área donde se localiza. En este sentido, la cerámica ubicada sobre las estructuras subterráneas presentan pasta delgada, color marrón oscuro, superficie principalmente alisada. Los tipos se definieron en base a la forma de los bordes, existen aquellos de lados convexos y labio biselado o redondeado; lados cortos y evertidos con labio pronunciado hacia el exterior; lados ligeramente divergentes y borde biselado, pertenecientes a cántaros, jarras y ollas. Del mismo modo, se aprecia regular concentración de restos óseos humanos visiblemente alterados y esparcidos sobre la superficie o dentro de las estructuras subterráneas. Aún se conserva restos de las vigas que sostuvieron la cubierta de las estructuras, de piedras planas o lajas que cubrieron la boca de los recintos funerarios (troncos de molle).

En la superficie del área con estructuras cuadrangulares es posible reconocer restos de vasijas fragmentadas de pasta gruesa correspondientes a recipientes de gran magnitud correspondientes a un espacio destinado al almacenaje.

Asociación cronológica: Intermedio Tardío-Horizonte Tardío.

Estado de conservación: Malo. El sitio evidencia el derrumbe parcial de los paramentos interiores y cubierta de los recintos funerarios a causa de constantes excavaciones clandestinas (huaqueo); así como la erosión superficial del revoque y pintura que cubre los paramentos de los muros a causa del intemperismo y rozamiento constante con material de naturaleza eólica y aluvial que se deposita periódicamente en el área acarreado desde la cima del cerro Mal Paso. 


\section{CERRO MAL PASO II}

Ubicación: El sitio se ubica sobre una pequeña quebrada de pendiente regular en la ladera noroeste del cerro Mal Paso, a unos 300 m río abajo de la quebrada de Guanaco, margen izquierda del río Cañete. La ubicación UTM del sitio es: 8575006 N, 0383634 E a 700 m de altitud. Se accede al sitio siguiendo el sendero que bordea la parte baja del flanco noroeste del cerro Mal Paso, paralelo al canal de regadío, desde la quebrada de Guanaco.

Descripción: El sitio está conformado por un conjunto de terrazas de carácter funerario, distribuidas de forma irregular sobre la ladera del cerro Mal Paso. Estas terrazas se han construido con mampostería ordinaria unida con argamasa de barro y cascajo. Gran parte de ellas alojan una pequeña construcción subterránea de planta semicircular y de sección troncocónica, cuyas medidas promedios son 0,50 $\mathrm{m}$ de diámetro mayor, 0,30 m de diámetro menor y 0,60 $\mathrm{m}$ de profundidad, edificadas con mampostería careada levemente labrada unidas con argamasa de barro y cascajo sin rastros de revoque sobre los paramentos.

Materiales asociados: Solo se identificó algunos fragmentos de cerámica llana no diagnóstica dispersos sobre la superficie del terreno asociados a restos de material óseo muy erosionado.

Asociación cronológica: Intermedio Tardío-Horizonte Tardío.

Estado de conservación: Muy Malo. Los muros presentan colapso parcial y, en la mayoría de los casos, total de los paramentos que definen las estructuras subterráneas instaladas en el interior de las terrazas arquitectónicas debido a las intensas excavaciones clandestinas realizadas en el sitio (huaqueo).

\section{CERRO MAL PASO III}

Ubicación: Se ubica sobre una hendidura poco profunda de la ladera noroeste del cerro Mal Paso, extendiéndose desde la base, donde se forma un delta aluvial, hasta la parte alta del cerro, dentro de los límites del territorio del anexo de Jacaya, a unos $400 \mathrm{~m}$ aproximadamente del sitio cerro Mal Paso I, margen izquierda del río Cañete. Se accede al sitio siguiendo un camino delimitado por muros que atraviesa los campos de cultivo y se dirige hasta la base del cerro Mal Paso, partiendo desde la carretera afirmada Pacarán-Lunahuaná, muy cerca a la quebrada de Jacaya.

Descripción: Está conformado por 2 sectores:

- Sector "A": Este sector se localiza en la parte baja de la ladera noroeste del cerro Mal Paso, sobre un terreno irregular cubierto con material de naturaleza aluvial, acarreado desde la cima del cerro. Presenta forma alargada, orientado de este-oeste, y se distribuye siguiendo el contorno de esta sección de la ladera del cerro. La ubicación UTM de este sector es: 8574666 N, 0383211 E, a $694 \mathrm{~m}$ de altitud. Se compone de una serie de estructuras subterráneas aterrazadas de planta rectangular, generalmente, orientadas de este-oeste, cuyos muros se han construido plenamente con material local, es decir, mampostería careada unida con argamasa de barro y cascajo sin rastros de revoque sobre la superficie de sus paramentos. Estos recintos miden entre 5-6 $\mathrm{m}$ de largo y 2-3 $\mathrm{m}$ de ancho como promedio y, evidentemente, operaron como espacios destinados a actividades de carácter específicamente funerarias.

- Sector "B": Este sector se ubica en la parte alta de una estribación rocosa que sobresale del cerro Mal Paso a manera de espolón que manifiesta una superficie regular compuesta de material de origen aluvial, en las coordenadas UTM: 8574674 N, 383191 E y a 808 m de altitud. Se encuentra seccionado por la construcción de 2 caminos que atraviesan longitudinalmente el espacio ocupado por las estructuras arqueológicas. Está constituido por un conjunto de estructuras subterráneas de planta semicircular y sección troncocónica, construidas directamente sobre terreno 
natural. Se han construido completamente con mampostería ordinaria unida con argamasa de barro y cascajo sin restos de revoque sobre la superficie de los paramentos. Se empleó como cubierta piedras plana o lajas que se colocaron en sentido radial, convergiendo hacia el centro de la estructura, fijadas sobre un soporte de madera, generalmente un tronco de molle. Indudablemente este sector funcionó como un área particularmente de carácter funerario.

Material asociado: Sobre la superficie de ambos sectores es posible identificar una vasta cantidad de restos óseos humanos, emplazados originalmente en el interior de las estructuras subterráneas antes descritas. Podemos reconocer cráneos completos y fragmentados, restos de huesos largos seccionados, vértebras y otras partes del armazón humano muy deterioradas. Asociados a las estructuras subterráneas de planta rectangular del sector "A" se registró una regular cantidad de material cerámico diagnóstico y no diagnóstico pertenecientes a cántaros de lados convexos y labio biselado, de lados rectos o ligeramente evertidos y labio plano pronunciado o redondeado; ollas sin cuello y labio biselado o cuello corto evertido con labios biselados, siempre con asas cintadas verticales que se disponen en lados diametralmente opuestos de la vasija. Además, se recuperó restos de telas llanas muy deterioradas por agentes externos como el fuego y la humedad. La mayoría no exhibe decoración; sin embargo, algunas muestran restos de pintura distribuidas en bandas transversales de color azul y marrón. En el interior de una estructura muy alterada se observó una concha spondylus en regular estado de conservación.

En el sector "B" se identificó restos fragmentados de vasijas llanas diagnósticas y no diagnósticas. Los tipos cerámicos son similares a los reconocidos en el sector "A". También, recuperamos algunos fragmentos de cerámica de pasta muy fina con decoración pintada en la superficie externa que consisten en bandas alternas de color rojo, marrón y azul o diseños escalonados empleando los mismos colores.

Asociación cronológica: Intermedio Tardío-Horizonte Tardío.

Estado de conservación: Malo. Se aprecia el colapso de los paramentos que constituyen los recintos subterráneos y la destrucción total de los contextos funerarios arqueológicos, debido principalmente a excavaciones clandestinas o huaqueo intensivo que se ha llevado a cabo en el sitio arqueológico.

\section{CERRO MANZANILLA I}

Ubicación: Se ubica sobre una terraza aluvial en la parte baja de la ladera noroeste del cerro Manzanilla, aproximadamente un kilómetro río abajo desde la quebrada de Jacaya, en las coordenadas UTM: 8572744 N, 0381571 E y a 630 m de altitud, en la margen izquierda del río Cañete. Se accede al sitio siguiendo un camino transversal que atraviesa los campos de cultivo y se dirige a la base del cerro Manzanilla, donde se ubica un pequeño Asentamiento Humano denominado Jacaya Chico, ubicado a la altura del kilómetro 48 de la carretera Pacarán-Lunahuaná.

Descripción: cerro Manzanilla I se emplaza sobre un delta aluvial de pendiente regular orientada de norte a sur. Las estructuras arquitectónicas se distribuyen desde la base hasta alcanzar las primeras estribaciones rocosas del cerro Manzanilla, adoptando una forma irregular. Se compone de un conjunto de ambientes y plazas aterrazadas de planta rectangular que se disponen sucesivamente a lo largo de la base del cerro. Estos espacios se comunican longitudinalmente por medio de accesos y pasadizos, y transversalmente, a través de escalinatas que comunican espacios localizados en distintos niveles.

Hemos reconocido dos áreas funcionalmente diferentes: La primera concentra ambientes de regulares dimensiones articulados entre si y asociados a dos pequeñas plazas, de carácter administrativo. La segunda se ubica próxima a las estribaciones rocosas, en la parte superior del sitio, y se compone de estructuras arquitectónicas de planta cuadrangular (2,50 m por lado aproximadamente) evidentemente con propósitos de almacenaje. 
La técnica constructiva es a base de mampostería careada (aparejo regular) unida con argamasa de barro y cascajo dispuesta en doble hilera con un relleno en el centro de piedra, cascajo y barro apisonado a fin de brindarle solidez y estabilidad estructural. Los paramentos están cubiertos con revoque de barro de 0,02 $\mathrm{m}$ de grosor con rastros de pintura de color rojo ocre.

Materiales asociados: Sobre la superficie del sitio hemos identificado regular cantidad de restos de cerámica fragmentada diagnóstica que presentan rasgos similares a los descritos para la mayoría de los sitios antes registrados. Principalmente se registró, fragmentos de pasta gruesa (0.02 m.) pertenecientes a grandes vasijas (tinajas), de color naranja y marrón oscuro con inclusiones de piedra y arena. Los bordes manifiestan formas diversas: algunos presentan lados divergentes y labio redondeado o biselado, otros poseen lados cóncavos y labio biselado o con un reborde plano hacia el exterior.

Asociación cronológica: Intermedio Tardío.

Estado de conservación: Pésimo. Se aprecia la reutilización de algunas estructuras arquitectónicas como viviendas modernas y habilitación de silos en otros ambientes menores. Del mismo modo, los espacios arquitectónicos de la parte baja se emplean como corrales de ganado caprino, lo que produce el colapso de los muros y el desgaste de la superficie de los paramentos; así como el intenso traslado de ganado sobre las estructuras no habilitadas para uso moderno que produciendo fuerte desgaste de las cabeceras, base y superficie de los muros arqueológicos.

\section{CERRO MANZANILLA II}

Ubicación: El sitio se ubica sobre una loma o proyección de la ladera norte del cerro Mal Paso hacia los campos de cultivo a manera de espolón, sobre una superficie regular altamente erosionada por la constante actividad aluvial y eólica, en la margen izquierda del río Cañete. Se accede siguiendo un sendero, cuesta arriba desde la carretera Pacarán-Lunahuaná, en el tramo donde se ubica el núcleo poblacional del anexo de Jacayita.

Descripción: Este sitio está conformado de una construcción de planta rectangular de aproximadamente $30 \mathrm{~m}$ de largo y $18 \mathrm{~m}$ de ancho orientado de norte a sur. En su interior se construyó una plataforma de $0,25 \mathrm{~m}$ de alto aproximadamente adosada paralelamente a uno de los muros de mayor longitud, dejando espacio regular a manera de patio o pequeña plaza. Se edificó empleando mampostería ordinaria sin argamasa.

Materiales Asociados: Se registró restos de cerámica fragmentada diagnóstica y no diagnóstica, dispersas sobre la superficie del terreno, pertenecientes a bordes de cántaros y ollas.

Estado de Conservación: Malo. Se aprecia el colapso parcial de los muros perimétricos y paramento exterior de la plataforma a causa de factores naturales.

\section{CERRO MANZANILLA III}

Ubicación: Se ubica en las márgenes izquierda y derecha de la quebrada de Jacayita, ocupando las zonas de regular pendiente que delimitan el cono de deyección de la quebrada, ocupada por un asentamiento humano moderno, en la margen izquierda del río Cañete. Se accede siguiendo un camino de herradura desde la carretera Lunahuaná-Pacarán hacia el asentamiento humano emplazado en el cono de deyección de la quebrada de Jacayita, a la altura del anexo de Jacayita.

Descripción: El sitio está conformado por dos sectores:

- Sector "A": Este sector se ubica en la margen izquierda de la quebrada de Jacayita, sobre una pendiente regularmente pronunciada, en las coordenadas UTM: 8577548 N, $0386241 \mathrm{E}$, a 760 $\mathrm{m}$ de altitud. Posee forma alargada, orientada de norte-sur. Se constituye de un conjunto de recintos de planta cuadrangular que miden entre 2,20-3 m por lado, dispuestos en sentido transversal a su eje de orientación, sin vías de comunicación o accesos interiores que articulen 
estos espacios. En la parte superior se han edificado cinco niveles de terrazas, muy dañadas, con el propósito evidente de contener el acarreo de material de origen aluvial desde la cima del cerro. En la sección inferior se sitúa una plaza o patio aterrazado de planta rectangular, orientada de norte a sur y de regulares dimensiones, asociado a una pequeña plataforma adosada al muro de contención que se fija en la ladera del cerro. En la parte baja existen construcciones arqueológicas habilitadas como viviendas modernas o corrales de ganado caprino. Los muros se han edificado en base a mampostería careada (aparejo regular) unida con argamasa de barro y cascajo, dispuesta en dos hileras con un relleno central que le brinda solidez a los muros, sin revoque que recubra los paramentos de los muros.

- Sector "B": Este sector se emplaza sobre una pendiente muy irregular de la margen derecha de la quebrada de Jacayita, en las coordenadas UTM: 8577548 N, 0386241 E y a 760 m de altitud. Presenta forma alargada y se orienta de este a oeste. Está compuesto por una construcción de planta rectangular dividida en pequeños ambientes de forma cuadrangular sin accesos interiores edificados con mampostería careada unida con argamasa de barro y cascajo dispuesta en dos hileras con relleno de tierra, piedras y cascajo apisonado, cuyos paramentos están cubiertos con revoque de barro de 0,02 $\mathrm{m}$ de grosor muy erosionado.

Materiales asociados: No se identificó material cultural asociado dada las fuertes condiciones de alteración de la superficie de los distintos ambientes que conforman este sitio.

Asociación cronológica: Intermedio Tardío.

Estado de conservación: Pésimo.

\section{HUACA SAN CARLOS}

Ubicación: Se ubica a $500 \mathrm{~m}$ al oeste del pueblo de Pacarán y a $200 \mathrm{~m}$ aproximadamente al sur de la carretera afirmada que une Pacarán con Lunahuaná, en el límite con el anexo de Romaní, margen izquierda del río Cañete, dispuesto sobre el piso del valle, rodeado de campos de cultivo en plena actividad y un bosquecillo de caña guayaquil; en las coordenadas UTM: 8576840 N, 0385031 E, y a $703 \mathrm{~m}$ de altitud. Se accede al sitio recorriendo $500 \mathrm{~m}$ en dirección oeste desde el pueblo de Pacarán a través de la carretera afirmada. No existe un camino formalizado para ingresar al sitio; por lo que se realiza atravesando los campos de cultivo ubicados al sur de la carretera afirmada.

Descripción: El sitio está conformado por un pequeño montículo de casi $4 \mathrm{~m}$ de altura, de planta rectangular, orientado de este a oeste y comprendiendo un área relativamente pequeña. Se compo-
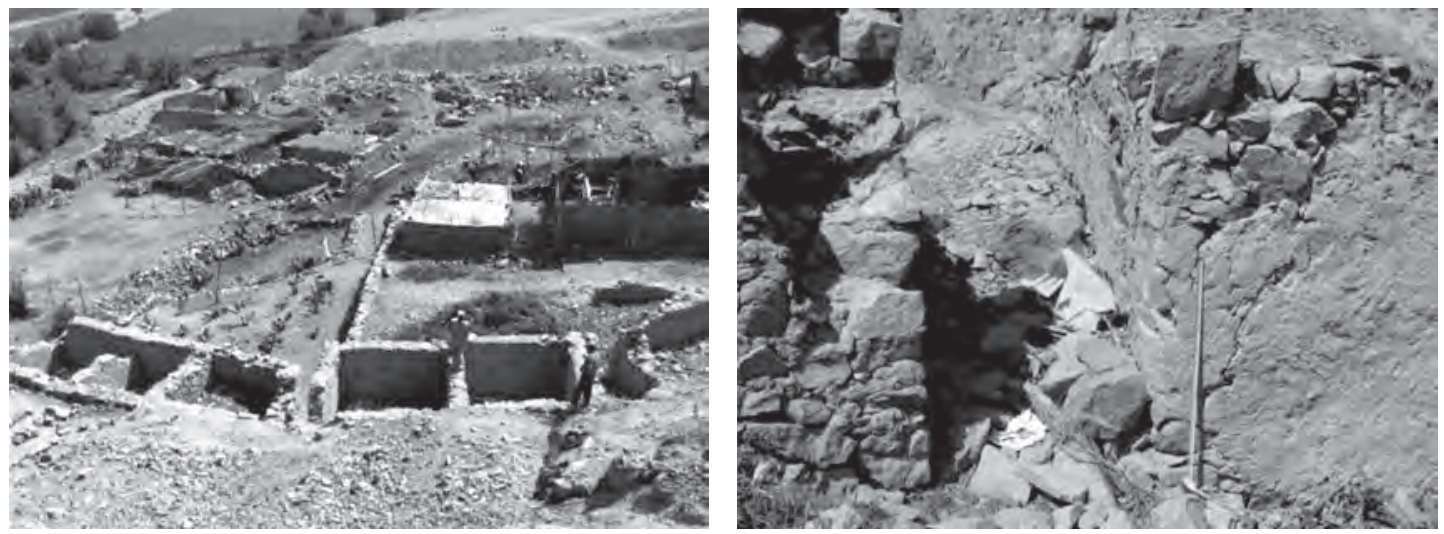

Figura 11. Izquierda: Vista panorámica del sitio Cerro Manzanilla III. Derecha: Vista de una estructura funeraria. 
ne de un núcleo o cuerpo de central de $15 \mathrm{~m}$ por lado, y una plaza cuadrangular hacia el lado norte de $20 \mathrm{~m}$ de largo y 1,5 m de altura sobre el nivel de los campos de cultivo, ocupada completamente por sembríos de viña. El montículo está conformado por tres pequeños patios y un ambiente poco definido a causa del colapso parcial de los muros que lo delimitan, situados a diferente nivel en un eje norte-sur. El patio ubicado en el lado sur luce uno de sus paramentos decorado con dos hornacinas de planta trapezoidal, de manera similar al pequeño ambiente del lado este que exhibe dos nichos u hornacinas de una jamba y una de doble jamba de planta similar, dispuestas frente a frente. En el centro del montículo se observan tres recintos cubiertos completamente con un relleno de tierra, cantos rodados, piedras de cerro y cascajo, siendo en uno de ellos aún evidente parte de las vigas de madera de lúcumo que sirvieron de soporte a la cubierta que techó este ambiente.

En el flaco oeste del montículo, debido al desplome de una sección del muro perimétrico, quedó en evidencia parte de la estructura interna del edificio, específicamente aquella que constituye el basamento del patio sur. Se realizó una leve remoción de tierra definiéndose un perfil donde se pudo observar una sucesión de hasta 4 pisos arquitectónicos cubiertos por un relleno homogéneo de barro y piedra de 0,20 $\mathrm{m}$ de grosor entre cada piso. Cada uno estos pisos estaban asociados a un muro construido con mampostería careada unida con argamasa de barro y cascajo dispuestas en dos hileras dejando un boquete en el centro que fue rellenado con cascajo y tierra, con los paramentos recubiertos por un revoque de barro de $0,01 \mathrm{~m}$ de grosor que se proyectaba hasta casi la cima del montículo, sirviendo de base a un muro de adobón que se superpone. Estos pisos exteriorizaban escaso desgaste y un buen estado de conservación.

El paramento exterior del muro perimetral este, cuyo frontis se orienta a la plaza, exhibe un gran nicho u hornacina de 1,5 $\mathrm{m}$ de altura y $0,8 \mathrm{~m}$ de ancho en su base; posee planta trapezoidal de una jamba con el paramento enlucido y su interior muestra un diseño escalonado obtenido intencionalmente cortando vertical y alternadamente las juntas o llagas de que se dejan entre adobes.

Materiales asociados: En el corte del lado oeste, dentro del relleno que conforma el núcleo del montículo, se observó algunos restos de cerámica fragmentada no diagnóstica. Presenta pasta gruesa irregular con inclusiones de pequeñas piedras y arena, de color naranja claro y superficie exterior alisada. No muestra decoración y debido al tamaño de los fragmentos y grosor de la pasta, probablemente forme parte de algún tipo de tinaja o cántaro.

Asociación cronológica: Ocupación durante el Horizonte Tardío, con evidencia de remodelaciones en el núcleo arquitectónico.

Estado de Conservación: Malo. Se nota el colapso parcial del muro perimetral sur, permitiendo el deslizamiento del material que compone el interior del montículo, afectando las estructura basal del edificio; así como el desgaste y erosión del enlucido y pintura que decora la superficie de los paramentos e interior de los nichos u hornacinas; y, en general, de las cabeceras de los muros y estructuras arquitectónicas secundarias montadas en el sitio. Destrucción de la plaza norte a causa de su uso como campo de cultivo de viñas, y la adición de estructuras arquitectónicas modernas en el centro del área con el propósito de sostener dichas plantaciones.

\section{QUEBRADA PAMPA GRANDE}

Ubicación: El sitio arqueológico Quebrada Pampa Grande se ubica sobre un terraplén de la ladera este del cerro Chilco que penetra en la quebrada Pampa Grande, en la margen derecha del río Cañete. Esta formación es seccionada por pequeñas quebradas en dos áreas con significativa presencia de ocupación humana, patente en restos de estructuras arquitectónicas y cerámica fragmentada que se extiende en gran parte de la superficie del sitio. Ambos sectores presentan características arquitectónicas y espaciales similares; en este sentido, el criterio para justificar nuestra sectorización se funda en la concentración de unidades arquitectónicas en áreas topo- 
gráficas específicas. El sitio, en general, ocupa un espacio de forma alargada, orientado de norte a sur, sobre un eje longitudinal a la ladera del cerro. Se accede siguiendo un camino pedestre que marcha al oeste del puente Pacarán que flanquea la ladera sur del cerro Chilco, hasta la desembocadura de la quebrada Pampa Grande (100 m. aproximadamente), ascendiendo por un pequeño sendero hasta la cima, donde se ha colocado una Cruz blanca.

Descripción: El sitio está conformado por dos sectores:

- Sector "A": Este sector ocupa el lado sur del sitio arqueológico, en las coordenadas UTM: 8577964 N, 385342 E, a 751 m de altitud; con una orientación norte-sur. Se compone de un conjunto de unidades arquitectónicas de características similares, que se extienden desde la base del cerro, pendiente abajo, hasta los límites de la terraza con la depresión central de la quebrada Pampa Grande. El diseño y organización de las unidades arquitectónicas se adapta a la topografía del terreno, de ligera pendiente, por medio de la construcción de pequeñas terrazas que se suceden sucesivamente en un sentido transversal a su eje de orientación, sin un aparente orden o patrón reconocible.

Estas unidades arquitectónicas alcanzan medidas de 2,5 m de largo y 1,5 m de ancho aproximadamente, con acceso independiente, en todos los casos, hacia el lado este, zona de ubicación de la depresión central de la quebrada. Solo dos estructuras presentan más de un ambiente, comunicados entre sí por accesos estrechos, formando una pequeña unidad multicomponente. Se han edificado a base de mampostería de piedra ordinaria unida con argamasa de barro y cascajo, sin rastros de revoque y dispuestas en dos hileras con un relleno central de tierra, piedra y cascajo apisonado. Solo es posible identificar las bases de las estructuras y, en pocos casos, es posible observar muros de 0,15 m como máximo de altura.

- Sector "B": Este sector se localiza surcando una pequeña quebrada en el lado norte del sitio, donde se erigen construcciones similares a las registradas en el sector "A"; pero, en mejor estado de conservación, en las coordenadas UTM: 8578098 N, 385269 E y a 758 m de altitud. Ocupa un espacio de forma irregular con orientación este-oeste. Exhibe estructuras arquitectónicas aterrazadas compuestas, principalmente, de un ambiente de acceso independiente; siendo exclusivo tres casos donde se pueden observar unidades arquitectónicas de hasta tres ambientes, incluso, desnivelados y articulados por medio de accesos estrechos y escaleras de hasta tres peldaños. Sus medidas son similares a las calibradas para las unidades del sector "A", es decir un promedio de 2,8 m de largo y 1,6 m de ancho. Las unidades mayores llegan a alcanzar los 3,6 $\mathrm{m}$ de largo y $2 \mathrm{~m}$ de ancho. Los muros mejor conservados alcanzan la altura de 1,15 m como máximo. Se han edificado totalmente con mampostería de piedra ordinaria unida
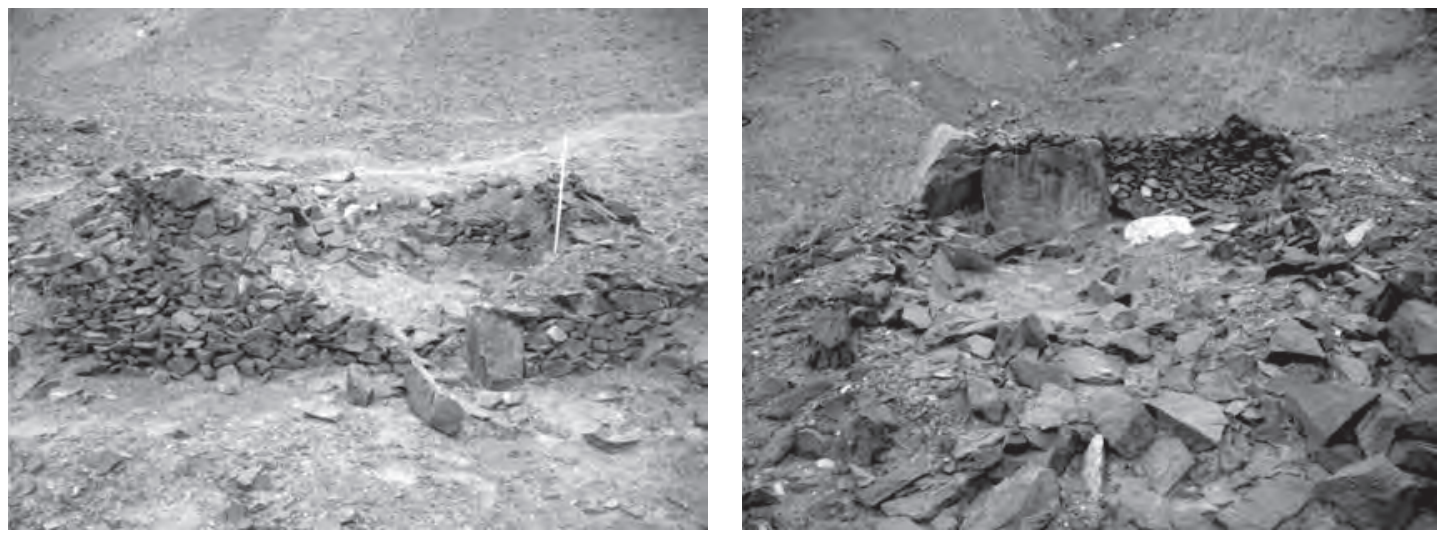

Figura 12. Izquierda y Derecha: Vista de dos habitáculos Sitio Quebrada Pampa Grande. 
con argamasa de barro y cascajo, sin rastros de revoque, muros dobles con un relleno central de tierra, piedra y cascajo compactado.

En la parte alta del cerro, donde la ladera presenta un talud pronunciado, se han construido algunas estructuras aterrazadas, de $2 \mathrm{~m}$ de largo y 1,5 $\mathrm{m}$ de ancho promedio; en cuyo interior aloja, por lo general, una pequeña estructura subterránea de sección troncocónica y planta semicircular, construida en base a mampostería careada, unida con argamasa de barro y cascajo, sin rastros de revoque en el paramento. Dada su configuración morfológica, cumplia una función funeraria.

Sobre el sector "A", se observó un camino prehispánico cuya trayectoria es de este-oeste; construido en la ladera del cerro en base a empalizadas o muros de contención de mampostería ordinaria de 0,80 $\mathrm{m}$ de ancho, aprovechando, en algunas zonas, las afloraciones rocosas del cerro. Este camino tiene una longitud aproximada de $850 \mathrm{~m}$ de largo, y se pierde a la vista debido a los deslizamientos de material aluviónico de la cima del cerro Chilco.

Materiales Asociados: En el sector "A" se ha registrado baja densidad de material cultural asociado, esencialmente cerámica fragmentada, de las cuales presentan rasgos diagnósticos tan solo una pequeña porción del total registrado. Contrariamente, en el sector "B", hemos identificado altas cantidades de material cerámico diagnóstico, algunos corresponden a la tercera parte de una vasija. Las formas reconocidas del análisis in situ del material cerámico diagnóstico de ambos sectores muestran una correspondencia tanto en el tipo de pasta como en las formas. La pasta es de color marrón oscuro, el grosor y las inclusiones está de acuerdo al tipo de vasija que se ha fabricado, siendo arena y cascajo para aquella de mayores dimensiones. Las formas reconocidas son de ollas de cuerpo achatado, borde ligeramente divergente y labios biselados o redondeados con una ligera proyección hacia el exterior del cuerpo; tinajas de borde plano o biselado; cántaro de borde cóncavo y labio redondo.

Asociación Cronológica: Intermedio Tardío.

Estado de Conservación: Malo. Se nota el colapso de gran parte de los muros debido a causas naturales, deslizamientos y acarreo de material aluvionico desde la parte alta del cerro Chilco; y excavaciones clandestinas, principalmente, practicadas en las estructuras ubicadas en la ladera del cerro y en el sector "A". Nótese además, el colapso de los muros de contención del camino prehispánico a causa de deslizamientos de la cima del cerro Chilco.

\section{CERRO CHILCO I}

Ubicación: Se ubica sobre una pequeña explanada natural en la base de la ladera sur del cerro Chilco, al este de una pequeña quebrada de nombre no registrado, y $500 \mathrm{~m}$ al oeste del sitio anterior, adyacente al camino que comienza en el puente Pacarán, en un zona de "pie de monte" en la margen derecha del río Cañete, sobre terrenos eriazos.. Esta zona se conoce como Pata. Se accede continuando en dirección oeste el mismo sendero que bordea el flanco sur del cerro Chilco, desde quebrada Pampa Grande.

Descripción: Este sitio se compone de dos pequeños grupos de estructuras arquitectónicas halladas en pésimo estado de conservación, dispuestos en un eje este-oeste y divididos por una pequeña quebrada que se orienta de norte a sur.

- Sector "A": Se ubica en las coordenadas UTM: 8577502 N, 0385070 E, a 711 m de altitud. Este sector se compone de dos pequeñas estructuras de planta rectangular ubicadas en el lado este de la pequeña quebrada de nombre no registrado. La primera estructura se localiza en el extremo oeste del sector, sobre una pequeña terraza natural, y, probablemente, formó parte de un complejo arquitectónico ligeramente mayor, actualmente destruido por la construcción del camino que bordea la ladera sur del cerro Chilco. Este pequeño ambiente mide 2,8 $\mathrm{m}$ de largo y 1,60 m de ancho, con un muro transversal en el lado S que constituyó, en otro tiempo, otro ambiente. Los 
muros miden $1,30 \mathrm{~m}$ de altura y $0,30 \mathrm{~m}$ de ancho como promedio. La siguiente estructura arquitectónica se ubica $20 \mathrm{~m}$ al oeste, sobre una pequeña terraza, construida para adaptar su diseño a la topografía del terreno, orientada hacia el pequeño cono de deyección de la quebrada. Se compone de un ambiente simple que mide 4,25 $\mathrm{m}$ de largo y 2,30 $\mathrm{m}$ de ancho; sus muros tienen 0,80 $\mathrm{m}$ de altura y $0,30 \mathrm{~m}$ de ancho como promedio.

Los muros de ambas estructuras se construyeron en base a mampostería careada, levemente labrada, unida con argamasa de barro y cascajo dispuestas en una hilera simple. Sus paramentos exhiben un revoque de 0,02 $\mathrm{m}$ de grosor sin rastros de pintura.

En la parte superior del cerro, sobre la ladera más abrupta se han construido pequeñas terrazas con mampostería ordinaria, cuyas dimensiones son 1,5 $\mathrm{m}$ de largo y $1 \mathrm{~m}$ de ancho, que conformaban espacios netamente funerarios.

Sector "B": Se ubica a 200 m al oeste del sector "A", en las coordenadas UTM: 8577406 N, 384983 E y a $701 \mathrm{~m}$ de altitud; sobre una pequeña terraza natural en el flanco sur del cerro Chilco. Se compone de una estructura arquitectónica de planta rectangular, orientada de este a oeste, muy seriamente dañada; dividida en algunos ambientes como lo patentan los restos del basamento de algunos muros que alcanzan en promedio $0,10 \mathrm{~m}$ de altura. Se ha construido en base a muros de una sola hilera con mampostería careada unida con argamasa de barro, con rastros de revoque de 0,02 m de grosor. No es muy clara su función desempeñada, probablemente representan los restos de un antigua vivienda familiar aislada.

Materiales asociados: Sobre la superficie de ambos sectores se observó restos dispersos de cerámica fragmentada, principalmente no diagnósticas, concentradas, significativamente en el sector "A". Solo se recuperó algunos bordes de ollas de lados evertidos de pasta rojo oscuro-marrón oscuro, y bordes de cántaros o jarras de lados evertidos, pasta color naranja claro-marrón claro. Ambos tipos presentan superficie alisada, sin ninguna decoración. Así mismo, se observó una regular cantidad de restos óseos humanos esparcidos tanto en la ladera del cerro, como en la parte baja del mismo. Dentro del recinto del lado oeste, sector "A", se observó una muestra regular de secciones de cráneo, partes de los miembros inferiores y superiores y de la pelvis, etc. Fue posible identificar un fragmento de tejido llano, muy deteriorado y quemado, de color negro.

Asociación Cronológica: Intermedio Tardío.

Estado de conservación: Pésimo. El área arqueológica ha sido reducida a un pequeño grupo de estructuras diseminadas a lo largo de la ladera o pie de monte del cerro Chilco, constituyendo la principal causa de deterioro la construcción de una carretera en el flanco sur del cerro Chilco, en conjunción con las constantes intervenciones clandestinas o "huaqueos" que han destruido grosera y sistemáticamente el sitio arqueológico.

\section{CERRO CHILCO II}

Ubicación: Se ubica sobre un pequeña delta formado en la parte baja de la ladera sur del cerro Chilco, a $300 \mathrm{~m}$. al oeste de cerro Chilco I, en el sector conocido como Pata, en las coordenadas UTM: 8577338 N, 0384935, a $701 \mathrm{~m}$ de altitud. Se accede al sitio siguiendo el trayecto hacia el oeste del camino que bordea el flanco sur del cerro Chilco.

Descripción: Este sitio se extiende sobre un pequeño lecho formado por material de naturaleza aluvial acarreado desde la cima del cerro Chilco y depositado en esta zona, formando un grueso relleno de superficie muy regular, sobre la cual se ha edificado un grupo de estructuras arquitectónicas de planta rectangular que se extiende, en parte, hasta la parte media de la ladera del cerro Chilco, adaptándose a este contexto topográfico por medio de la construcción de un sistema de terrazas que nivelan el terreno regularmente abrupto. En la parte baja, sobre el lecho aluvial, se concentra la mayor parte de edificaciones, dispuestas en forma lineal trazando un eje oeste- 
este y seccionada por dos tramos de un mismo camino que se bifurca en esta zona para volverse a acoplar al final de la misma. Se compone de una serie de ambientes de regulares dimensiones (3,90-4 $\mathrm{m}$ de largo y 2,40-3 $\mathrm{m}$ de ancho promedio) no muy bien definidos a causa de su lamentable estado de conservación.

En la parte media de la ladera del cerro Chilco se han edificado dos estructuras arquitectónicas aterrazadas subdivididas en pequeños espacios, de 1,8 $\mathrm{m}$ de largo y $1 \mathrm{~m}$ de ancho, probablemente destinada como área de depósito.

Estas construcciones se han edificado básicamente con mampostería de piedra careada, levemente labrada, dispuestas en doble hilera con un relleno central a manera de sarga que le brinda mayor estabilidad a los muros, cuyos paramentos muestran rastros de revoque de barro de 0,01 $\mathrm{m}$ de grosor. También, han construido una serie de pequeñas terrazas diseminadas en gran parte del ámbito de la ladera del cerro, construidas con mampostería ordinaria de $1 \mathrm{~m}$ de largo y 0,80 $\mathrm{m}$ de ancho aproximado, cumpliendo la función de amortiguar la caída de material aluvial acarreado desde la cima del cerro sobre las estructura arquitectónicas.

Asociación cronológica: Intermedio Tardío.

Estado de conservación: Pésimo. Se nota el seccionamiento del sitio por el cruce y bifurcación de un camino pedestre construido, según información recolectada de los pobladores de la zona, hace 5 años. Su construcción ha significado el allanamiento del área y derrumbe de grupos de estructuras arquitectónicas para que faciliten la habilitación de la nueva obra. Se aprecia el colapso de las estructuras arquitectónicas debido al constante transito de personas y, sobre todo, de ganado; así como el desgaste y erosión de las cabeceras, basamento y superficies de los muros debido al factor climático, patente en las condiciones hidrotérmicas inestables (temperatura/humedad).

\section{CERRO CHILCO III}

Ubicación: Se ubica sobre una pequeña quebrada, transversal al valle en la margen derecha del río Cañete, que forma, en su desembocadura, un pequeño delta o cono de deyección donde se emplaza parte del sitio, a un kilómetro aproximadamente al oeste del puente de Pacarán. Se accede al sitio continuando la trayectoria hacia el oeste del camino que bordea el flanco sur del cerro Chilco, desde el sitio cerro Chilco II.

Descripción: Este sitio se compone de dos sectores formal y funcionalmente distintos, expresado en la configuración espacial y en los aspectos y rasgos constructivos de las edificaciones, condicionadas, en parte, por las ventajas y desventajas particulares que brindan los diferentes espacios topográficos ocupados. Ocupan la ladera sur del cerro Chilco y se disponen longitudinalmente a su perfil topográfico en un eje este-oeste.
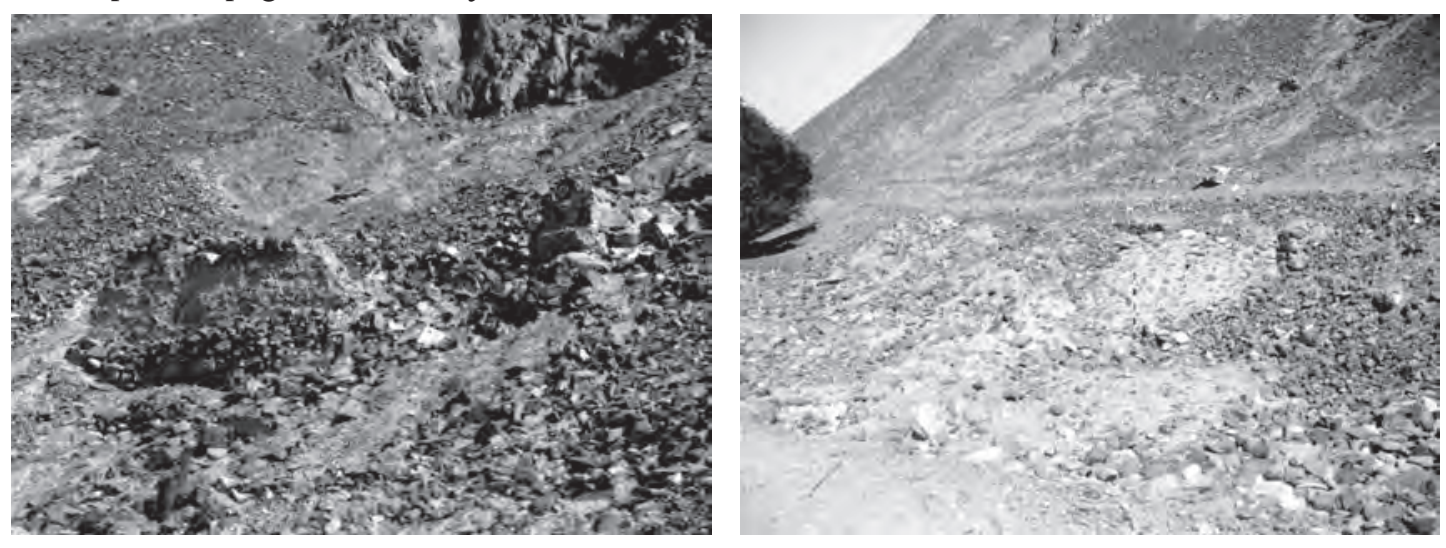

Figura 13. Izquierda y Derecha: Vista panorámica del sitio Cerro Chilco II. 
- Sector "A": Este sector se extiende sobre el cono de deyección de la pequeña quebrada, en las coordenadas UTM: 8577204 N, 0384935 E, a 722 m de altitud. Está conformado por un conjunto de estructuras arquitectónicas de planta rectangular, acondicionadas a la leve pendiente de la superficie del cono de deyección por medio de terrazas o plataformas construidas con mampostería ordinaria que nivelan las depresiones del terreno. Dichas estructuras se encuentran dañadas debido a la reutilización y adición de construcciones modernas en la parte central del conjunto, habilitando áreas para vivienda y corrales de ganado caprino y ovino. Por este motivo, no es posible observar claramente la configuración arquitectónica y espacial de este sector; sin embargo, restos del basamento mural permiten reconocer un área conformada de ambientes de regular tamaño, algunos articulados entre si a través de vanos accesos. En la parte alta, adosada a un farallón del cerro Chilco se emplaza un pequeño grupo de construcciones aterrazadas de planta cuadrangular, actualmente utilizadas como corrales, que miden $3 \mathrm{~m}$ de largo y 2,50 m de ancho. En la parte baja, en la base del cono de deyección, se erigen otro grupo de construcciones de planta cuadrangular que miden $3 \mathrm{~m}$ de largo y $2 \mathrm{~m}$ de ancho promedio. Estas edificaciones se han construido básicamente con mampostería de piedra careada, ligeramente labrada, dispuestas en doble hilera con un relleno central a manera de sarga que le brinda mayor estabilidad a los muros, cuyos paramentos muestran rastros de revoque de barro de $0.02 \mathrm{~m}$. de grosor.

- Sector "B": Este sector se localiza hacia el lado oeste del sitio, y se extiende sobre una pendiente bien pronunciada del cerro Chilco, en las coordenadas UTM: 8577204 N, 0384935 E y a $720 \mathrm{~m}$ de altitud. Se constituye de varios tipos de estructuras arquitectónicas de planta rectangular acondicionadas sobre terrazas y dispuestas sucesivamente a lo largo y alto de toda la pendiente, cuyo núcleo se sitúa en la parte central de la ladera, a $30 \mathrm{~m}$. aproximadamente de altura sobre el sector "A". Estas construcciones se organizan irregularmente sobre el espacio de la ladera, dibujando la forma del perfil topográfico del cerro. Se ha identificado, en general, dos tipos de edificaciones, de carácter funerario. El tipo más simple lo constituyen las terrazas construidas con mampostería ordinaria de 1,5 $\mathrm{m}$ de largo por 0,80 $\mathrm{m}$ de ancho, en cuyo interior se aloja una construcción de planta semicircular y sección troncocónica de 0,80-0,90 m de profundidad, que hemos calificado como "cistas funerarias". Se ubican, por lo general, en los alrededores del área de mayor concentración de edificaciones.

Otro tipo lo conforman recintos de 3,50 $\mathrm{m}$ de largo y $2 \mathrm{~m}$ de anchos como promedio, con muros que lo delimitan de hasta $1,5 \mathrm{~m}$ de altura, divididos en dos espacios regulares por medio de un pequeño murete de 0,10 m de altura como máximo, que albergan estructuras subterráneas similares a las descritas para el tipo anterior. En las pocas estructuras mejor conservadas se observan unas pequeñas "ventanas" de forma cuadrada de 0,10 m por lado, ubicadas en los muros de contención o empalizadas que proyectan, desde el exterior, un panorama parcial de la "cista" funeraria sin necesidad de aperturar su cubierta original de lajas de piedra. Todas estas construcciones se han edificado en base a mampostería ordinaria (aparejo irregular), unidas con argamasa de barro y cascajo. Los muros bajos o muretes se disponían en 2 hileras de piedra con relleno interior de cascajo y piedra apisonada. No se observó rastros de revoque barro u otro tipo de cubierta superficial.

Materiales asociados: En el sector "A" no se ubicó una cantidad significativa de material cultural; caso contrario sucedió en el sector "B", donde hemos registrado una densa concentración de material cultural, específicamente cerámica diagnóstica fragmentada. El tipo más representativo dentro de los bordes identificados corresponden a cántaros o jarras de lados convexos, algunos con labio reforzado en la superficie exterior, otros presentan borde ligeramente evertido con labio plano que se proyecta $0,02 \mathrm{~m}$ hacia el exterior del cuerpo de la vasija (tipo aríbalo Inca). Otro tipo corresponde a vasijas de mayores dimensiones (caso tinajas) de pasta gruesa, bordes 

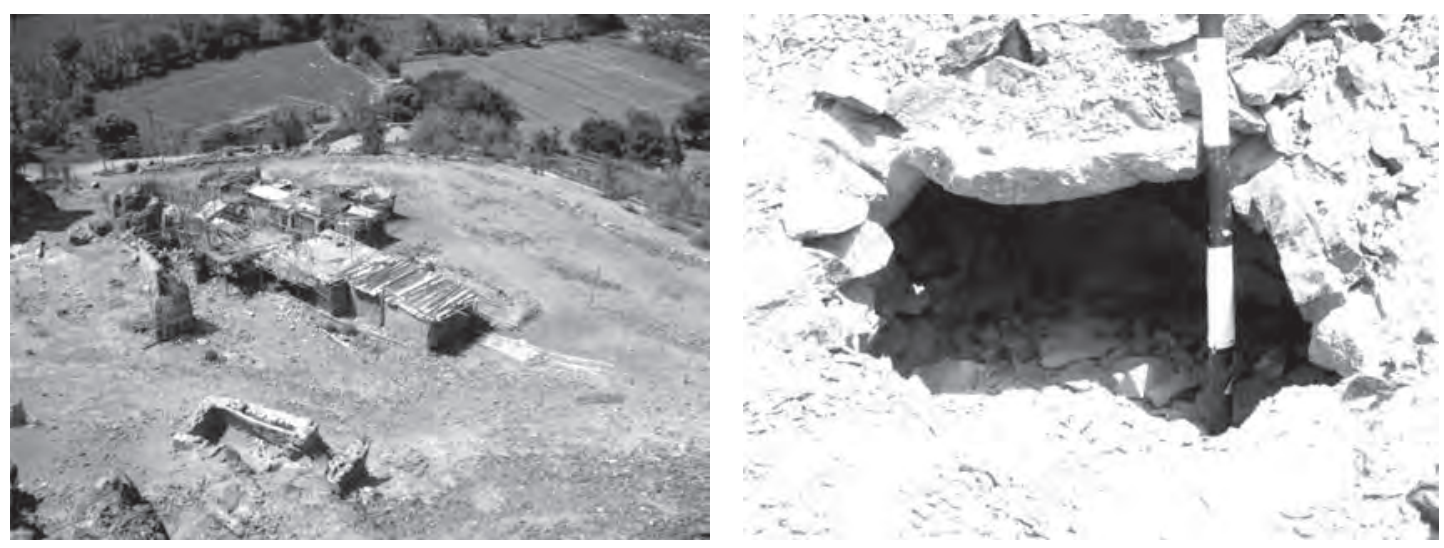

Figura 14. Izquierda: Vista panorámica del sitio Cerro Chilco III. Derecha: Detalle de una estructura de depósito.

biselados levemente evertidos o bordes redondeados convexos. El color de la pasta varía desde el naranja claro hasta el marrón oscuro, y las inclusiones están de acuerdo al grosor de la misma. Hemos registrado tres fragmentos de bordes de vasijas distintas de superficie alisada con labio expandido y doblado hacia fuera, cerca al cual se ha aplicado un motivo en alto relieve que consiste en un pequeño punto de arcilla fijado por presión circunscrito por un círculo pequeño. En otro caso hemos identificado dos pequeños fragmentos de pasta fina y color naranja claro, con su superficie exterior pintada en base a bandas de color marrón sobre un engobe naranja. También, hemos registrado un alta cantidad de asas, generalmente, cintadas y de tamaño regular.

Asociación cronológica: Intermedio Tardío-Horizonte Tardío.

Estado de Conservación: Malo. La ocupación moderna ha reutilizado las estructuras arqueológicas del sector "A" con fines habitacionales y para crianza de ganado, acelerando el colapso y derrumbe de las estructuras arquitectónicas. Se aprecia el seccionamiento y allanamiento de una porción del sitio -en la base del cono de deyección, adyacente a los campos de cultivo- debido a la construcción del camino pedestre que bordea el flanco sur del cerro Chilco. El huaqueo intensivo en el sector "B", ha desmontado las cubiertas de las estructuras funerarias y destruido el núcleo de las estructuras arquitectónicas. Las estructuras en parte están cubiertas y los muros derrumbados por los constantes deslizamientos de material aluvial acarreado desde la cima del cerro Chilco.

\section{CERRO CHILCO IV}

Ubicación: Se ubica sobre la una pendiente regularmente pronunciada de la ladera sur del cerro Chilco, a $300 \mathrm{~m}$. aproximadamente al oeste de cerro Chilco III, en las coordenadas UTM: 8576708 N, 0384070 E, a $720 \mathrm{~m}$ de altitud, en la margen derecha del río Cañete. Se accede al sitio siguiendo el trayecto hacia el oeste del camino que bordea el flanco sur del cerro Chilco, ladeando un canal de riego, probablemente reutilizado, que discurre paralelo al camino y al río Cañete.

Descripción: Está conformado por una pequeña concentración de estructuras arquitectónicas aterrazadas en la ladera del cerro, poco definidas debido a su deplorable estado de conservación causado por la construcción de la carretera pedestre que borde este flanco del cerro, el constante trafico de personas y ganado sobre las construcciones y el frecuente deslizamiento de material aluvial acarreado desde la cima del cerro Chilco. Los muros se han construidos con mampostería de piedra careada unida con argamasa de barro y cascajo, dispuestas en dos hileras con un relleno central de tierra, piedra y cascajo apisonado, sobre cuya superficie se observa rastros de revoque de barro. 
Materiales Asociados: No se identificó ningún tipo de material cultural sobre la superficie del sitio. Estado de Conservación: Pésimo. Casi todas las construcciones están destruidas.

\section{ANTAHUAYA I}

Ubicación: Se ubica sobre un lecho aluvial o delta de la ladera sur del cerro Chilco, presenta leve pendiente, acentuándose conforme se aproxima a las estribaciones rocosas del cerro, a un kilómetro aproximadamente al oeste de cerro Chilco IV. Se accede al sitio siguiendo el trayecto hacia el oeste del camino que bordea el flanco sur del cerro Chilco, bordeando un canal de riego que discurre paralelo al camino y al río Cañete.

Descripción: Este sitio está conformado por dos sectores:

- Sector "A": Se ubica en las coordenadas UTM: 8576356 N, 0383632 E, y a 696 m de altitud. Este sector ocupa un área de forma alargada, orientada de este a oeste, compuesto por una serie de ambientes multifuncionales, como plazas, patios, cámaras funerarias, plataformas, entre otros; construidos con una técnica mixta que combina muros de mampostería careada unida con argamasa de barro, dispuestas en doble hilera con un relleno central de tierra, cascajo y piedra apisonada, con revoque de barro que cubre los paramentos de los muros; y muros de adobe paralelepípedos de 0,40-0,45 $\mathrm{m}$ de largo y 0,28-0,30 $\mathrm{m}$ de ancho, asentados en doble hilera alternas de tizón y soga, cuyos paramentos, también, muestran revoque de barro. Ambos tipos murarios se superponen indistintamente.

El diseño de construcción se ha adaptado a la topografía del terreno, edificando hasta tres niveles de amplias terrazas, siendo el segundo nivel donde se han edificado las construcciones de mayor complejidad. En esta terraza se erige una plaza delimitada por el lado norte por un muro decorado con hornacinas trapezoidales y dos pequeñas plataformas superpuestas en la esquina noroeste. Hacia el lado oeste, atravesando un pequeño pasadizo se dispone una pequeña cancha, donde los muros este y oeste se han edificado con adobón, superpuestos a un pequeño muro de adobes que funcionó como su basamento. Presentan dos hornacinas de forma trapezoidal y dos adobes colocados en posición transversal al muro a manera de ménsulas. En esta área es posible apreciar como, parte de un muro de mampostería colapsó y, posteriormente, fue reedificado con adobes paralelepípedos. Hacia el extremo oeste, se levantan un pequeño grupo de estructuras arquitectónicas de planta rectangular edificadas íntegramente en base a mampostería careada.

Hacia el lado sur del este sector, sobre los muros de contención o empalizadas que permiten darle solidez al terreno se observó tres estructuras de planta rectangular de 4,20 m de largo y $4 \mathrm{~m}$ de ancho, cubiertas intencionalmente por un relleno de tierra, piedra y cascajo. En uno de los rellenos se observa restos de un tronco que sirvió de viga, dado que su superficie indica cierto desgaste.

Sobre la plaza, en el norte del sector, se han construido un grupo de estructuras arquitectónicas de planta rectangular de $3 \mathrm{~m}$ de largo por 2,20 $\mathrm{m}$ de ancho, edificadas con técnica mixta. Sobre la cabecera de los muros se aprecia pequeños hoyos con restos de caña guayaquil en su interior que sirvieron de vigas a una cubierta ya degradada por el tiempo. Una de estas estructuras en particular esta asociada a gran cantidad de restos óseos humanos y tejidos llanos fragmentados y completos, evidentemente proveniente de un contexto funerario múltiple. En la parte superior se ha construido una amplia terraza o plataforma de al menos $15 \mathrm{~m}$ de largo y $3 \mathrm{~m}$ de ancho, donde se ha edificado un conjunto de recintos de planta cuadrangular usados actualmente como corrales.

En el extremo este, parte baja de la ladera del cerro y adyacente al camino moderno, se ha construido una estructura subterránea de planta rectangular de $2 \mathrm{~m}$ de largo y $1 \mathrm{~m}$ de ancho, 
edificada completamente con cantos rodados, asociada a restos óseos humanos y material textil fragmentado y quemado.

- Sector "B": Se localiza a 100 m. al oeste del sector "A", sobre un terreno de pendiente regular, en las coordenadas UTM: 8576266 N, 0383517 E, a 691 m de altitud. Tiene forma irregular, orientada de norte a sur. Se constituye de una serie de recintos aterrazados que se suceden desde la base del cerro hasta aproximada mente la mitad del mismo, donde cualquier vestigio debió ser destruido por la construcción de un camino.

Estas construcciones se han edificado sobre cuatro niveles de terrazas con recintos simples de planta rectangular y con 2,20 m de largo y $2 \mathrm{~m}$ de ancho. El mayor de todos se ubica en la parte media de la ladera, mide 4,20 m de largo y 2,20 m de ancho. Estos ambientes no presentan accesos que los articulen entre sí. En su interior albergan construcciones subterráneas de sección troncocónica (cistas funerarias), una de ellas presenta restos de troncos de molle que sirvieron como vigas que probablemente sostuvieron una cubierta de lajas de piedra.

Materiales asociados: La mayor concentración de material cultural se observa cubriendo la superficie del sector "A". Se ha registrado restos de bordes y asas de vasijas fragmentadas, principalmente de cántaros o jarras de lados convexos, algunos con labio reforzado en la superficie exterior, otros presentan borde ligeramente evertido con labio plano que se proyecta $0.02 \mathrm{~m}$. hacia el exterior del cuerpo de la vasija (tipo aríbalo Inca). Otro tipo corresponde a vasijas de mayores dimensiones (caso tinajas) de pasta gruesa, bordes biselados levemente evertidos o bordes redondeados convexos. El color de la pasta varía desde el naranja claro hasta el marrón oscuro, y las inclusiones están de acuerdo al grosor de la misma. Una de las estructuras del lado norte de la plaza fue recientemente alterada por excavaciones clandestinas, dejando sobre la superficie restos óseos humanos correspondientes a dos cráneos de adultos y uno de infante, secciones de los miembros inferiores y superiores. Del mismo modo, restos de material textil fragmentado (tejidos llanos) y quemados exprofésamente por los autores de dichas excavaciones, que corresponden a partes de fajas, turbantes, mantos, algunos presentan decoración con diseños pintados de bandas de colores alternos azul, marrón.

Asociación cronológica: Intermedio Tardío-Horizonte Tardío.

Estado de conservación: Malo. Se aprecia la reocupación moderna de las estructuras arquitectónicas del lado oeste, sobre una pequeña elevación en el centro del sitio arqueológico, habilitando áreas de vivienda sobre algunas edificaciones que aún se mantenían en pie. Seccionamiento y allanamiento de una porción del sitio - en el lado noroeste del sector "B"- debido a la construcción del camino pedestre que bordea el flanco sur del cerro Chilco. Las excavaciones clandestinas
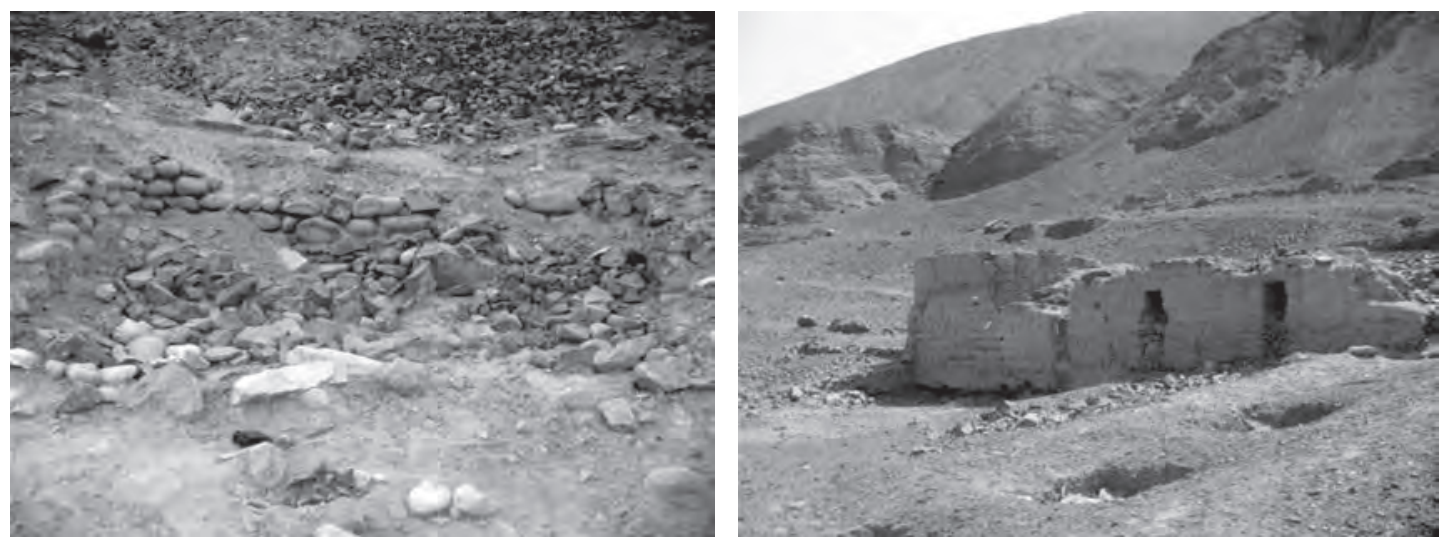

Figura 15. Izquierda y derecha: Vista panorámica del sector "A". sitio Antahuaya I. 
han afectado severamente la estructura interna de algunas edificaciones y destruido contextos arqueológicos significativos. Hay erosión y desgaste de la cabecera, basamento y superficie de los muros a causa del constante trafico de personas y ganado en el sitio.

\section{ANTAHUAYA II}

Ubicación: Se ubica sobre el delta de una pequeña quebrada, cubierto con material aluvial en la base de la ladera sur del cerro Chilco, en la zona de Antahuaya en la margen derecha del río Cañete, a $700 \mathrm{~m}$ aproximadamente al suroeste del sitio arqueológico Antahuaya I. Se accede siguiendo el camino hacia el oeste del camino que bordea el flanco sur del cerro Chilco, ladeando un canal de riego que discurre paralelo al camino y al río Cañete, desde el sitio Antahuaya I.

Descripción: El sitio está conformado por dos sectores, uno al este y el otro al oeste.

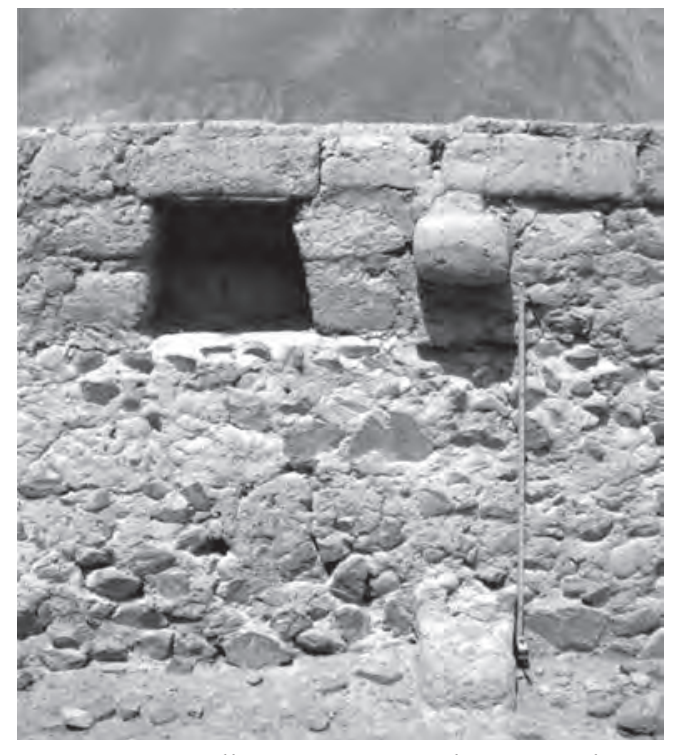

Figura 16: Detalle constructivo y decorativo de un muro Tawantinsuyu en el sitio de Antahuaya I.

- Sector "A": Se ubica en las coordenadas UTM: 8575876 N, 0383080 E, a 675 m de altitud en el extremo noreste del área del sitio, muy próximo a los campos de cultivo y seccionado, en parte, por la construcción de un camino moderno y una vivienda en el lado este. Presenta forma alargada, orientada de noreste a sureste. Se compone de un conjunto de recintos de carácter habitacional distribuidos sobre dos niveles de terrazas en el lado oeste y una construcción de regulares dimensiones que ocupa una terraza en el extremo este. Estas construcciones poseen planta de forma rectangular y acceso independiente hacia el oeste y este. Se disponen de manera regular sobre el terreno, trazando dos ejes o niveles arquitectónicos que se yuxtaponen entre sí. Dos ambientes, en particular, manifiestan un buen estado de conservación; miden en promedio 5,30 $\mathrm{m}$ y 5,50 $\mathrm{m}$ de largo y 3,30 $\mathrm{m}$ y $4 \mathrm{~m}$ de ancho respectivamente. La altura de uno de los muros bien conservados alcanza los 2,10 m. En algunos ambientes se distinguen indicios de remodelaciones, como el cierre o clausura de accesos que permitían una comunicación fluida entre sí. Los muros se han edificado íntegramente de mampostería careada unida con argamasa de barro, dispuesta en doble hilera con un relleno central de tierra, cascajo y piedra apisonada, con revoque de barro que cubre los paramentos de los muros. Los muros de contención de las terrazas o empalizadas se han construido con mampostería ordinaria unida con argamasa de barro y cascajo.

En la ladera del cerro Chilco (a $25 \mathrm{~m}$ de altitud con respecto al área de este sector "A"), aprovechando los pequeños espacios nivelados que se forman y alternan con la pendiente, se construyó pequeñas estructuras subterráneas aterrazada; principalmente, de planta semicircular y sección troncocónica, y, en menor medida, construcciones semisubterráneas de planta cuadrangular con una pequeña antecámara en uno de sus lados. Ambos tipos se edificaron íntegramente con mampostería careada unida con argamasa de barro y cascajo con rastros de revoque de barro sobre la superficie de los paramentos. Para el primer tipo se utilizó una cubierta de lajas de piedra que cerraban la boca de casi $1 \mathrm{~m}$ de diámetro y el interior de 1,10 $\mathrm{m}$ de altura promedio. En el segundo tipo se empleó soportes de madera (troncos de molle), aún perceptible dentro de las construcciones notablemente alteradas por el constante huaqueo y cubierta de piedras planas o lajas. Los rasgos arquitectónicos presentes en este sector 
enfatizan en dos espacios funcionalmente distintos. El primero, ubicado en la parte baja, probablemente, de carácter habitacional o administrativo; y el segundo, sobre la ladera del cerro, evidentemente, reflejaba la expresión funeraria de parte del grupo humano que habitaba en las zonas adyacentes.

- Sector "B": Se ubica en las coordenadas UTM: 8575778 N, 0382917 E, a 670 m de altitud. En este sector se manifiestan dos expresiones arquitectónicas morfológica y funcionalmente distintas, ocupando espacios diferenciados pero continuos. El primero se localiza en la parte baja del cerro, dividido por la construcción de un camino moderno, a $100 \mathrm{~m}$ aproximadamente al oeste del sector "A". Está conformado por un grupo de estructuras arquitectónicas casi destruidas por completo, emplazadas sobre un espacio muy regular, concentradas en tres núcleos compuestos, principalmente, por cuatro pequeños ambientes de planta cuadrangular de $1 \mathrm{~m}$ de lado aproximadamente yuxtapuestos entre sí, que se asientan sobre una plataforma nivelada. Se han construido en base a mampostería ordinaria unida con argamasa de barro y cascajo formando muros de una hilera de 0,20 m de grosor como promedio. En uno de estos núcleos se registró una alta concentración de vasijas de cerámica fragmentadas, que constituían, en muchos casos, piezas completas. Esta área, dada su configuración arquitectónica, funcionó como depósitos o almacenes.

En la parte superior se erige un espacio nivelado por una amplia terraza y delimitado por muros de mampostería careada unida con argamasa de barro y cascajo muy deteriorados. Este gran espacio mide $21,7 \mathrm{~m}$ en su eje noreste a suroeste y $16 \mathrm{~m}$. en su eje noroeste a sureste, actualmente habilitado como depósito de paja y corral de ganado.

Hacia $50 \mathrm{~m}$ aproximadamente al noroeste, sobre un terreno regularmente inclinado se identificó una regular concentración de construcciones subterráneas aterrazadas y de distinto tipo que se suceden desde la parte baja del lecho aluvial hasta converger con los farallones del cerro Chilco, en un radio aproximadamente de $25 \mathrm{~m}$ a la redonda desde un punto central. Se observa material asociado y rasgos arquitectónicos notablemente ligados a la práctica funeraria.

Estas construcciones se disponen sobre cuatro niveles de terrazas que miden entre 8 y $10 \mathrm{~m}$ aproximadamente de ancho, albergando construcciones que se distribuyen, en muchos casos, en dos series sucesivas y alineadas al perfil que dibuja la pendiente. Como patrón recurrente, observamos que las construcciones mayores se asientan en la parte más alta del sitio y poseen planta rectangular, a diferencia de aquellas edificadas en la parte baja que tienen menores dimensiones y pueden adoptar formas de planta y sección variadas. Las construcciones subterráneas mayores
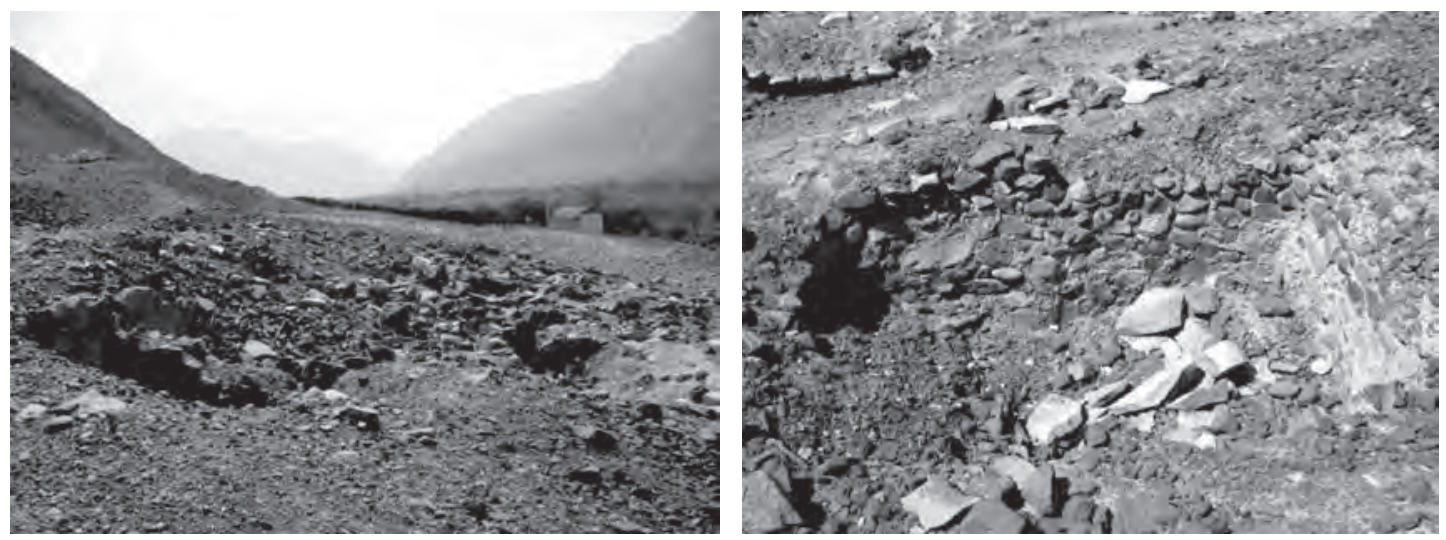

Figura 17. Izquierda: Vista panorámica del sitio Antahuaya II. Derecha: Vista panorámica de un recinto, sitio Antahuaya II. 
alcanzan hasta los 8,50 m de largo y 4,20 m de ancho, formadas por 4 muros de contención edificados con mampostería careada unida con argamasa de barro y cascajo con rastros de revoque de barro sobre la superficie de los paramentos. En su interior, aún se conservan restos de las vigas de madera (troncos de mallo) que soportaron una cubierta, probablemente de piedras planas o lajas. Las estructuras subterráneas de menor magnitud poseen dimensiones muy variadas; sin embargo, han sido edificadas empleando los mismos materiales y técnica constructiva, es decir, mampostería careada de aparejo regular unida con argamasa de barro y cascajo con rastros de revoque de barro sobre la superficie de los paramentos. Todos los casos manifiestan restos de troncos de molle que se utilizaron como vigas que soportaron una cubierta de lajas.

Ha sido posible reconocer tres tipos de estructuras arquitectónicas y una variante tomando como criterio la morfología de la planta. El primer tipo exhibe planta rectangular y es el más común, alcanza medidas que fluctúan entre 2,60 y 1,60 m de largo y 1,70 y $1 \mathrm{~m}$ de ancho, una variante de este tipo lo constituye una estructura subterránea de 2,10 m de largo y 1,60 m de ancho con la parte superior (que da a la superficie del terreno) recubierta totalmente de piedras empotradas que confluyen hacia el centro a manera de ménsulas. El segundo tipo lo constituyen estructuras subterráneas que miden 3,10 m de largo y 2,10 m, de ancho y 1,60 m de altura promedio, de planta semicircular (ovalada). El tercer tipo lo integran estructuras pequeñas de 1,10 $\mathrm{m}$ de profundidad, $1 \mathrm{~m}$ de diámetro (especie de cistas funerarias), de planta semicircular y sección troncocónica.

Materiales asociados: En el sector "A" se observó baja densidad de material cultural asociado, solo algunos fragmentos de cerámica no diagnóstica dispersa sobre la superficie del terreno. En la parte alta, donde se localizan las estructuras arquitectónicas aterrazadas se identificó asociada restos de una vasija empotrada en el terreno, de pasta gruesa (0,02 $\mathrm{m}$ aproximadamente) color marrón oscuro. La boca tiene un diámetro 0,24 $\mathrm{m}$ aproximadamente y una altura de 0,43 $\mathrm{m}$ de altura. Posee forma ovoide en posición normal, sin cuello, labio biselado y base considerablemente convexa con una superficie alisada. Además, se observó dos fragmentos de bordes de pasta color naranja, lados rectos y labio ligeramente biselado que lucen su superficie exterior pintada con bandas paralelas verticales de color marrón sobre un engobe naranja, perteneciente a un cántaro o jarra.

En el sector "B" se registró una alta cantidad de material cultural disperso, concentrado en áreas específicas del sitio. Asociado a las pequeñas construcciones de la base del delta aluvial, se identificó restos de cerámica fragmentada que constituían, en algunos casos, piezas completas. Los tipos identificados consisten en ollas de cuerpo globular achatado con pasta delgada de color marrón oscuro, base convexa, cuello corto o levemente carenado y boca estrecha con labios biselados o redondeados. La mayoría exhibe asas laterales cintadas en posición horizontal. Algunas vasijas presentan decoración digitada a presión en el labio. Del mismo modo, otras ostentan como decoración una banda de arcilla de 0,01 m de grosor aplicada al contorno de la vasija, señalada con incisiones oblicuas sucesivas realizadas con la uña antes de ser expuestas al fuego.

Dispersos sobre la superficie y en el interior de las estructuras subterráneas de la parte media se aprecia una gran cantidad de restos óseos dispersos y evidentemente alterados, sobresaliendo los cráneos de adultos y huesos de los miembros inferiores y superiores. También, una vasta cantidad de material cerámico arqueológico. Entre el material diagnóstico distinguimos bordes de cántaros o jarras de cuello recto o convexo y labio de biselado o redondeado; bordes de ollas de pasta delgada similares a las descritas para la zona ubicada en la parte baja en este mismo sector.

Asociación Cronológica: Intermedio Tardío-Horizonte Tardío.

Estado de Conservación: Malo. El allanamiento de una gran parte del sitio arqueológico a propósito de la construcción de un camino moderno que circula por la parte baja del delta aluvial ha destruido gran proporción del sitio. Se ha producido la reutilización de una porción de las edificaciones arqueológicas como corrales de ganado, depósito de paja o alimentos pecuarios, causando 
severos daños en la estructura de los muros y cimientos, a causa del constante transito del propio ganado sobre las estructuras arqueológicas; la construcción de nuevas edificaciones como una capilla y viviendas modernas dentro de los linderos del sitio arqueológico; excavaciones clandestinas persistentes que han destruido los contextos arqueológicos; la erosión basal y superficial, desfasamientos de algunos paramentos y colapso parcial de estructuras arquitectónicas debido a la exposición directa con los agentes de deterioro ambiental producto de las extremas condiciones ambientales existentes en esta región geográfica.

\section{QUEBRADA DE NIGACHO I}

Ubicación: Se ubica en el extremo oeste de la margen derecha del río Cañete, en el límite de los distritos de Pacarán y Lunahuaná, pero perteneciendo políticamente al primero; Sobre el amplio cono de deyección de la quebrada de Nigacho cubierto completamente con material de naturaleza aluvial. Se accede siguiendo el camino que flanquea la ladera sur del cerro chilco, hacia el oeste de Antahuaya II.

Descripción: Está conformado por dos sectores:

- Sector "A": Se ubica en las coordenadas UTM: 8575274 N, 0382534 E, 679 m de altitud. Este sector se ubica sobre un terreno ligeramente inclinado, adyacente a los campos de cultivo. Tiene forma irregular con el eje mayor orientado de norte a sur. Consiste en un conjunto de recintos de carácter habitacional dispuestos sobre una amplia terraza que nivela la superficie irregular, y una extensa superficie aterrazada en la parte superior de forma irregular limitada por uno de sus lados por grupo de estructuras subterráneas de planta rectangular y semicircular de naturaleza funeraria.

El conjunto habitacional de la parte baja se compone de una serie de ambientes de planta rectangular y de diversas dimensiones, articulados por medio algunos accesos y un pasadizo de 2,50 m de largo aproximadamente El ingreso se localiza en el lado sur, en dirección al valle. Son evidentes las remodelaciones arquitectónicas realizadas en todo el conjunto, se sellaron accesos y se rellenaron pasadizos formando especies de bancas o banquetas, adosadas a estructuras de carácter funerario, de planta semicircular y sección troncocónica, de 1,10 $\mathrm{m}$ de diámetro y 1,60 m de profundidad; se construyeron muros delgados que se adosaron sobre muros que aún mantenían su enlucido, dividiendo los ambientes de mayores dimensiones.

No es posible identificar espacios diferenciados debido a la gran acumulación de material aluvial sobre las estructuras arquitectónicas y el colapso y erosión de gran parte de los muros que configuraban los espacios arquitectónicos arqueológicos.

En la parte alta se aprecia un espacio abierto aterrazado de forma irregular a manera de plaza de regulares dimensiones, delimitado por el lado norte, cerca de las estribaciones rocosas del cerro Chilco, por un conjunto de estructuras funerarias subterráneas de planta rectangular y semicircular. Una en particular, había sido recientemente perturbada, quedando en evidencia el paciente "trabajo" que se esgrimía durante la exhumación del cadáver y la sustracción del material asociado; pues, no se registró ningún tipo de elemento cultural fragmentado o disperso sobre la superficie del terreno y menos aún restos del individuo al cual pertenecía el ajuar. Las vigas de madera de tronco de molle estaban apiladas hacia un lado y la cubierta de lajas de piedra del mismo modo.

Todas las estructuras arquitectónicas están construidas íntegramente con mampostería careada de aparejo regular, levemente labradas, unidas con argamasa de barro y cascajo, dispuesta en dos hileras con un boquete en el centro, rellenado con cascajo y piedras bien apisonada, alcanzando un ancho de 0,60 $\mathrm{m}$ y una altura de $1 \mathrm{~m}$ en los ambientes mejor conservados. Los paramentos estuvieron recubiertos por un grueso revoque de barro de 0,02 $\mathrm{m}$ de grosor sin 

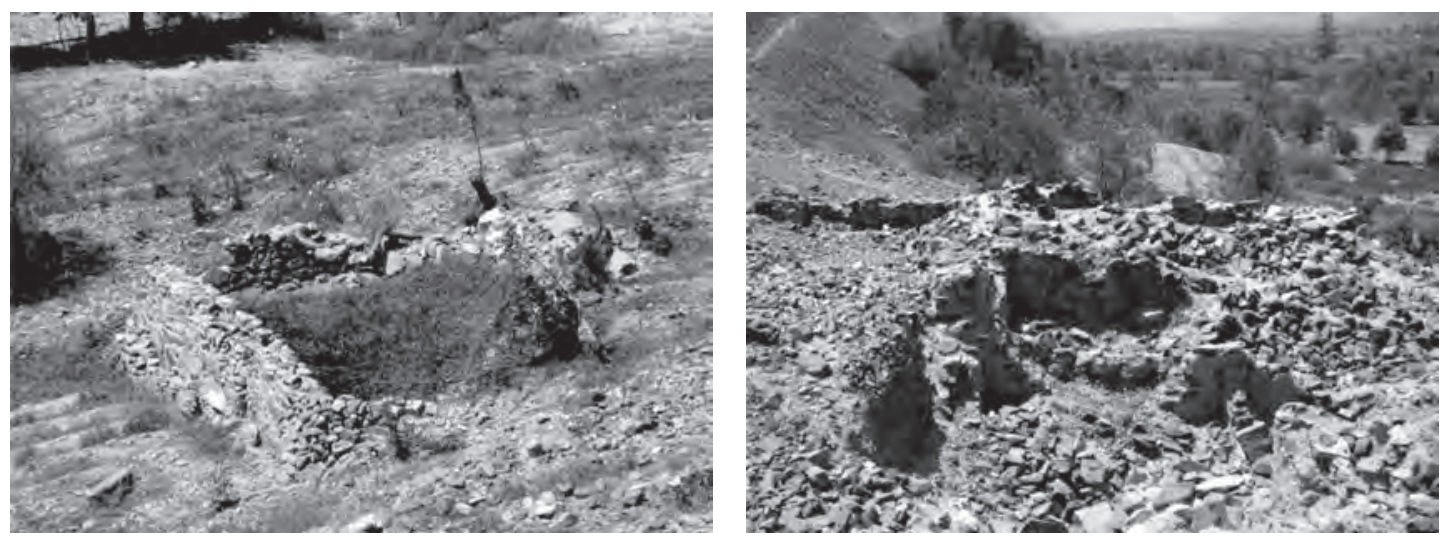

Figura 18. Izquierda y Derecha: Vista panorámica de dos estructuras arquitectónicas sitio Quebrada de Nigacho I.

rastros de pintura.

- Sector "B": Este sector se localiza al oeste del sector anterior, en las coordenadas UTM: 8575120 N, 0382362 E, a 686 m de altitud; sobre un área sumamente afectada por el deslizamiento de material aluvial y las constantes caídas de huaycos que han deteriorado en gran nivel las superficies y espacios arquitectónicos, modificando la real configuración del sitio. Este sector ha sido dividido en dos zonas a causa de la fuerte deposición de material aluvial cubriendo las estructuras arquitectónicas y en el peor de los casos destruyéndolas. Tiene forma irregular y se orienta de norte a sur.

Está constituido por un conjunto habitacional aterrazado, cuyas unidades se componen de espacios multifuncionales, con zonas de carácter domestico, de depósitos y funerario, que interactúan en un mismo contexto espacial y se comunican a través de accesos y pequeños pasadizos. Del mismo modo se observó pequeñas plataformas delimitadas por muros bajos asemejando, por su ubicación y morfología, pequeños altares.

Estas estructuras fueron construidas íntegramente en base a mampostería careada de aparejo regular, levemente labradas, unidas con argamasa de barro y cascajo, muros dobles con un relleno central de cascajo y piedras bien apisonada, alcanzando un ancho de 0,60 $\mathrm{m}$ y una altura de $1,40 \mathrm{~m}$ en los ambientes mejor conservados. Los paramentos estuvieron recubiertos por un grueso revoque de barro de 0,02 $\mathrm{m}$ de grosor $\sin$ rastros de pintura.

Materiales asociados: El material observado corresponde a vasijas de superficie alisada sin Quebrada de Nigacho I.

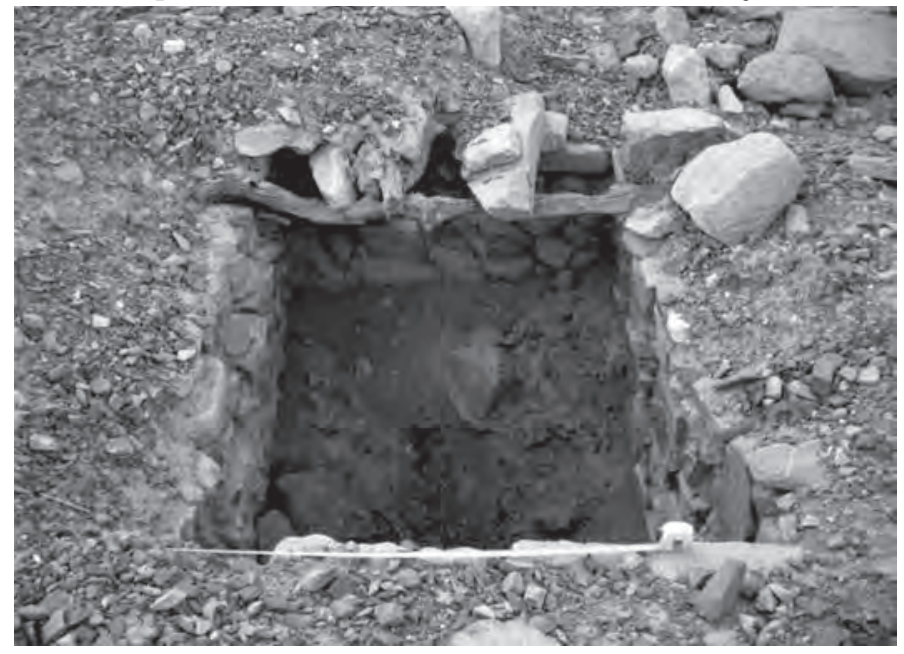


ningún tipo de decoración, similar al identificado en los sitios de Antahuaya I y II.

Asociación cronológica: Intermedio Tardío.

Estado de conservación: Pésimo. Muy destruido.

\section{QUEBRADA DE NIGACHO II}

Ubicación: Se ubica en la margen derecha del río Cañete, en las coordenadas UTM:8575062 N, 382273 E, a 684 m de altitud; en el extremo oeste del cono de deyección de la quebrada de Nigacho, sobre una franja de pendiente regular delimitada por un cauce aluvial hacia el este que lo separa del sector "B" de Quebrada de Nigacho I; por el noroeste limita con una loma rocosa del cerro Riverón, cuya superficie está cubierta por altas cantidades de arcilla y oxido de fierro, brindándole una coloración rojiza muy encendida. Posee forma alargada, orientada de norte-sur y se compone de un conjunto habitacional aterrazado que alberga áreas funcionalmente diferentes.

Descripción: Este conjunto habitacional se distribuye uniformemente sobre el terreno sin un patrón definido. Las estructuras arquitectónicas ubicadas en la parte baja, próximas a los campos de cultivo, se encuentran en pésimo estado de conservación, cubiertas, en parte, por un grueso relleno de material aluvial. Sin embargo, en la base de algunos depósitos aluviales naturales muy antiguos se cavó y acondicionó pequeñas oquedades con fines funerarios, actualmente muy disturbados por acción humana. Las edificaciones del lado norte, adyacentes a las estribaciones rocosas del cerro Riverón, se aprecian en buenas condiciones, siendo aun perceptible la forma de organización de los espacios a nivel de unidades arquitectónicas independientes que convergen en espacios amplios a manera de patios. Estas unidades integran ambientes de regulares dimensiones, articulados a través de accesos y espacios que hacen las veces de corredores con una pequeña construcción adjunta de carácter funerario (cista funeraria). Los ambientes mejor conservados miden 4,10 m de largo por 3,30 m de ancho como promedio, tienen planta de forma irregular, solo en algunos casos se define un trazo ortogonal. Los muros se han edificado íntegramente con mampostería de regulares dimensiones sin argamasa (mampostería en seco), dispuesta en dos hileras con un relleno de piedras y cascajo en el interior. La superficie de los paramentos no exhibe rastros de revoque $u$ otro tipo de tratamiento. Miden entre $0,60-0,80 \mathrm{~m}$ de ancho y 1-1,20 $\mathrm{m}$ de altura.

Materiales asociados: No se identificó, solo material cerámico no diagnóstico.

Asociación cronológica: Intermedio Tardío.

Estado de conservación: Pésimo.

A continuación presentamos las características de otros sitios ubicados en los distritos de Zúñiga y Lunahuaná.

36. CANTAGALLO

Ubicación: El sitio se encuentra ubicado en la margen izquierda del valle medio del río Cañete. Políticamente se ubica en la estancia de Cantagallo, anexo de Catapalla, en el distrito de Lunahuaná, provincia de Cañete. La ubicación UTM del sitio es: N 8570730, E 0378878 y la altitud es de 597 $\mathrm{m}$ sobre el nivel del mar. Se accede al sitio por un camino ancho que proviene desde la vía carrozable que a su vez viene desde el Puente de Catapalla. El camino llega hasta el sitio cruzando por diferentes zonas agrícolas que han destruído parte del asentamiento prehispánico. La distancia aproximada del pueblo de San Pedro al sitio es de 1 kilómetro.

Emplazamiento: El sitio se encuentra emplazado sobre el cauce mismo de la quebrada Catapalla y la plataforma aluvial oriental aledaña. El terreno es pedregoso, producto del arrastre eólico. Hacia el lado oeste hay una terraza aluvial de considerable altura. La presencia de agua es limitada y se constituye en canales modernos de irrigación. El sitio se encuentra orientado en un eje 
noroeste-sureste. El área aproximada del sitio es de 5 hectáreas.

Tipo de sitio: Complejo y Sitio Arqueológico Monumental.

Categoría de sitio: Sitio Monumental.

Descripción: El sitio es un asentamiento monumental conformado por estructuras domésticas, residenciales, corrales, áreas de almacenamiento y patios. En base a la disposición de las estructuras se ha dividido el sitio en tres Sectores:

- Sector "A": Ubicado en el lado sur del asentamiento, conformado por un conjunto de recintos de planta cuadrangular, de 6 x 6 m en promedio, de función doméstica. Muchas de estas estructuras presentan en una esquina interna una pequeña construcción de forma cuadrangular que cumpliría una función de almacenamiento. En el interior de los recintos se aprecian batanes y fragmentería cerámica de estilo Inca local. Algunos presentan osamentería humana. Los
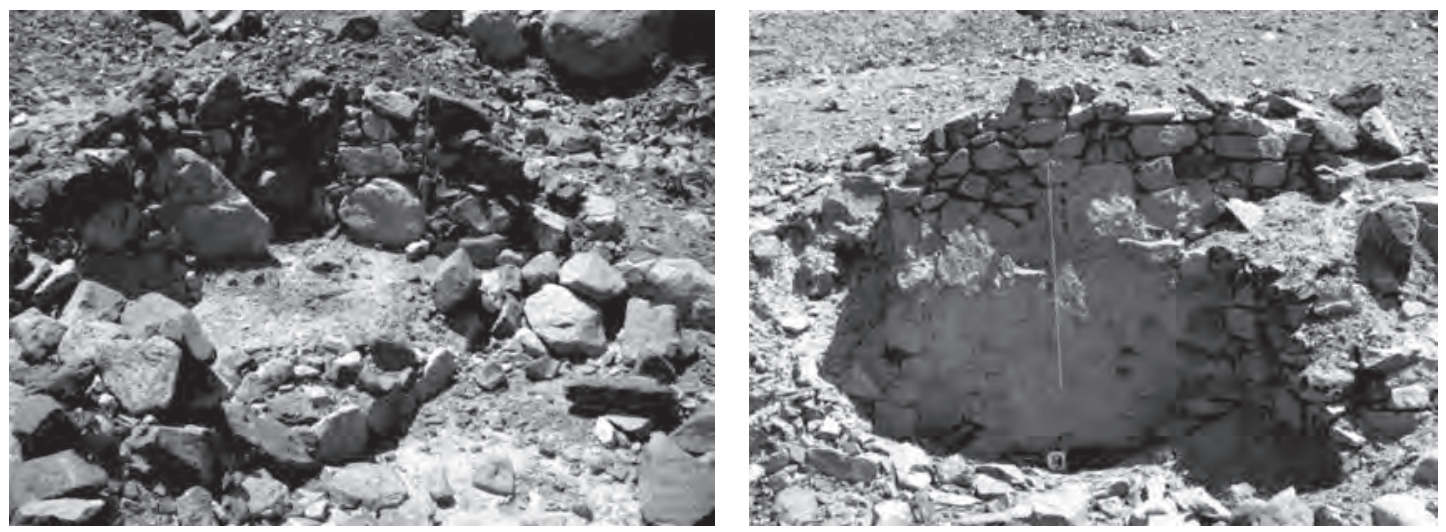

Figura 20. Izquierda y derecha: Vista panorámica del sitio de Nigacho II.

muros de las construcciones están edificados a base de piedras canteadas de cerro de tamaño grande, unidas entre sí con una capa tosca de argamasa de barro. Los muros tienen 0,80 m de grosor y alcanzar hasta 1,80 m de altura, siendo la mayoría muros dobles. Por su ubicación en medio del cauce de la quebrada, se aprecian grandes rocas naturales aflorantes, las cuales están en muchos casos, sirviendo como basamento para los muros. En la superficie interna de los recintos se aprecia una gruesa capa de yapana producto de la acumulación aluviónica. En uno de los recintos se pudo apreciar un batán grande con tres concavidades anchas para fines de molienda, una de estas aún con su moledor (canto rodado). Hacia el lado oeste del sector se aprecian algunos recintos asociados en su interior a estructuras funerarias de planta rectangular de un metro a un 1,20 m de altura, con un pequeño vano frontal central de acceso, de 0.40 metros de alto y $0,45 \mathrm{~m}$ de ancho.

- Sector "B": Ubicado inmediatamente al norte del anterior, conformado por un extenso patio de forma rectangular de $24 \mathrm{~m}$ de ancho por $11 \mathrm{~m}$ de largo; asociado en el lado norte a una banqueta o "altar" de 0,65 $\mathrm{m}$ de altura con respecto a la superficie del patio, la cual presenta una escalinata en el medio de la parte frontal, de dos o tres peldaños (no se puede definir), que lo comunica con el patio. Esta estructura está orientado hacia el sur (hacia el río). Hacia el lado posterior de esta estructura se encuentran asociados un conjunto de hasta ocho recintos de planta rectangular y cuadrangular, algunos de los cuales presentan los muros con un fino acabado, con tartajeo de barro. Estos recintos presentan muros de hasta 1,80 m de altura.

- Sector "C": Conformado por un conjunto residencial, ubicado inmediatamente hacia el este del sector "B", de estructuras de forma rectangular y cuadrangular, que se expanden hasta la 

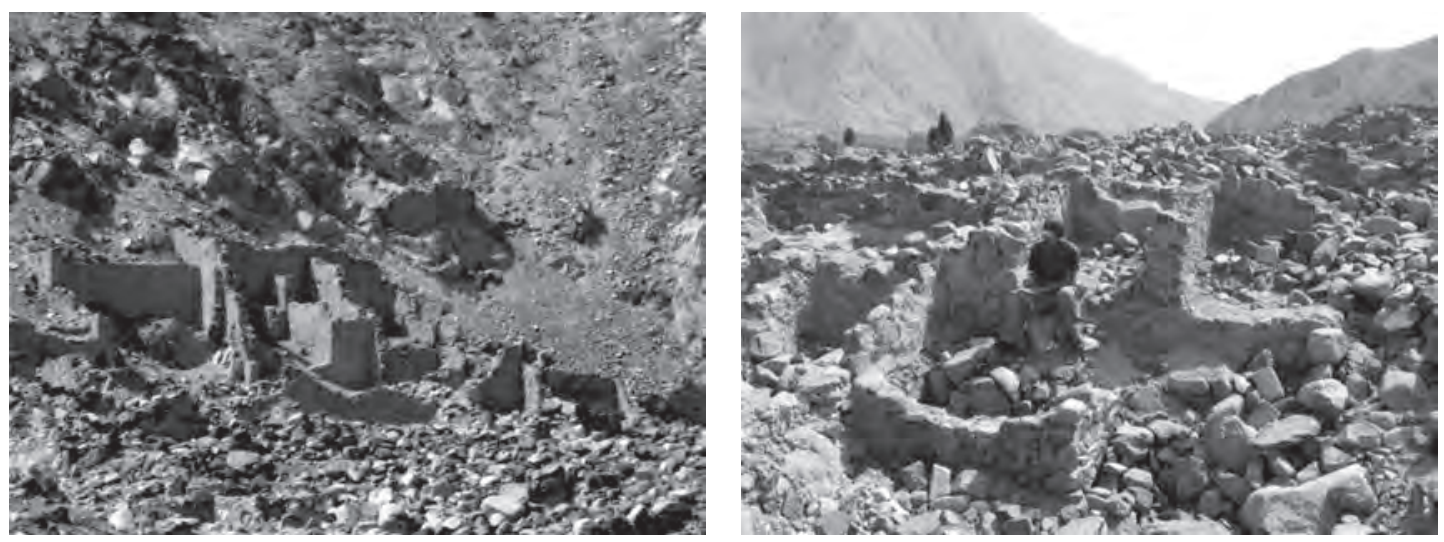

Figura 21. Izquierda: Vista del sector residencial, sitio Cantagallo (Sector C). Derecha: Vista del sector doméstico, en medio de la quebrada, sitio Cantagallo (Sector A).

ladera misma del cerro. Presenta una tecnología constructiva mejor elaborada, con muros de hasta 3,50 m de alto, asociados a patios de forma rectangular, con vanos y nichos trapezoidales, edificaciones de hasta dos niveles constructivos. Todos los muros presentan tartajeo de barro y enlucido de pintura color rojo ocre. Se aprecian también pasadizos y calles de hasta $1,20 \mathrm{~m}$ de ancho. Las edificaciones se van emplazando y adecuando a la topografía de la ladera del cerro mediante aterrazamientos.

Materiales asociados: Se aprecia material cerámico, en especial en el sector "A", correspondiente al estilo Inca Local, de función doméstica, pasta color naranja y bordes evertidos. En el Sector " C" se halló material cerámico de estilo Inca Provincial. Se identificó también batanes en el interior de recintos del sector "A", lo que indica que se trataría de áreas de actividad doméstica. También se identificó restos óseos en el interior de las estructuras funerarias de este sector.

Filiación cultural: Cronológicamente estaría relacionado con el Intermedio Tardío y el Horizonte Tardío. Sin embargo la primera ocupación no habría sido tan densa, como la última; constituyéndose en un asentamiento de control en el periodo Tawantinsuyu.

Estado de conservación: Se encuentra en regular estado de conservación. El avance de las chacras aledañas y el huaqueo son los principales factores de deterioro de las construcciones; así como la acción eólica de la quebrada.

\section{CRUZ BLANCA o APOTARA}

Ubicado en el distrito de Zuñiga, margen derecha del valle medio del río Cañete, a dos kilómetros del pueblo de Zuñiga, en las coordenadas UTM: 0387873E y $8578790 \mathrm{~N}$, a $860 \mathrm{msnm}$. Se trata de un extenso asentamiento de función política y administrativa, con recintos a base de piedras canteadas con revestimiento de barro, de planta cuadrangular y rectangular. Presentaban cubierta a dos aguas. En el extremo este se aprecia un patio de función ceremonial con columnas trapezoidales. El sitio se encuentra en buen estado de conservación.

\section{CONDORILLO}

Se ubica en el distrito de Lunahuaná, anexo de Uchupampa, margen izquierda del río Cañete, sobre el cono de deyección de una quebrada pequeña (de $200 \mathrm{~m}$ de ancho y terreno pedregoso) y en las laderas bajas de los cerros aledaños, junto al límite de las zonas de cultivo. La ubicación UTM (WGS-84) del sitio es: $8568558 \mathrm{~N}, 0377620 \mathrm{E}$ y la altitud es de $558 \mathrm{msnm}$. Se accede al sitio por un 

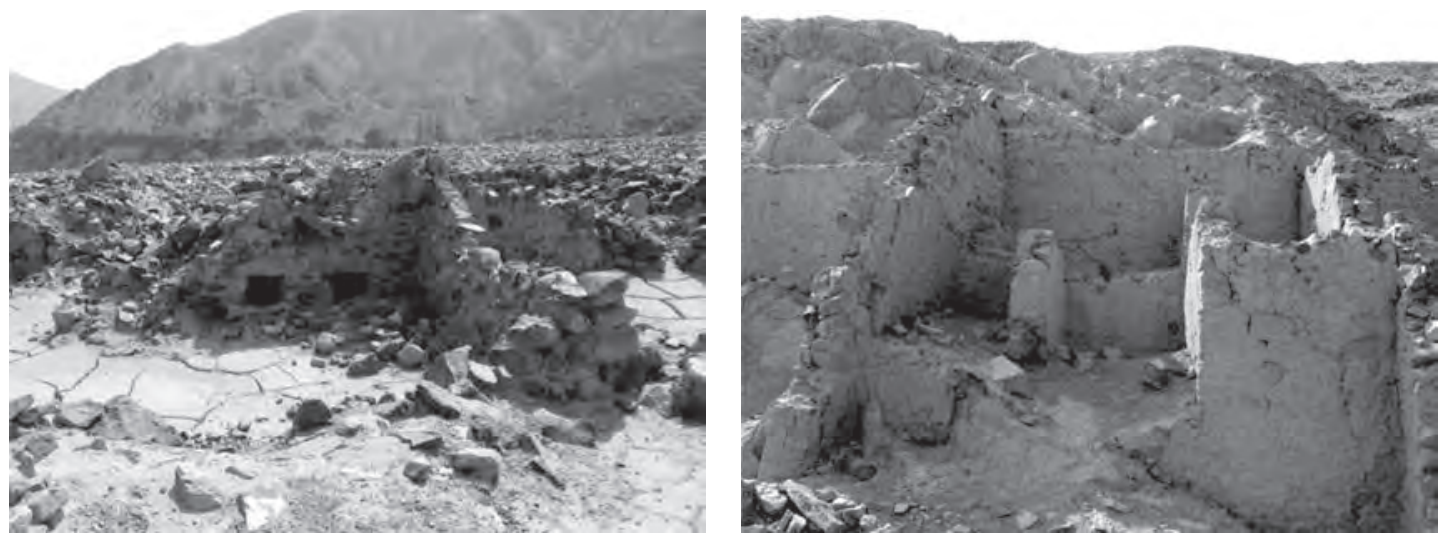

Figura 22. Izquierda: Vista panorámica del sector A, nótese los elementos constructivos y los nichos. Derecha: Vista panorámica del sector residencial, Cantagallo.

camino angosto que proviene desde la carretera Lunahuaná-Pacarán, frente al hotel Embassy.

El sitio está conformado por tres sectores pequeños:

- Sector A: Ubicado en la ladera media del cerro Condorillo, al oeste de la quebrada. Presenta un conjunto de estructuras semi subterráneas, de planta cuadrangular de 2 a $3 \mathrm{~m}$ por lado, edificados previa excavación en la ladera del terreno para dar horizontalidad al mismo. Las estructuras se agrupan en tres conjuntos dispuestos a manera extendida, y separados entre sí (los conjuntos) por amplios corrales. El conjunto superior está conformado por tres recintos cuadrangulares adyacentes y alienados en un eje noroeste-sureste. Por debajo de estos tres recintos hay un corral de forma rectangular, con un largo de igual dimensión que los tres recintos, aproximadamente $750 \mathrm{~m}$. Adyacentes a este corral, por debajo, hay un conjunto de dos recintos, con la misma orientación que los primeros y de iguales dimensiones. Por debajo hay otro corral también de forma rectangular y debajo, otro conjunto de 8 recintos cuadrangulares semi subterráneos orientado en el mismo eje que los anteriores. Los muros tienen hasta 2,50 $m$ de altitud y están edificadas a base de piedras canteadas medianas y grandes, unidas con argamasa, con enlucido de barro.

- Sector B: Se ubica en el cauce mismo de la quebrada, conformada por un área doméstica, subdividida en dos subsectores. El primero ubicado en la parte superior del cauce, con 20 recintos de planta cuadrangular y rectangular, pasadizos de acceso y vanos rectangulares, muros de 0,60 m de ancho y 1,40 m de altitud, con estructuras cuadrangulares internas subterráneas, donde se aprecian restos de osamentas humanas. Los muros presentan en su paramento interno nichos cuadrangulares pequeños, de 0,30 m de lado. El subsector bajo se ubica junto al primero, pero diferenciado por presentar un conjunto de ocho recintos rectangulares de 3 a $4 \mathrm{~m}$ de largo, con muros de piedras canteadas sobre aterrazamientos; y sobre estos muros presentan la superposición de muros de tapiales, edificados en paños murarios, definiendo recintos rectangulares.

- Sector C: Ubicada en la ladera media del cerro adyacente a la quebrada por el lado oriental. Presenta 15 recintos de planta cuadrangular y rectangular, con depósitos subterráneos de forma cuadrangular y muros de piedras canteadas con enlucido y nichos cuadrangulares similares a los del Sector B. Se trata de un sector doméstico. 

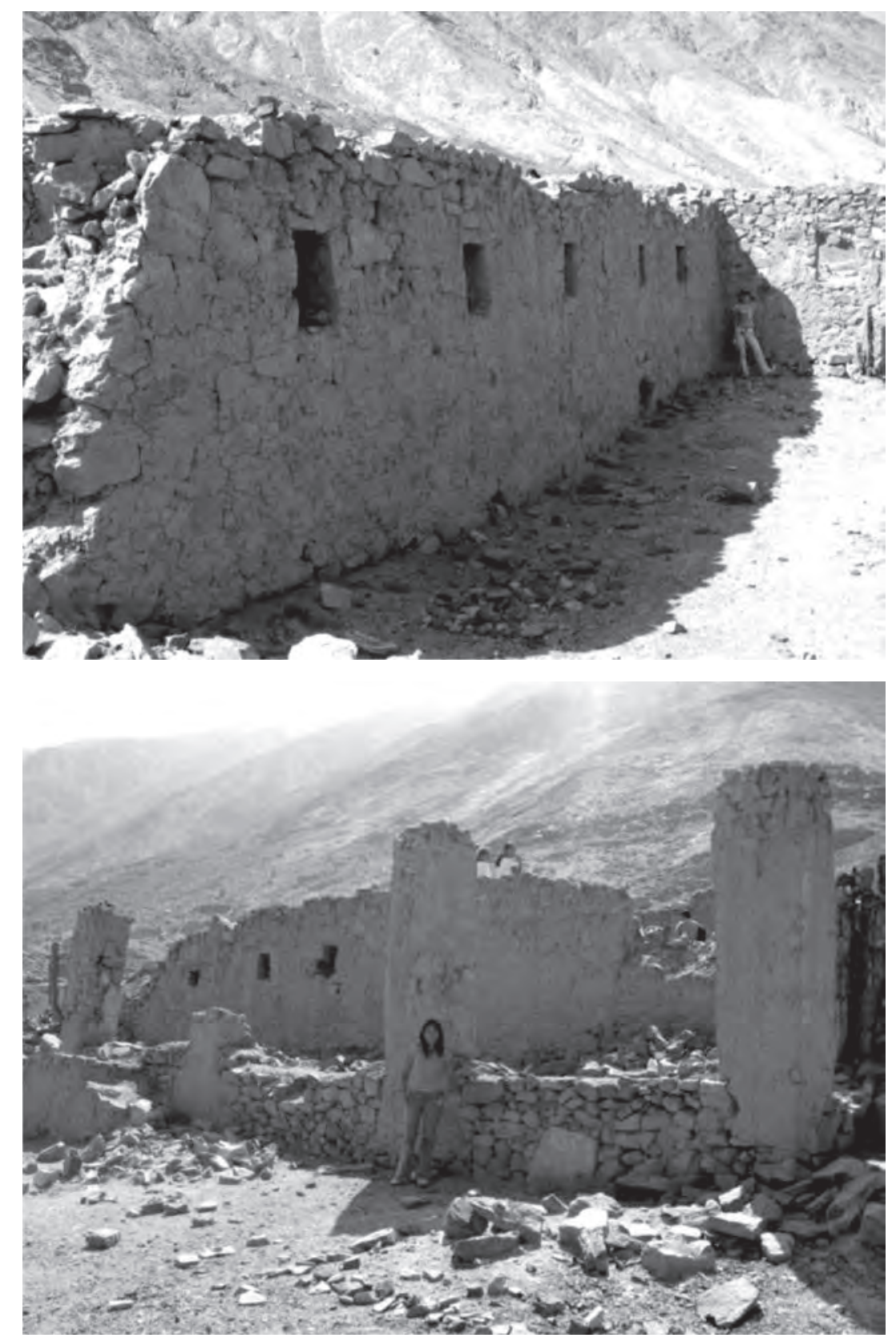

Figura 23. Arriba y abajo respectivamente.

Vista del sitio de Cruz Blanca, nótese los elementos Tawantinsuyu: columnas, nichos, etc.

\section{INTERPRETACIÓN DE DATOS}

El reconocimiento arqueológico realizado en esta zona del valle medio del río Cañete ha arrojado la identificación de 38 sitios arqueológicos, muchos de los cuales abarcan extensiones de terreno muy amplias, ocupando generalmente los conos de deyección de las quebradas y las terrazas aluviales late- 
rales al valle de Cañete. Es preciso reconocer las diferencias cuantitativas y cualitativas en la arquitectura de los sitios que se emplazan a ambas márgenes del río Cañete, es decir nuestro reconocimiento nos ha brindado datos sobre diferencias notables en el patrón de asentamiento de las poblaciones prehispánicas de acuerdo a la margen ocupada. En la margen izquierda hemos registrado un total de 27 sitios arqueológicos, principalmente destinados a actividades de carácter administrativos y almacenaje de productos no definidos, ubicados en áreas de difícil acceso, construidos en base a una misma técnica y sistema constructivo. Ocupan áreas pequeñas y se ubican en tramos casi regulares. Los sitios de mayor magnitud se emplazan hacia el norte del actual territorio de Pacarán, sobre el piso del valle, muy afectados por actividades agrícolas. Estos sitios manifiestan remodelaciones significativas de sus componentes arquitectónicos que implican cambios superlativos en la estructura espacial y orgánica del sitio. Claros ejemplos representan El Complejo Guagil, San Marcos de Pacarán, Huaca Daris.

En la margen derecha se han identificado 11 sitios arqueológicos, que se emplazan principalmente en terrazas aluviales y conos de deyección de las quebradas laterales al valle. Estos sitios se componen generalmente de dos o más sectores, uno de características administrativas-habitacionales y otro sector de carácter funerario. Presentan una arquitectura de mayor magnitud a las identificadas en la margen izquierda del valle y presentan remodelaciones relacionadas a una ocupación posterior de naturaleza foránea (Tawantinsuyu).

Con respecto al emplazamiento de los principales asentamientos de control del periodo Tawantinsuyu, estos se ubican en zonas estratégicas del valle, desde donde se pueda controlar a la población y los recursos. Por ejemplo Guagil, se ubica en las proximidades de la bocatoma del canal, con la finalidad de controlar el agua y su distribución.

\section{EL INTERMEDIO TARDÍO}

El panorama a nivel de la cuenca del río Cañete durante el Intermedio Tardío es complejo y aún, un enigma. En la cuenca baja se aprecia una formación política conocida como Guarco, la cual se expandía hasta los vecinos valles de Asia y Mala, la cual pasamos a revisar líneas mas adelante.

En la cuenca alta, sin embargo, la situación es muy diferente, así cada sub cuenca afluente del río Cañete presentaba una formación política diferente, las cuales sin embargo presentaban una unidad cultural, ya que por lo general compartían un mismo patrón espacial, arquitectónico y de asentamiento. Entre los principales grupos tenemos a los Tupi (cuenca del río Tupe, distrito de Tupe), Yawyu (cuenca del río Yauyos, distrito de Yauyos y alrededores), Laraws (distrito de Laraos), entre otros grupos como los de Tomas, Carania y Miraflores. Todos estos grupos son conocidos en general con el nombre de Yauyos. Además de estos existían otros grupos en la cuenca alta del río Asia u Omas y Mala. Sin embargo todos estos grupos de habla Jaqaru, habrían tenido alianzas defensivas para hacer frente a sus enemigos comunes, especialmente a los huancas del valle del Mantaro. La aparición de estos grupos se dio mucho antes del Intermedio Tardío, posiblemente a inicios del Horizonte Medio o mucho antes. Los asentamientos de estos grupos son simples, con un crecimiento espontáneo, sin una planificación previa, ubicados en las partes altas, especialmente en la cima de los elevados cerros de la cuenca.

\section{Huarco}

Es muy poca la información que se tiene sobre los Huarco, nación y entidad política que abarcó la cuenca baja del río cañete, al igual que valles contiguos como Mala y Asia, caracterizado por la edificación de grandes asentamientos. Luego de la caída de la Influencia cultural altoandina Huari-Tiahuanaco en la Costa Central, y la decadencia de los grandes centros ceremoniales y político-administrativos, como Huaca Malena, entre otros, se produce una disgregación política y cultural, apareciendo numerosos señoríos a razón de cada valle costeño, o por dos o tres valles contiguos. Este es el caso del valle bajo de Cañete, que junto con los valles de Mala y Asia (área de una misma co-tradición cultural común), 
fueron el escenario en el cual se desarrolló la cultura o señorío de Huarco, cuya población se asentó a lo largo de estos valles, edificando sus asentamientos especialmente en las quebradas laterales y sobre las terrazas aluviales que se elevan en cada valle. La base de la subsistencia fue la agricultura y la pesca. Las fuentes etnohistóricas nos demuestran la presencia de numerosos ayllus de pescadores en la línea de playa. Sus edificaciones fueron hechas básicamente utilizando el barro, elaborando adobes y tapiales, en el valle bajo; y piedras canteadas de cerro unidas con argamasa en el valle medio.

\section{El Valle medio: El Curacazgo de Runaguanac}

Se aprecia, sin embargo, durante el Intermedio Tardío, la presencia de una formación política social autónoma, no perteneciente ni a los grupos Huarco, ni a las naciones Yauyos de la cuenca alta, los cuales pertenecieron a la entidad política señalada por los cronistas, como Runaguanac, denominado en la colonia como Lunahuaná, el cual al momento de la invasión de los ejércitos del Inca hicieron tenaz resistencia junto con los Huarco del valle bajo. Este señorío ocupaba toda el área del valle medio del río Cañete y quebradas laterales, pertenecientes a las actuales jurisdicciones de los distritos de Lunahuaná, Pacarán y parte de Zúñiga.

Bernabé Cobo, señala al respecto, al igual que en la cita que hemos presentado líneas arriba, al señalar sobre la denominación que "lo cual hacen también en muchos vocablos, como se puede echar de ver por este: Lunahuaná, que significa un pueblo del arzobispado de esta ciudad, el cual nombre en la puridad de la lengua inga es Runahuanac, que quiere decir hombre corregible, y los indios de la costa lo pronuncian Lunahuanac" COBO, Bernabé; 1964 (1653): Cap. IV, Libro I.

Este curacazgo de Runaguanac, estaba limitando por el oriente con otro curacazgo, que mas adelante durante la época Tawantinsuyu, conformaría la provincia inca de Yauyos, como es el de Picamará, reducido en la colonia por el corregidor de Yauyos Diego Dávila Briceño, como San Cristóbal de Picamarán, en el actual distrito de Zúñiga. Mientras que como señalamos por el occidente limitaba con el señorío de Huarco.

\section{Los asentamientos}

El territorio del valle medio del río Cañete, del curacazgo de Runaguanac, estuvo conformado por numerosos asentamientos, emplazados sobre las quebradas laterales del valle y sobre terrazas aluviales. Se trata de asentamientos amplios, con diferenciación de sectores administrativos y de vivienda, así como áreas funerarias. El patrón de asentamiento, es así, concentrado, pues los sitios se hallan concentrados en el rincón del valle, a poca distancia entre sí.

\section{Análisis arquitectónico}

En cuanto a las construcciones del Intermedio tardío para la zona de estudio, se nota que las edificaciones son muy desordenadas, no presentan una disposición ordenada, con pocas estructuras en patrón ortogonal, plantas rectangulares (en poca proporción) e irregulares. Las edificaciones se emplazan sobre pequeños aterrazamientos, con la finalidad de dar horizontalidad al terreno. Las estructuras básicas están asociadas a áreas de depósitos subterráneos, pasadizos y otras estructuras asociadas, notándose incluso asociaciones de estructuras funerarias de planta rectangulares y semicirculares. El diseño y organización de las unidades arquitectónicas se adapta a la topografía del terreno, de ligera pendiente, por medio de la construcción de pequeñas terrazas que se suceden sucesivamente en un sentido transversal a su eje de orientación, sin un aparente orden o patrón reconocible.

Los muros están edificados a base de piedras canteadas de cerro, simples o en pocos casos trabajados, unidos con una delgada y tosca capa de argamasa de barro entremezclada con pequeñas piedras. Los muros son dobles, con un relleno interno de cascajo y basura, lo que le da una articulación con el 
amarre de lagunas piedras grandes entre ambos bloques. Algunos muros presentan enlucido, de hasta 0.02 metros de grosor, sin pintura. Los muros presentan hasta dos muros de alto, apreciándose en algunos casos cubiertas de piedras alajadas que se disponen a modo de ménsulas. Los vanos se orientan generalmente hacia el río.

\section{La cerámica}

Con respecto a la cerámica perteneciente al Intermedio Tardío, esta correspondería a un estilo cerámico local, el cual tentativamente nos atrevemos a denominar de manera preliminar como "Estilo Runaguanac", el cual presenta una pasta medianamente gruesa, de granos gruesos y temperantes de granos grandes, conformado por roca molida, cuarzo y mica.

La cerámica del estilo Runaguanac ha sido clasificada en los siguientes tipos:

\section{RUNAGUANAC LLANO}

Está conformado por un tipo de cerámica de pasta roja, cocción oxidante, sin decoración, de acabado de superficie es alisado o restregado. Este tipo es el más común y se halla disperso en la mayoría de sitios analizados en este trabajo. Las principales formas identificadas dentro de este tipo son:

Forma 1: Ollas. Vasijas de cuello esférico o globular, de cuello alto o bajo, con o sin asas, de boca ancha o media, usada para cocer o almacenar alimentos o agua. Dentro de los tipos de ollas tenemos:

* Olla Tipo 1: Olla de cuerpo globular y cuello corto divergente y recto de $4 \mathrm{~cm}$ de alto, de labio redondeado, con paredes de 0,8 cm de grosor. No presenta asa. (Lámina 4, Figura A).

* Olla Tipo 2: Olla de cuerpo globular, cuello corto, cóncavo y evertido de $2 \mathrm{~cm}$ de alto, de labio redondeado y adelgazado, con paredes delgadas de $0,40 \mathrm{~cm}$ de grosor. El asa es cintada y vertical ubicada en el ecuador del cuerpo. (Lámina 4, Figura A).

* Olla Tipo 3: Olla de cuerpo globular, cuello corto casi recto y convergente, de 1,6 cm de altura. El cuello presenta reforzamiento interno, las paredes son delgadas, de $0,3 \mathrm{~cm}$. Presenta asas horizontales de tamaño pequeño, ubicadas en la parte superior del cuerpo. (Lámina 4, figura C).

* Olla Tipo 4: Olla de cuerpo globular, cuello corto, recto y medianamente extendido, de $6 \mathrm{~cm}$ de altura (Lámina 5, figura F).

* Olla Tipo 5: Olla de cuerpo globular, cuello corto, recto y vertical, de $3 \mathrm{~cm}$ de altura (Lámina 6, Figura B).

* Olla Tipo 6: Olla de cuerpo globular, de cuello extendido, evertido y recto, de $9.5 \mathrm{~cm}$. de altura. El labio es redondeado con reforzamiento externo (Lámina 6, figura E).

Forma 2: Cántaros. Vasijas de cuerpo esférico, cuello corto y boca reducida, de mayor tamaño que las ollas, utilizada para almacenar o acarrear líquidos. Se han identificado los siguientes tipos de cántaros:

* Cántaro Tipo 1: Cántaro de cuello divergente, ligeramente cóncavo y extendido, de labio apuntado y de paredes medianamente gruesas, de $1 \mathrm{~cm}$ de grosor. (Lámina 6, Figura M).

* Cántaro Tipo 2: Cántaro de cuello extendido, ligeramente divergente, de $9 \mathrm{~cm}$ de alto, y paredes de 1,4 cm de grosor. (Lámina 6, Figura O).

* Cántaro Tipo 3: Cántaro de cuello medianamente alto $(9,8 \mathrm{~cm})$, cóncavo, ligeramente evertido y labio redondeado. (Lámina 6, Figura Q).

* Cántaro Tipo 4: Cántaro de cuello alto (17 cm de alto), ligeramente divergente y recto, de paredes medianamente gruesas $(1,6 \mathrm{~cm})$, labio biselado externo con reforzamiento externo. (Lámina 7, Figura A). 
Forma 3: Cuencos. Vasijas hemisféricas, hondas y anchas. Se han identificado los siguientes tipos de cántaros:

* Cuenco Tipo 1: Cuenco de paredes delgadas $(0,3 \mathrm{~cm})$, convexas, directas y convergentes. Al llegar a la base va aumentando de grosor. El borde es carenado. Tiene una altura de $8 \mathrm{~cm}$. (Lámina 8, Figura G).

Forma 4: Platos. Vasijas abiertas, de paredes fuertemente divergentes.

* Plato. Tipo 1. Plato de cuerpo convexo, con paredes de un espesor de 0,4 cm, con borde redondeado y reforzamiento externo. (Lámina 8, Figura $\mathrm{H}$ ).

\section{RUNAGUANAC NEGRO SOBRE CREMA}

Está conformado por un tipo de cerámica de pasta oxidante, color rojo claro, pero con una decoración conformada por pintura o engobe color crema, sobre el cual se delinean los motivos decorativos con pintura color negro. Este tipo es muy similar al identificado en otras regiones, como en Chincha, Ychma o Chancay. Las formas identificadas de este tipo son las siguientes:

\section{Forma 1: Jarras}

* Jarra. Tipo 1. Vasija cerrada, de cuello alto $(13 \mathrm{~cm})$, divergente, de paredes medianamente gruesas (de $1 \mathrm{~cm})$. (Lámina 3, Figura A).

\section{Forma 2: Platos.}

* Plato. Tipo 1: Plato de paredes delgadas, labio redondeado, y de cuerpo convexo. (Lámina 2, Figura E).

\section{Forma 3: Cuencos.}

* Cuenco Tipo 1: Cuenco de paredes delgadas $(0,4 \mathrm{~cm})$, convexas, directas y convergentes. El borde es carenado. (Lámina 3, Figura D).

En cuanto a la decoración, se han identificado los siguientes motivos:

1. Motivos lineales simples, de poco grosor $(0,4 \mathrm{~cm})$, los que por lo general se agrupan de a tres líneas o de a dos consecutivas, dispuestos en el eje horizontal, los cuales dan la vuelta alrededor de toda la vasija.

2. Decoración en bandas verticales, las que se alternan con el color crema de fondo, y se pueden distribuir tanto en el cuello como en el cuerpo de la vasija. El grosor de estas bandas es de 2,5 cm.

3. Decoración zigzageante, en los platos, en la parte interna, ubicados en el labio de la vasija.

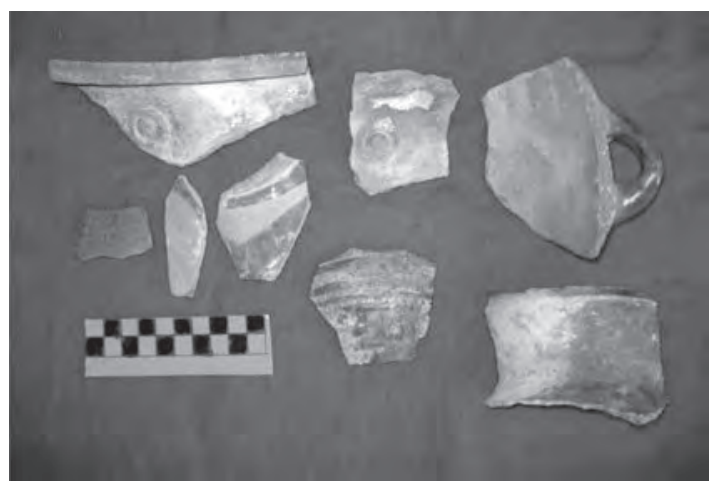

Figura 24. Estilo Runaguanac. Tipo Negro sobre Crema y Runaguanac Llano. Sitio Cerro Chilco IV.

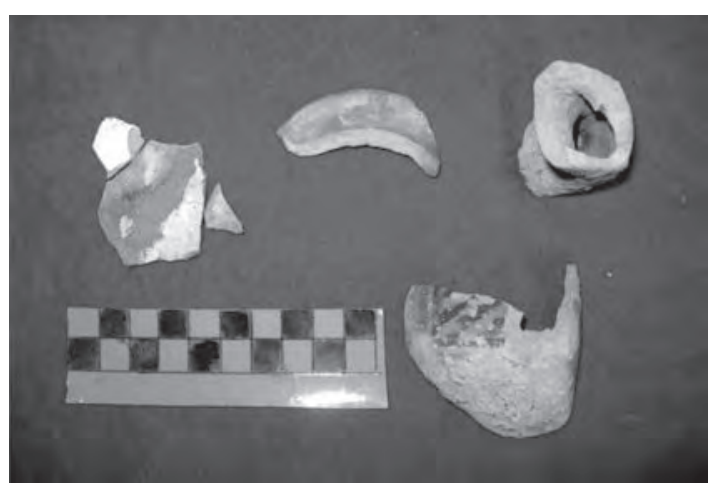

Figura 25. Cerámica Runaguanac Negro sobre Crema. Sitio Cerro manzanilla I. 


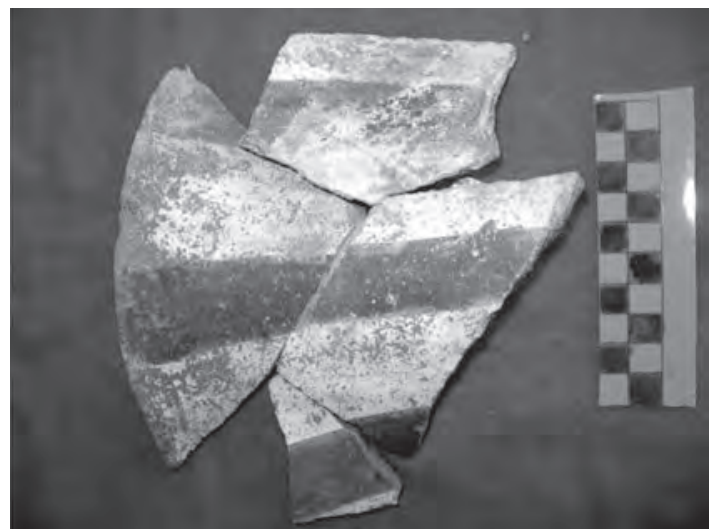

Figura 26. Estilo Runaguanac. Fragmento Tipo Negro sobre Crema Sitio Cerro Manzanilla I.

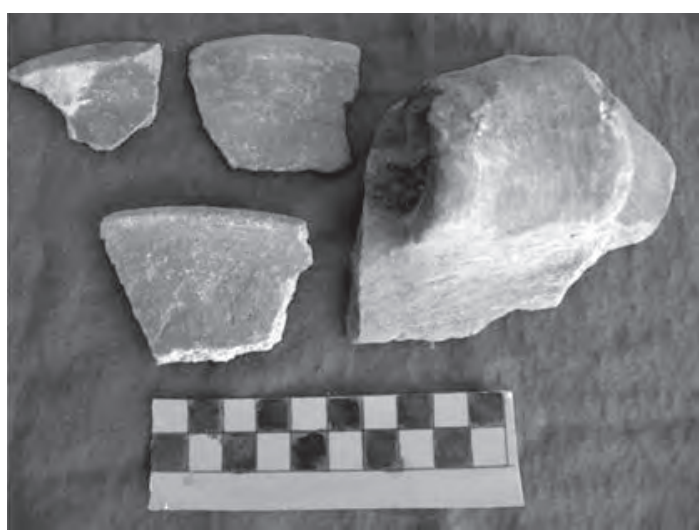

Figura 28. Estilo Runaguanac. Fragmentos Tipo Runaguanac Llano Sitio Antahualla II, Sector A.

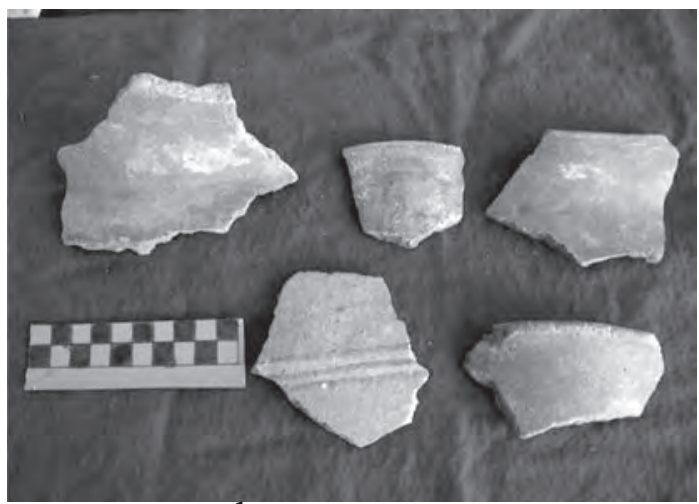

Figura 30. Estilo Runaguanac. Fragmentos Tipo Runaguanac Llano $y$ fragmento Tawantinsuyu (centro inferior). Sitio Antahualla II, Sector B.

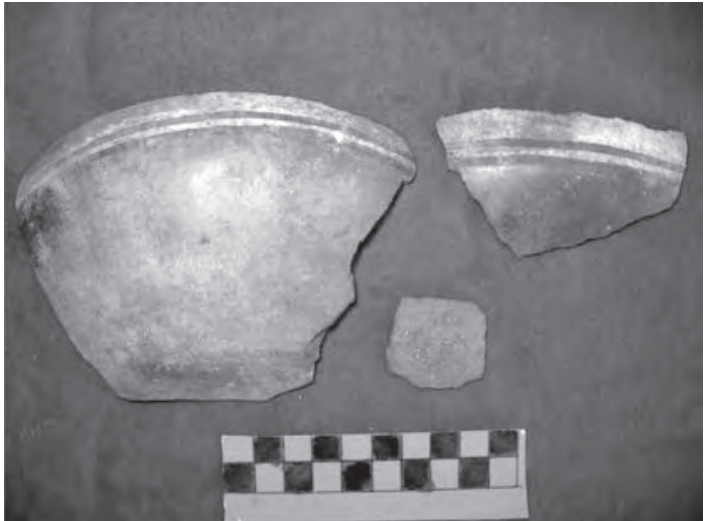

Figura 27. Cerámica Tawantinsuyu Provincial. Sitio Guagil, sector C.

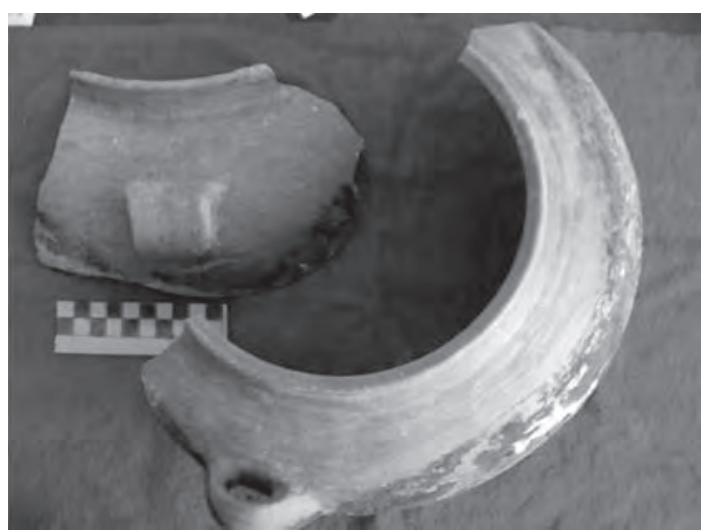

Figura 29. Estilo Runaguanac. Fragmentos Tipo Runaguanac Llano Sitio Antahualla II, Sector B.

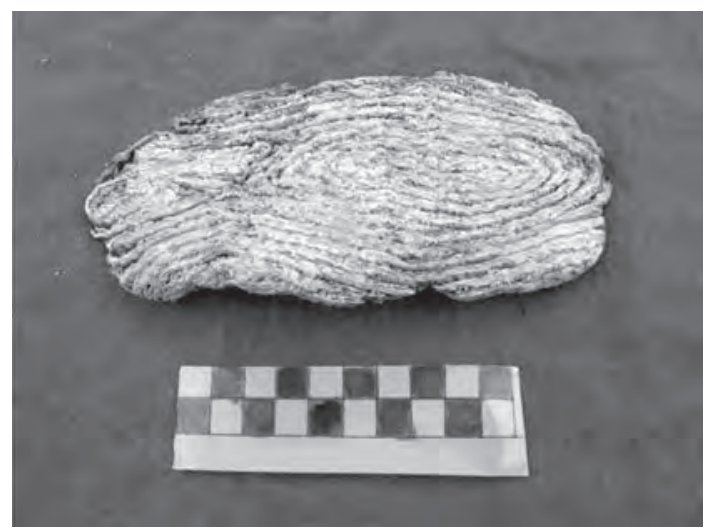

Figura 31. : Sandalia. Sitio Antahualla II, Sector B. 


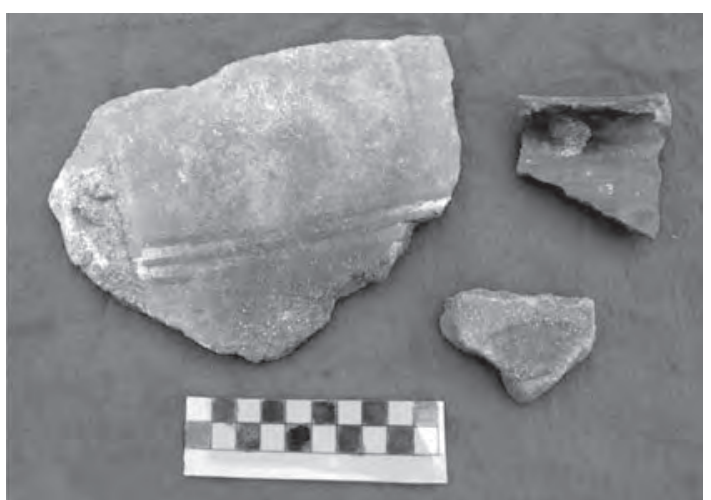

Figura 32. Estilo Runaguanac. Fragmentos Tipo Runaguanac Llano $y$ fragmento Tawantinsuyu (centro inferior). Sitio Antahualla II, Sector B.

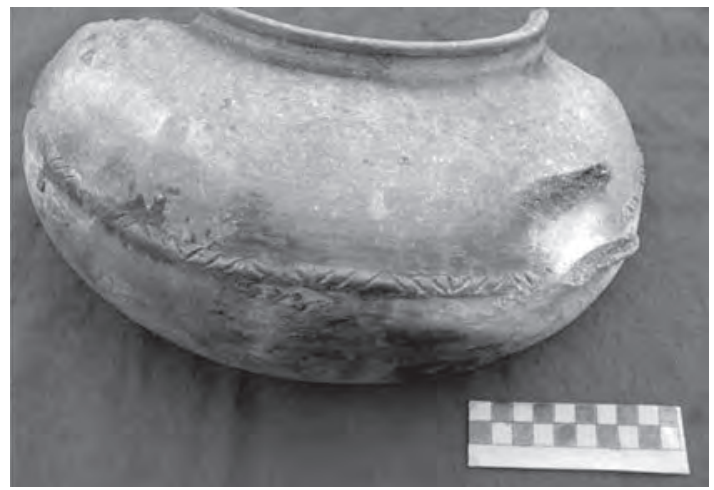

Figura 34. Estilo Runaguanac. Olla de cuello corto con decoración incisa lineal en el ecuador de la vasija. Tipo Runaguanac Llano Sitio Antahualla II, Sector B.

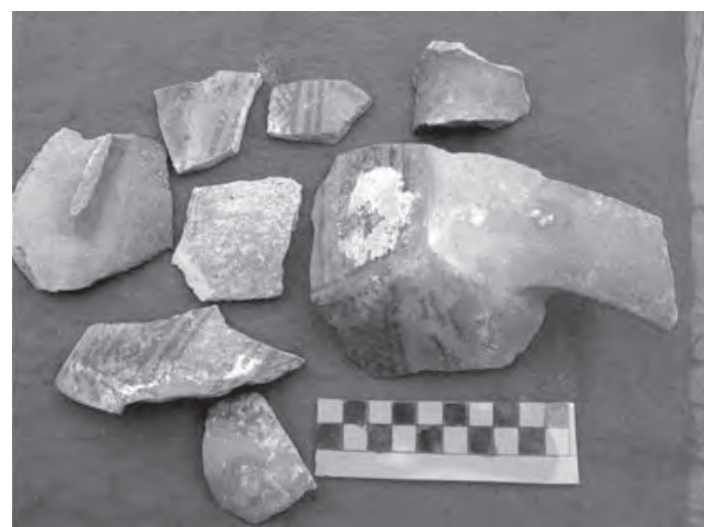

Figura 36. Estilo Tawantinsuyu. Olla Arybalo de base plana. Sitio Cerro Guanaco II, Sector B.

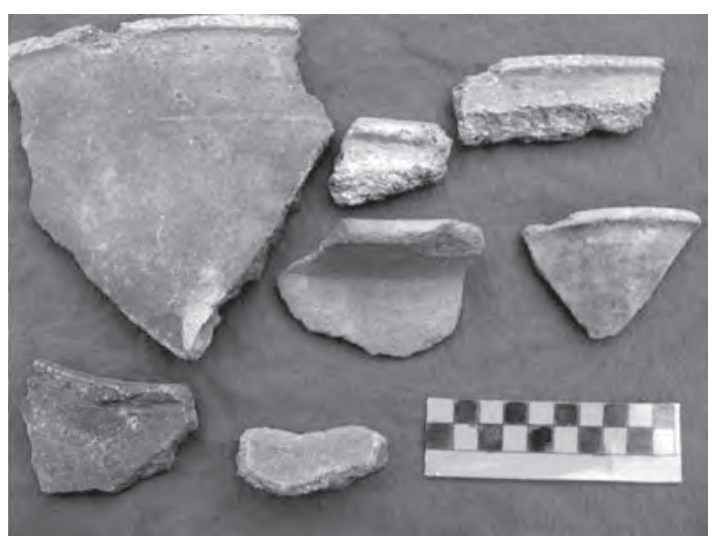

Figura 33. Estilo Tawantinsuyu Provincial. Sitio Guagil, sector B.

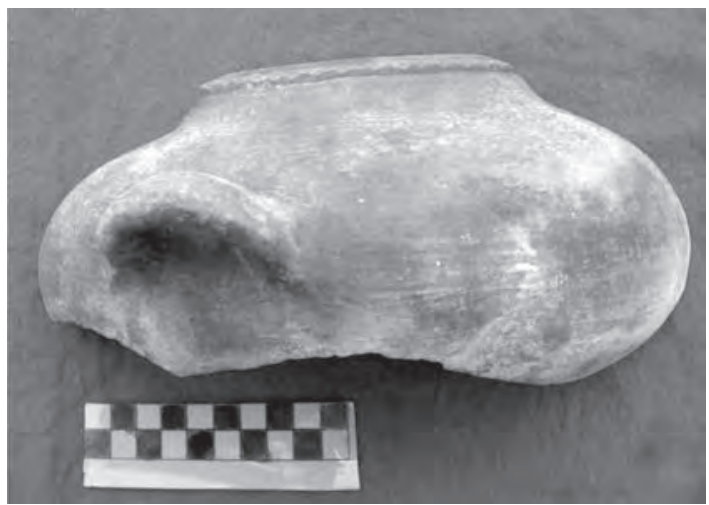

Figura 35. Estilo Runaguanac. Olla de cuello corto con decoración impresa en el cuello de la misma. Sitio Antahualla II, Sector B.

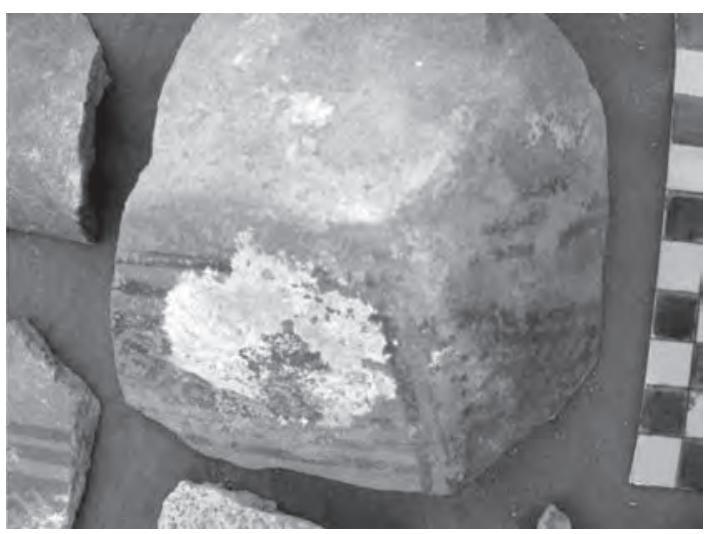

Figura 37. Detalle de la foto anterior. Sitio Cerro Guanaco II, Sector B. 


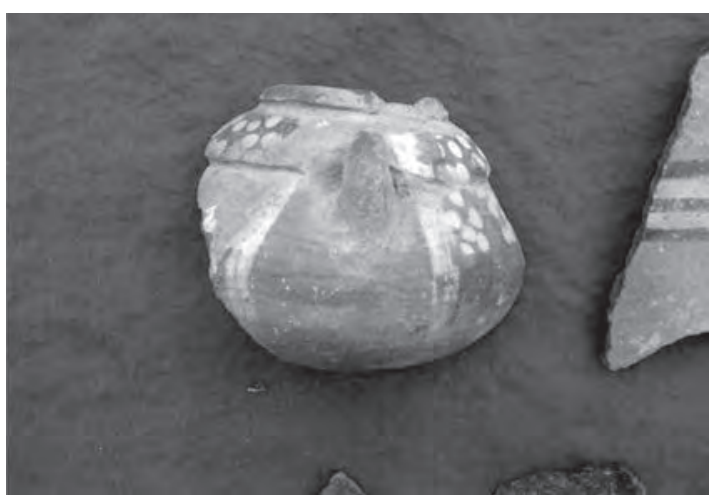

Figura 38. Cerámica Tricolor. Negro y Blanco sobre Rojo. Sitio Cerro Guanaco II, Sector B.

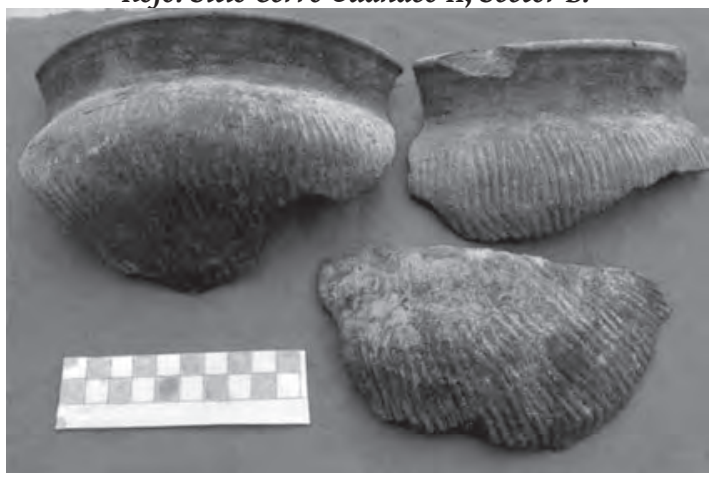

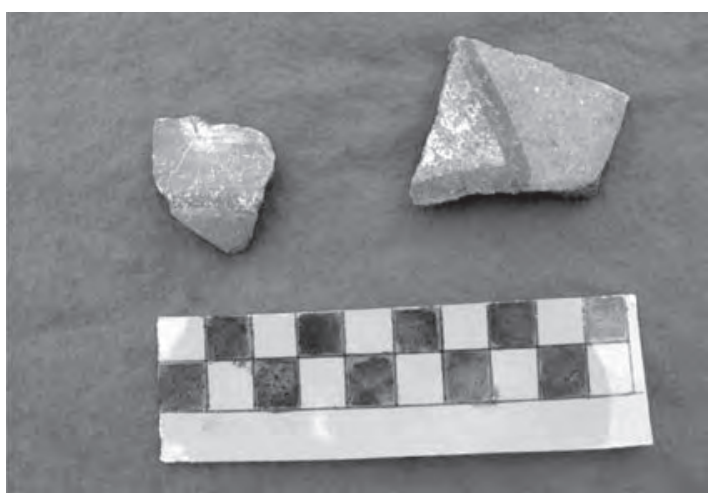

Figura 39. Estilo Tawantinsuyu. Sitio Cerro Mal Paso.

Figura 40: Cerámica en alto relieve.

\section{RUNAGUANAC IMPRESO}

Son vasijas llanas (sin decoración pintada), pero que presentan decoración conformada por círculos impresos, por lo general dispuestos en el cuello de las vasijas. Algunos de los ejemplares identificados son muy similares al Lauri Impreso del estilo Chancay, o al identificado a nivel de todo el departamento de Lima. El tipo Runaguanac impreso está conformado por vasijas monócromas, de acabado pulido, con la decoración a base de círculos impresos, posiblemente con cañas o punzones, siempre dispuesta en la tercera parte superior de la vasija, especialmente en el cuello de la misma.

Entre las formas identificadas, correspondientes a este tipo tenemos:

\section{Forma 1: Ollas}

* Olla Tipo 1: Olla de cuerpo globular y cuello corto convergente y directo de 1,4 cm de alto, de labio apuntado y ligeramente engrosado externamente, con paredes de $1 \mathrm{~cm}$ de grosor. Presenta asas horizontales, en la parte media de la vasija. (Lámina 5, Figura A). La decoración se ubica en el cuello del mismo, conformado por círculos alineados conformando un eje horizontal alrededor de toda la vasija.

\section{Forma 2: Cuencos}

* Cuenco Tipo 1: Cuenco de paredes medianas $(0,4 \mathrm{~cm})$, rectas, verticales y directas. El borde es evertido y ligeramente expandido. (Lámina 8, Figura F). La decoración está conformado por un círculo impreso elaborado sobre una pequeña aplicación dispuesta en la parte media superior del cuerpo de la vasija.

Cabe señalar que se identificó un fragmento de olla de cuerpo globular, cuello corto, con decoración a base de pequeñas cuñas incisas, dispuestas zigzageantes, en diagonal, conformando una franja de 0,8 cm. de ancho, que da la vuelta alrededor de la vasija en un eje horizontal. (Lámina 5, Figura B).

\section{EL HORIZONTE TARDÍO}

\section{Anexión de la cuenca del río Cañete al Tawantinsuyu}

Durante el gobierno del Inca Pachacutec, se organizan dos campañas para conquistar el territorio de los Andes centrales y anexarlos al Tawantinsuyu. En la segunda campaña, el ejército cuzqueño al mando del 
general Cápac Yupanqui, hermano del Inca, conquistó a las naciones Huancas, Huarochirí, Yauyos, Chucurpu, Atavillo, Canta, Tarama, Chinchaycocha, Checra, Cajatambo, entre otros. Una vez instalados en toda la región andina central, los ejércitos cusqueños en algunos casos, descendieron por los angostos valles hacia la región de la costa, con la finalidad de subyugar a los pequeños señoríos que se asentaban en estos fértiles valles, y en otros, fueron avanzando desde el sur hacia el norte conquistándolos.

Las estrategias de dominación que utilizaron los Incas fueron diversas y específicas para cada región andina. En aquellas regiones en las que los ayllus locales se constituían en una amenaza latente para el imperio, los incas aplicaban un control riguroso y marcado, edificando extensos sitios de control, edificados en neto estilo arquitectónico imperial, como símbolo de poder y dominación, muchas veces superponiéndose a las edificaciones de poder locales. Además la población era reorganizada y parte de ella trasladada a otros lugares en calidad de mitqmas. En otros casos, cuando los grupos sometidos eran pacíficos y no constituian una amenaza para el imperio, la estrategia inca no permitía interferir con las actividades domésticas. A los incas solo les interesaba, en estos casos, administrar y recoger los tributos, más no la vida doméstica.

Bernabé Cobo (1956 (1653)) señala: "Muchos valles de la costa se dieron de paz y otros fueron guerreados; conquistó en breve (Pachacuti) todas las provincias marítimas. [...] Entrando por lo que al presente es el distrito deste arzobispado de Lima le ofrecieron la paz los valles de La Nasca, Ica y Pisco, con los indios de Chunchanga y Humay; mas los de Chincha tomaron las armas, que eran muchos, y pelearon muchas veces con la gente del Inca, de la cual quedaron vencidos. No anduvieron menos valientes en su defensa los del Huarco y Lunaguaná que los de Chincha, sus vecinos, porque mantuvieron la guerra con notable esfuerzo y constancia muchos meses, en los cuales pasaron cosas notables entre los unos y los otros. Finalmente los redujo el Inca a tal estado, que se le hubieron de sujetar. Alcanzada esta victoria por el Inca, le dieron la obediencia pacíficamente los valles de Mala, Chilca, Pachamama, Lima, Chancay, Guaura y La barranca, con todos los demás que hay antes del de Chimo". Cobo, Bernabé; 1964 (1653), Cap. XIII, Libro 12.

En el valle bajo del río Cañete notamos la presencia de varios sitios edificados por los Incas, tanto de carácter administrativo durante las largas campañas de conquista de los grupos locales, como el de los runahuanac, caso el sitio de Incahuasi y Ungará; como otros sitios ceremoniales, destinados al culto del sol, caso el sitio de Cerro Azul o Huarco, edificado en medio de un farallón rocoso inaccesible (destruido por la armada chilena tras confundirlo con un bastión militar). En todos los casos los asentamientos eran edificados a base de una arquitectura típicamente del estilo Inca, como símbolo de supremacía y poder.

Otro aspecto que señala la imposición del Tawantinsuyu en estos valles es la presencia de vasijas del estilo Inca Imperial. Las vasijas de este estilo, en la mayoría de los casos, fueron elaborados en el Cusco, y representaban estatus social y simbología política. Por otra parte también estaba el estilo Inca local (Huarco-Inca o Runaguanac-Inca), que se caracteriza por presentar formas Inca (formas aribaloides), con decoración y pasta local. Simboliza también la presencia de lo Inca como simbología de poder y dominio. Las vasijas de estilo Inca local fueron elaborados por grupos de mitqmas trasladados de otras regiones.

Otro aspecto importante que data de este periodo es la adecuación de una compleja red vial, constituido por caminos que recorren ambas márgenes. El camino de penetración que se dirige a Jauja, es uno de los mas importantes del Qhapaq Ñan, el cual recorre por la margen sur del valle de Cañete. En la actualidad está en aceptable estado de conservación, en especial en el tramo de Lunahuaná. De este camino principal se desprenden una gran cantidad de caminos secundarios que se introducen en los sub valles. Presentan en muchos tramos empedrados en el suelo y muros de contención, adaptándose perfectamente a la topografía del terreno.

\section{Los asentamientos}

Los asentamientos pertenecientes al periodo Tawantinsuyu que hemos identificado, se ubican en áreas estratégicas del valle, con elementos típicos imperiales como ushnus (en los sitios de Guagil e Incahuasi), en el caso de los sitios políticos-administrativos. Los sitios de control Tawantinsuyu denotan áreas 
desde donde se puede controlar tanto a poblados locales como el acceso al agua y las áreas productivas. Así, Guagil, por ejemplo, se ubica en una zona cercana a la bocatoma del canal que riega la margen izquierda del valle, canal de origen prehispánico. Otro sitio con marcada ocupación Tawantinsuyu, de función residencial es Cantagallo, ubicado en la parte baja de la quebrada del mismo nombre,

\section{Análisis arquitectónico}

La cuenca del río Cañete, tanto en su cuenca alta, media y baja, es una de las cuencas del Pacífico con una fuerte presencia del Tawantinsuyu, evidenciado a través de los restos materiales. El sitio más importante en el valle medio y con arquitectura Tawantinsuyu imperial es Incahuasi. Existen además por todo el valle medio numerosos sitios con presencia de arquitectura tipo Tawantinsuyu pero de factura local, como Guagil, Daris, Cantagallo, Apotara, entre otros, donde destacan las edificaciones tipo Kanchas, plataformas en plazas tipo ushnus y vanos y nichos trapezoidales.

\section{Análisis cerámico}

La cerámica identificada correspondiente al periodo Horizonte Tardío o Tawantinsuyu, está representada por el estilo Tawantinsuyu, en los tipos Imperial, Provincial y local. Es abundante la presencia de vasijas de forma arybaloide (piuñun), de base plana o apuntada, de pasta oxidante en color naranja, de finos temperantes, con asas en el ecuador del cuerpo y borde evertido, con una aplicación en la parte superior frontal del cuerpo de la vasija, como la vasija identificada en el sitio de cerro Guanaco II, Sector B (Foto 35). Se han identificado también chuas o platos medianos con decoración lineal en tricolor, procedente del sitio de Guagil. De igual manera se ha identificado innumerables muestras de fragmentos Tawantinsuyu local, hechos en la misma región, pero llevando consigo íconos y símbolos Tawantinsuyu, así como formas cusqueñas.

\begin{tabular}{|c|c|c|c|}
\hline \multirow[t]{2}{*}{ NOMBRE DEL SITIO } & \multicolumn{2}{|c|}{$\begin{array}{l}\text { SISTEMA DE COORDENADAS } \\
\text { UTM: WGS-84. }\end{array}$} & \multirow{2}{*}{$\begin{array}{l}\text { ALTURA } \\
\text { m.s.n.m }\end{array}$} \\
\hline & NORTE & ESTE & \\
\hline \multicolumn{4}{|c|}{ MARGEN IZQUIERDA } \\
\hline \multicolumn{4}{|l|}{ 1. QUEBRADA DE GUAGIL } \\
\hline Guagil a & 8577844 & 387814 & 772 \\
\hline Guagil b & 8577700 & 387567 & 790 \\
\hline Guagil c & 8577886 & 387640 & 767 \\
\hline Guagil d & 8577842 & 387465 & 759 \\
\hline Guagil E. Estructuras menores de Guagil & 8577868 & 387527 & 766 \\
\hline 2. SAN MARCOS DE PACARÁN & 8577792 & 386463 & 750 \\
\hline 3. HUACA DARIS O FORTALEZA DE PACARAN & 8577812 & 386068 & 736 \\
\hline 4. PETROGLIFOS DE SAN MARCOS & 8578086 & 386086 & 720 \\
\hline 5. CERRO GUANACO I-A & 8577838 & 386980 & 750 \\
\hline 6. CERRO GUANACO I-B & 8577750 & 386910 & 750 \\
\hline 7. CERRO GUANACO I-C & 8577686 & 386802 & 752 \\
\hline 8. CERRO GUANACO II & 8577588 & 386517 & 766 \\
\hline 9. CERRO GUANACO III & 8577548 & 386241 & 760 \\
\hline 10. CERRO GUANACO IV & 8577430 & 386397 & 758 \\
\hline 11. CERRO GUANACO V & 8577368 & 386229 & \\
\hline 12. CERRO GUANACO VI & 8576870 & 385489 & 772 \\
\hline 13. CERRO GUANACO VII & 8576662 & 385379 & 755 \\
\hline 14. CERRO GUANACO VIII & 8576440 & 385178 & 732 \\
\hline 15. CERRO GUANACO IX & 8576076 & 384820 & 730 \\
\hline 16. CERRO GUANACO X & 8575940 & 384484 & 737 \\
\hline 17. CERRO GUANACO XI & 8575938 & 384453 & 735 \\
\hline 18. CERRO GUANACO XU & 8575888 & 384191 & 724 \\
\hline \multicolumn{4}{|l|}{ 19. CERRO GUANACO XIII } \\
\hline cerro Guanaco XIII-A & 8575510 & 383934 & 721 \\
\hline cerro Guanaco XIII-B & 8575448 & 383911 & 721 \\
\hline cerro Guanaco XIII-C & 8575282 & 383914 & 751 \\
\hline 20. CERRO MAL PASO I & 8574918 & 383530 & 718 \\
\hline 21. CERRO MAL PASO II & 8575006 & 383634 & 700 \\
\hline 22. CERRO MAL PASO III & & & \\
\hline
\end{tabular}


Pieter van Dalen / Investigaciones arqueológicas en Pacarán, valle medio del río Cañete, Curacazgo de Runaguanac

\begin{tabular}{|c|c|c|c|}
\hline cerro Mal Paso III-A & 8574666 & 383211 & 694 \\
\hline cerro Mal Paso III-B & 8574674 & 383191 & 888 \\
\hline 23. CERRO MANZANILLA I & 8572744 & 381571 & 630 \\
\hline 24. CERRO MANZANILLA II & No tiene & No tiene & No tiene \\
\hline \multicolumn{4}{|l|}{ 25. CERRO MANZANILLA III } \\
\hline cerro Manzanilla IUA & 8577548 & 386241 & \\
\hline cerro Manzanilla IUB & & & \\
\hline 26 HUACA SAN CARLOS & 8576840 & 385031 & 703 \\
\hline \multirow{2}{*}{\multicolumn{4}{|c|}{ MARGEN DERECHA }} \\
\hline & & & \\
\hline \multicolumn{4}{|l|}{27 QUEBRADA PAMPA GRANDE } \\
\hline Quebrada de Pampa Grande A & 8577964 & 385342 & 751 \\
\hline Quebrada de Pampa Grande B & 8578098 & 385269 & 758 \\
\hline \multicolumn{4}{|l|}{28 CERRO CHILCO I } \\
\hline cerro Chilco IA & 8577502 & 385070 & 711 \\
\hline cerro Chilco IB & 8577406 & 384983 & 701 \\
\hline 29 CERRO CHILCO II & 8577338 & 384935 & 701 \\
\hline \multicolumn{4}{|l|}{30 CERRO CHILCO III } \\
\hline cerro Chilco IIIA & 8577204 & 384935 & 722 \\
\hline cerro Chilco IUB & No tiene & No tiene & No tiene \\
\hline 31 CERRO CHILCO IV & 8576708 & 384070 & 720 \\
\hline \multicolumn{4}{|l|}{32 ANTAHUAYA I } \\
\hline Antahuaya I-A & 8576356 & 383632 & 696 \\
\hline Antahuaya I-B & 8576266 & 383517 & 691 \\
\hline \multicolumn{4}{|l|}{33 ANTAHUAYA II } \\
\hline Antahuaya II-A & 8575876 & 383080 & 675 \\
\hline Antahuaya II-B & 8575778 & 382917 & 670 \\
\hline \multicolumn{4}{|l|}{ 34. QUEBRADA DE NIGACHO I } \\
\hline Quebrada de Nigacho I-A & 8575274 & 382534 & 671 \\
\hline Quebrada de Nigacho I-B & 8575120 & 382362 & 686 \\
\hline 35. QUEBRADA DE NIGACHO II & 8575062 & 382273 & 684 \\
\hline 36. CANTAGALLO & 8570730 & 378878 & 597 \\
\hline 37. CRUZ BLANCA & 8578790 & 0387873 & 860 \\
\hline
\end{tabular}

\section{CONCLUSIONES}

Las conclusiones a las cuales hemos llegado con la presente investigación son las siguientes:

1. Se ha registrado en el ámbito del distrito de Pacarán y alrededores un total de 38 sitios arqueológicos, correspondientes en su mayoría a periodos tardíos.

2. Los sitios identificados pertenecen a una entidad sociopolítica tardía que abarcó los territorios de los actuales distritos de Lunahuaná, Pacarán y Zúñiga, entidad que los cronistas españoles lo denominan como Runaguanac, la cual estuvo conformado por numerosos asentamientos, emplazados sobre las quebradas laterales del valle y sobre terrazas aluviales. Se trata de asentamientos amplios, con diferenciación de sectores administrativos y de vivienda, así como áreas funerarias. El patrón de asentamiento, es concentrado, pues los sitios se hallan concentrados en el rincón del valle, a poca distancia entre sí.

3. Se nota que las edificaciones Runaguanac son muy desordenadas, no presentan una disposición ordenada, con pocas estructuras en patrón ortogonal, plantas rectangulares (en poca proporción) e irregulares. Las edificaciones se emplazan sobre pequeños aterrazamientos, con la finalidad de dar horizontalidad al terreno. Las estructuras básicas están asociadas a áreas de depósitos subterráneos, pasadizos y otras estructuras asociadas, notándose incluso asociaciones de estructuras funerarias de planta rectangulares y semicirculares. El diseño y organización de las unidades arquitectónicas se adapta a la topografía del terreno, por medio de la construcción de pequeñas terrazas que se suceden en un sentido transversal a su eje de orientación, sin un aparente orden o patrón reconocible.

4. Los muros están edificados a base de piedras canteadas de cerro, simples o en pocos casos trabajados, unidos con una delgada y tosca capa de argamasa de barro entremezclada con pequeñas piedras. Los muros son dobles, con un relleno interno de cascajo y basura, lo que le da una articu- 


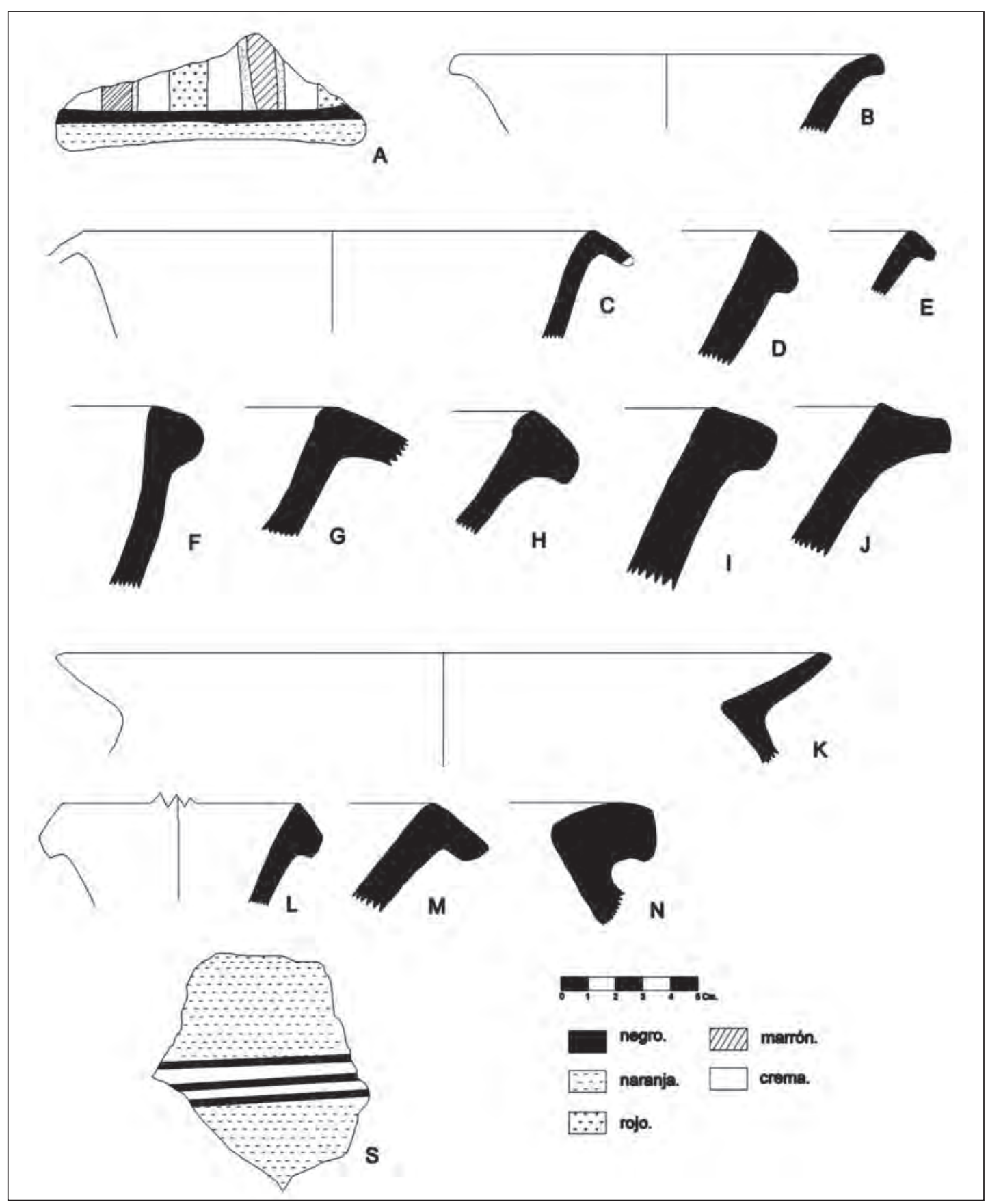

Lámina 1. Cerámica Tawantinsuyu: A: Base de vasija Tawantinsuyu imperial (sitio Guagil, Sector "C"). B: vasija Inca local, de borde ligeramente evertido, cuello divergente, sin decoración. (sitio Guagil B3). C: Tazón Inca local de cuerpo divergente y borde evertido, sin decoración (sitio Guagil B3) y variedades de la misma, D, E F, G, H, I (Bolsa 5). J (Bolsa 8). K. (Bolsa 5) L. (Bolsa 9) M. (Bolsa 9) N: Borde Inca imperial evertido (Antahuaya II, Sector B). S: Fragmento Tawantinsuyu imperial de pasta y engobe naranja, con decoración lineal en bandas alternado en negro y crema (Antahuaya I, sector A). 


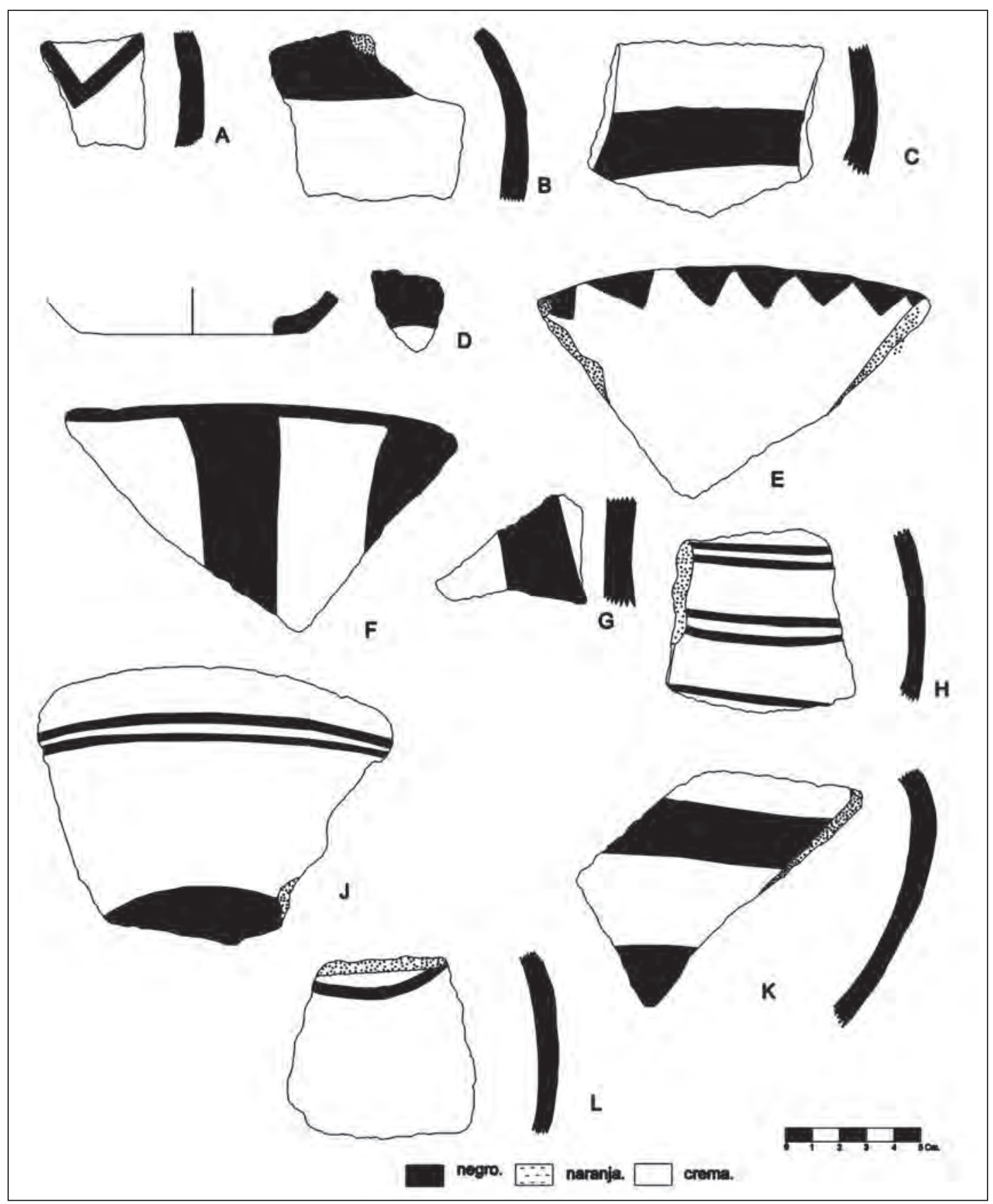

Lámina 2. Cerámica Intermedio Tardío (Runaguanac Negro sobre Crema), tipo Negro sobre Crema. A: (B3). B: (B3). C: fragmento con decoración en bandas horizontales. (B4).D: Base plana (B3). E: Fragmento de plato, con decoración en el borde, de motivos zigzageantes. (B4) F: Fragmento de plato con decoración en bandas verticales. (B4) G: Fragmento con decoración en bandas verticales. (B4). H: Fragmentos con decoración lineal horizontales. (B6) I: (B6) J: (B10). K: Fragmento con decoración en bandas horizontales gruesa (B4). L: (B10). 


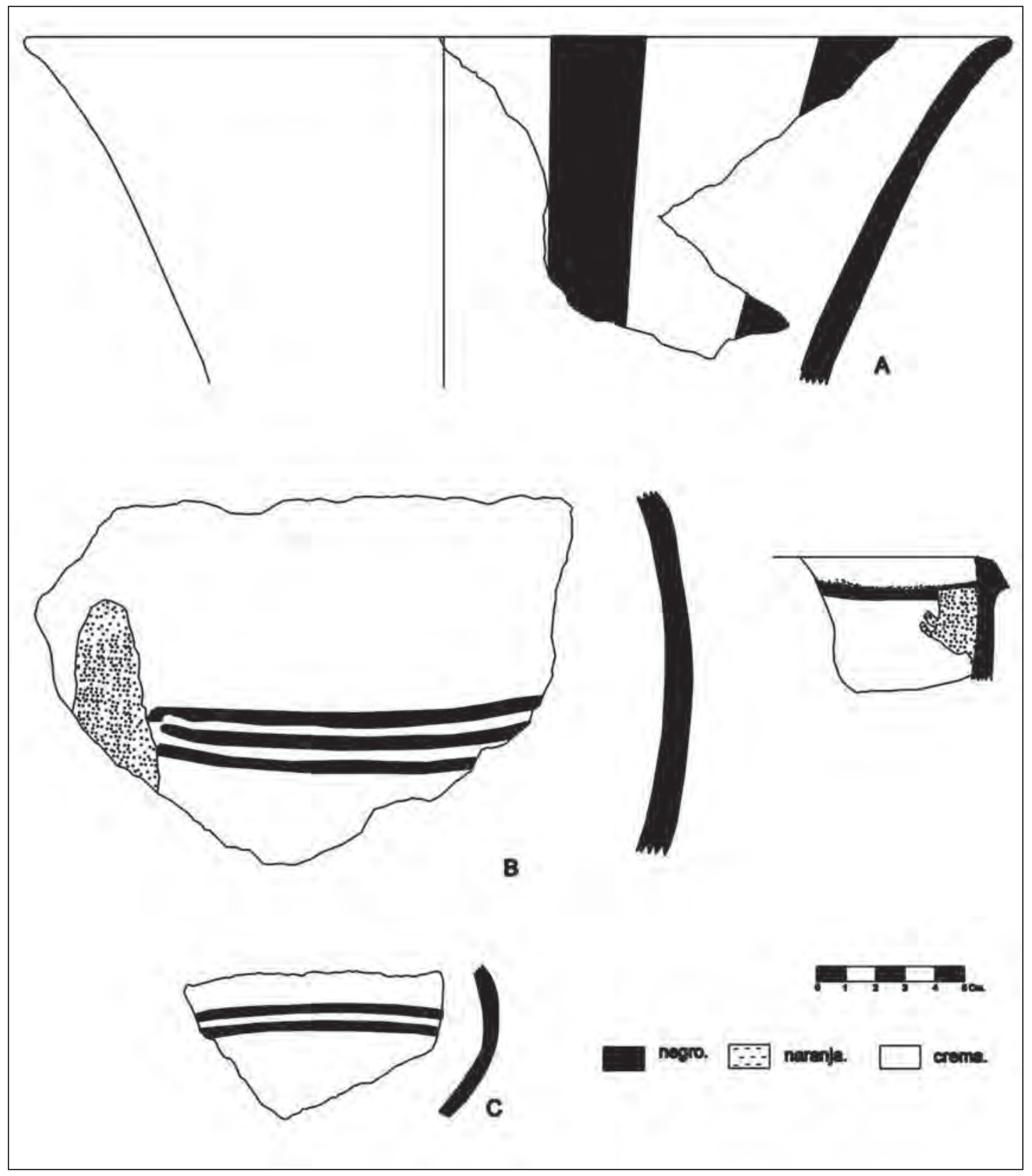

Lámina 3. Cerámica Intermedio Tardío (Runaguanac Negro sobre Crema), tipo Negro sobre Crema. A: Cuello de jarra, de borde divergente y largo, con decoración en bandas verticales; temperantes: abundante cuarzo y roca molida. (Cerro Manzanilla I) B: Fragmento con decoración en bandas delgadas horizontales. C: Fragmento con decoración lineal, horizontal (B10). 

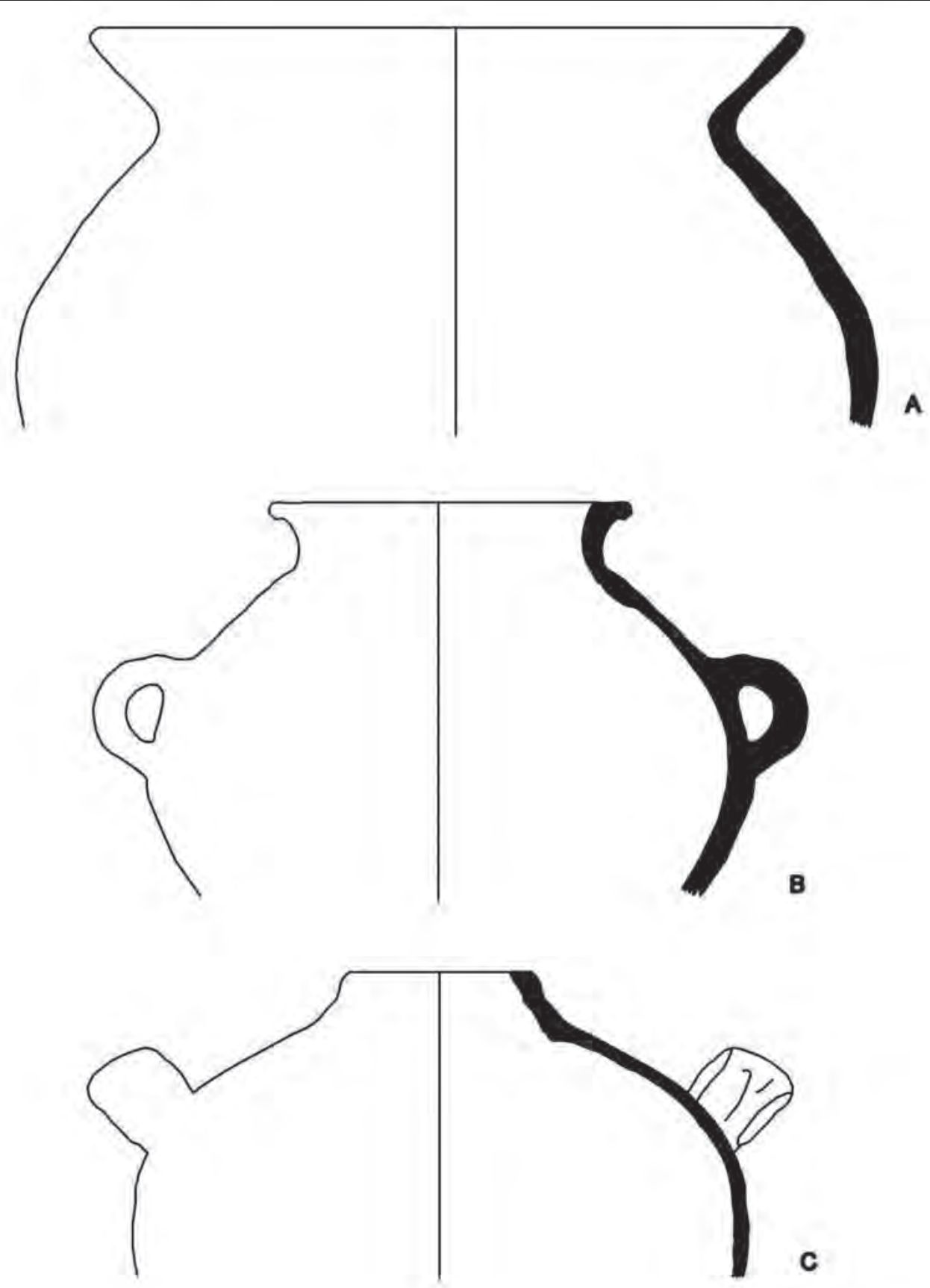

Lámina 4. Cerámica Intermedio Tardío (Runaguanac Llano). A: Olla de cuerpo globular y cuello corto divergente. (Antahuaya I, Sector A). B: Olla de cuerpo globular, cuello corto, cóncavo y evertido; asas verticales, cortas en el ecuador. (Antahuaya I, Sector B). C: Olla globular con cuello corto, y asas horizontales en la parte superior del cuerpo. (Antahuaya I, Sector B). 


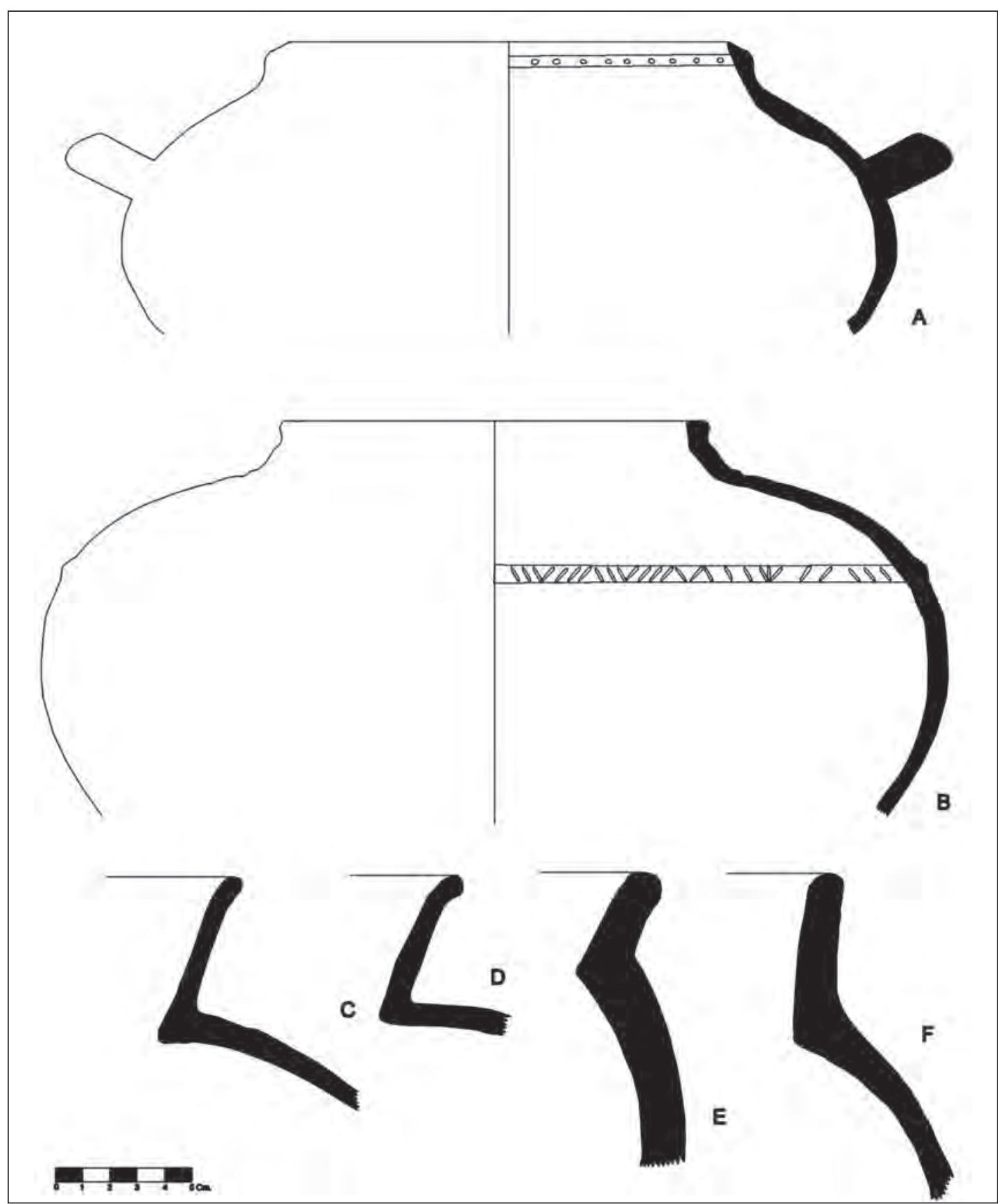

Lámina 5. Cerámica Intermedio Tardío (Runaguanac Llano). A: Olla con cuello corto, cuerpo globular, decoración a base de incisiones circulares pequeñas en el cuello de la vasija. (Antahuaya II, Sector B). B: Olla con cuello corto, cuerpo globular, con decoración a base de pequeñas incisiones lineales hechas con la uña en una banda horizontal en el cuerpo superior. (Antahuaya II, Sector B). C: Olla con cuello expandido, ligeramente divergente, cuerpo globular. (Nigacho I, sector B). D: Olla de cuello medianamente expandido, ligeramente divergente y de cuerpo gobular. (B 13). E: Olla de cuerpo globular y cuello corto, recto y divergente. (B11). F: olla de cuerpo globular y cuello vertical, recto y medianamente extendido. 


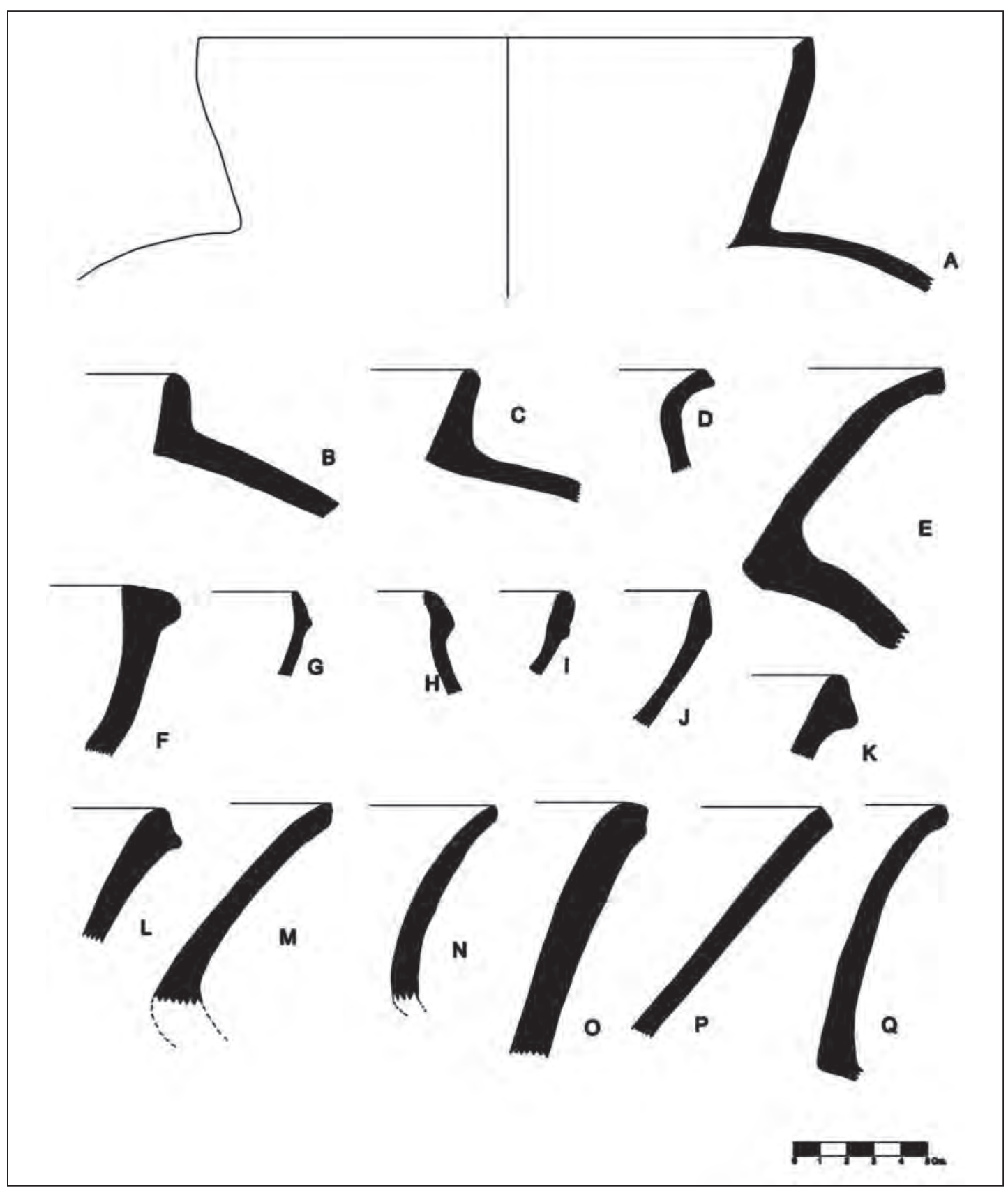

Lámina 6. Cerámica Intermedio Tardío (Runaguanac Llano). A: Olla con cuello mediano, ligeramente divergente y recto, cuerpo expandido. (B13) B: Olla de cuello corto, recto y vertical, cuerpo expandido. (B3). C: Olla de cuello corto, divergente. (Guagil, Sector C). D: Olla de cuello corto, ligeramente evertido. (Guagil, Sector C). E: Olla de cuello extendido, evertido (Cerro Chilco III). F: Borde de cántaro con reforzamiento externo. (B3). Variedades similares a F: G: (B5), H: (B5), I: (B12), J: (B12), K (B12), L: (B8). M: Cántaro de cuello divergente, ligeramente cóncavo y extendido. (Nigacho I, Sector B). N: Variedad del anterior. (Nigacho I, Sector B). O: Cántaro de cuello extendido, ligeramente divergente. (B11). P: Cántaro de cuello extendido, divergente y recto. (B11). Q: Cántaro de cuello medianamente alto, cóncavo, labio redondeado. (Antahuaya II, Sector B). 


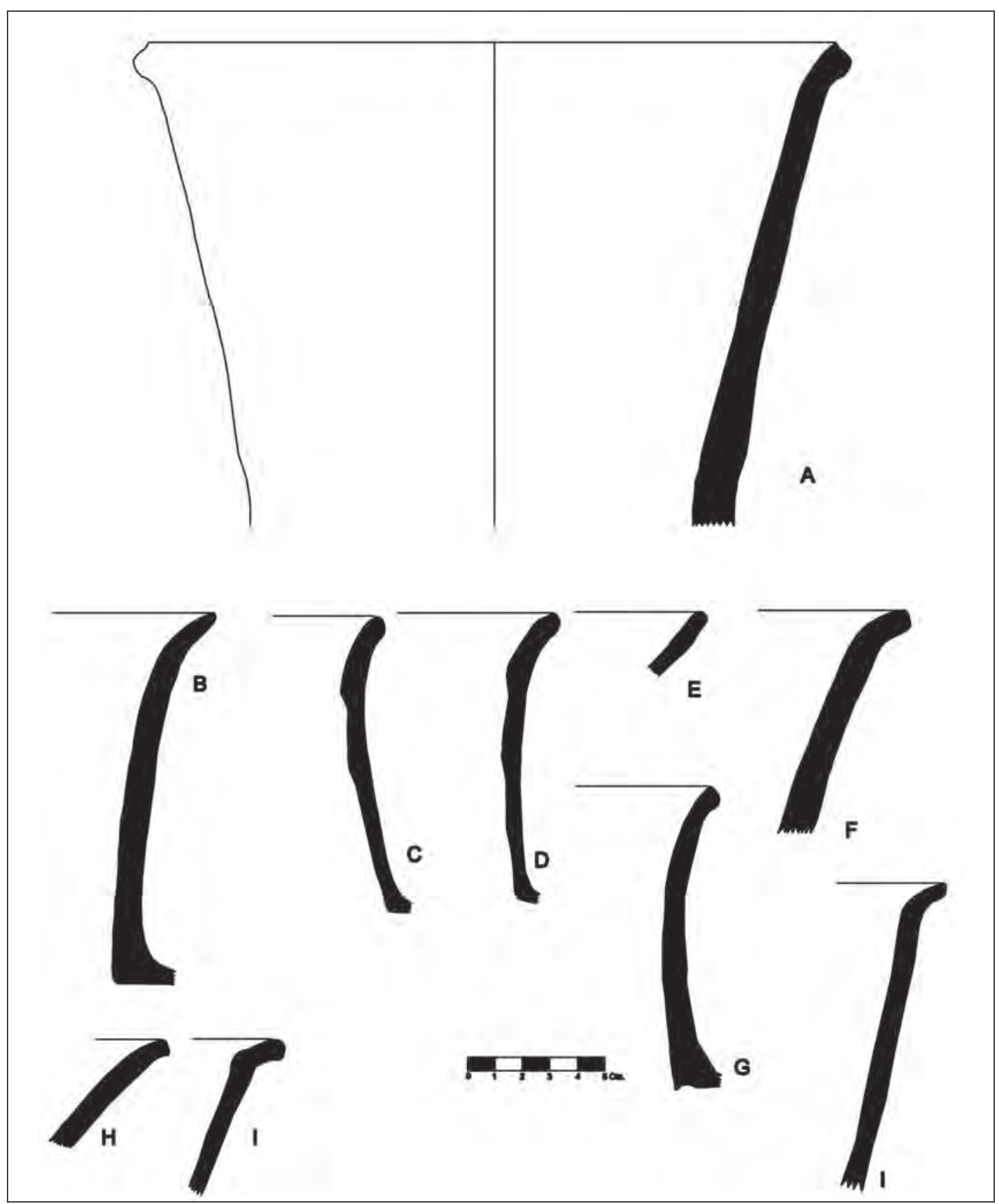

Lámina 7. Cerámica Intermedio Tardío (Runaguanac Llano). A: Cántaro de cuello alto, ligeramente divergente y recto, de paredes medianamente gruesas. (Antahuaya II, Sector B). B: Cántaro de cuello expandido, ligeramente cóncavo. (Nigacho I, Sector A). C: Cántaro de cuello expandido, ligeramente cóncava, pasta delgada. (Cerro Chilco IV). D: Cántaro de cuello extendido, ligeramente cóncavo. E Borde de cántaro, ligeramente evertido. (B2). F: Cántaro de cuello extendido, divergente y recto. (B3). G: Variedad de cuello expandido, recto, vertical; labio reforzado externo con engobe color ocre; pasta muy porosa, y erosionada. Temperantes de granos grandes, como roca molida y cuarzo. (Cerro Chilco IV). H: (B3). I: (Antahuaya II, Sector B). 


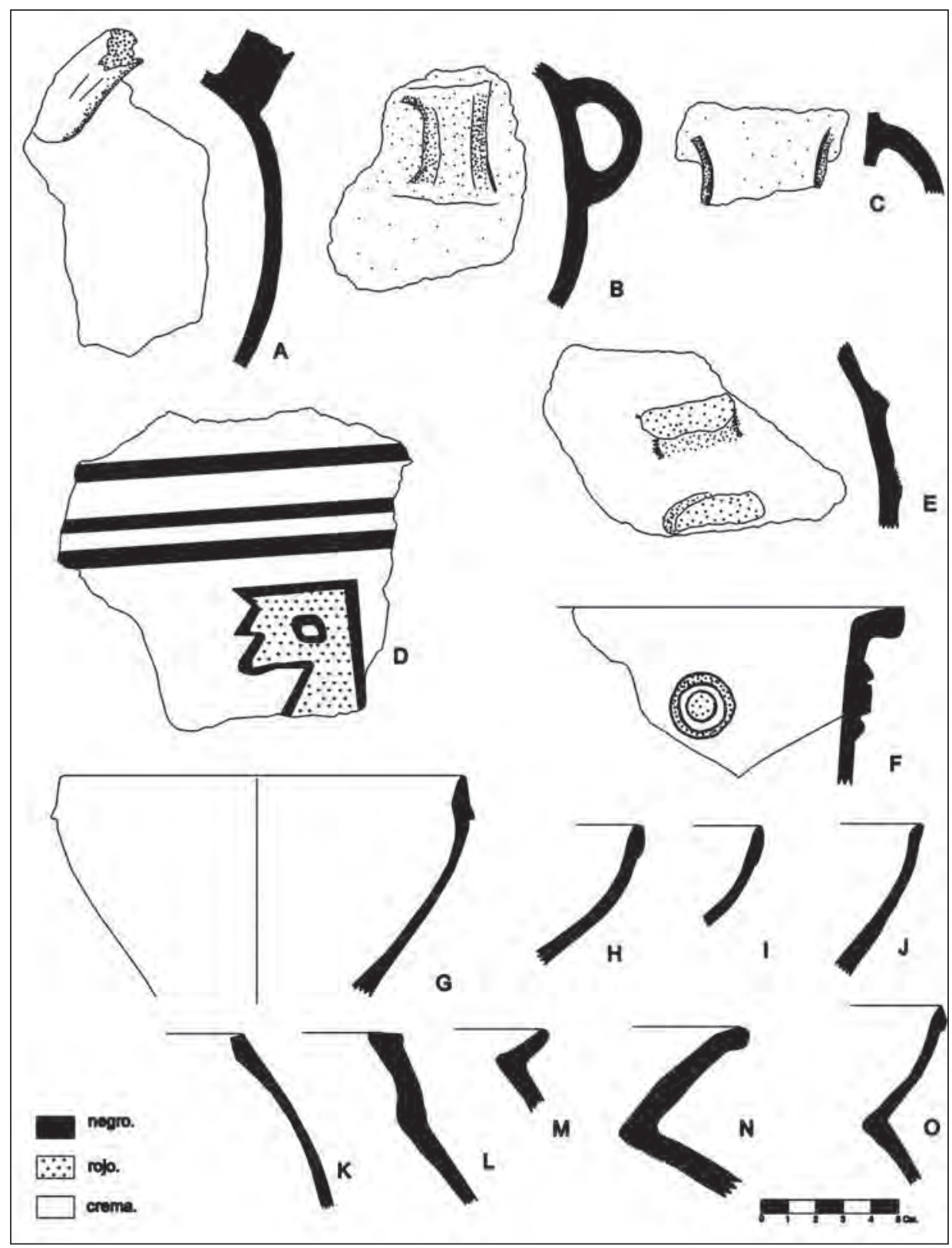

Lámina 8. Cerámica Intermedio Tardío (Runaguanac Llano, Runaguanac Impreso). A: Fragmento de Olla con asa tubular horizontal (B7). B: Fragmento de olla con asa vertical (B7). C: Asa cintada vertical. (B5). D: Fragmento decorado con líneas negras horizontales y geométricas, delineando figuras antropomorfas en color rojo (Cerro Chilco IV). E: Asa pequeña vertical (B11). F: Borde de labio evertido con decoración impresa circular concéntrica de gran tamaño (Cerro Chilco IV). G: Cuenco pequeño, ligeramente alto. (Antahuaya II, Sector B). H: Plato de poca altura, cuerpo convexo. (Nigacho I, Sector A). I: Plato pequeño, de abundantes temperantes de gran tamaño, como roca molida y cuarzo (Nigacho I, sector A). J: igual al anterior. K: Olla sin cuello. (Antahuaya II, Sector B). L: Olla con cuello corto (Nigacho I, sector A). M: Olla de cuello corto ligeramente evertido (Guagil). $\mathrm{N}$ : Olla de cuello ligeramente evertido, de mediana altura (Antahuaya II, Sector B). O: Olla de cuello divergente, ligeramente cóncavo, con labio redondeado y reforzado en el exterior (Antahuaya II, Sector B). 
lación con el amarre de lagunas piedras grandes entre ambos bloques. Algunos muros presentan enlucido, de hasta 0.02 metros de grosor, sin pintura. Los muros presentan hasta dos muros de alto, apreciándose en algunos casos cubiertas de piedras alajadas que se disponen a modo de ménsulas. Los vanos se orientan generalmente hacia el río.

5. La cerámica tardía local, que estamos denominando preliminarmente como "Estilo Runaguanac", presenta una pasta medianamente gruesa, de granos gruesos y temperantes de granos grandes, conformado por roca molida, cuarzo y mica. La cerámica del estilo Runaguanac ha sido clasificada en los siguientes tipos: Runaguanac llano, Runaguanac negro sobre blanco y Runaguanac impreso.

6. Los principales asentamientos políticos Runaguanac son los de cerro Guanaco, Cantagallo, Runaguanac, Guagil, cerro Mal Paso, cerro Manzanilla, cerro Chilco, Quebrada Nigacho, entre otros.

7. Durante el Tawantinsuyu y luego de tenaz resistencia de parte de los locales, el Inca ordena la administración de la población local, re-ocupando antiguos sectores político administrativo de los más importantes asentamientos, como es el caso de Guagil, Cantagallo y Huaca Daris. Se edifican nuevos recintos con elementos arquitectónicos de estilo Tawantinsuyu. Se aprecia una fuerte densidad de material cerámico de estilo Tawantinsuyu Imperial y provincial en los sitios.

\section{Agradecimientos}

Un agradecimiento especial a la Srta. Paola Vidal Pinedo, ex alcaldesa de la Municipalidad Distrital de Pacarán, quien propició y financió los trabajos en este distrito. De igual manera al Bach. en Turismo y Hotelería (UNJFSC-L) Germán Vicente Sánchez, al Bach. Franz Mexico, los entonces estudiantes de arqueología Carlos Barrientos Quilcaro, Favio Ramírez Muñoz, Magali Moreno Rodríguez, Kevin Huánuco Naupay (UNMSM) y Luis Rodrigo Flores Silva (UNT); así como a los estudiantes de Turismo y Hotelería Nelson Emilio Llamoca Huamaní, Sheena Janeth Herrera Canales, Delfina Felícita Hilda Rivadeneyra Candela, Jeholina Diaz Bravo, Sara Aurora Borja Quispe, Juan José Ore Candela (UNJFSCL); quienes participaron en el desarrollo del presente proyecto.

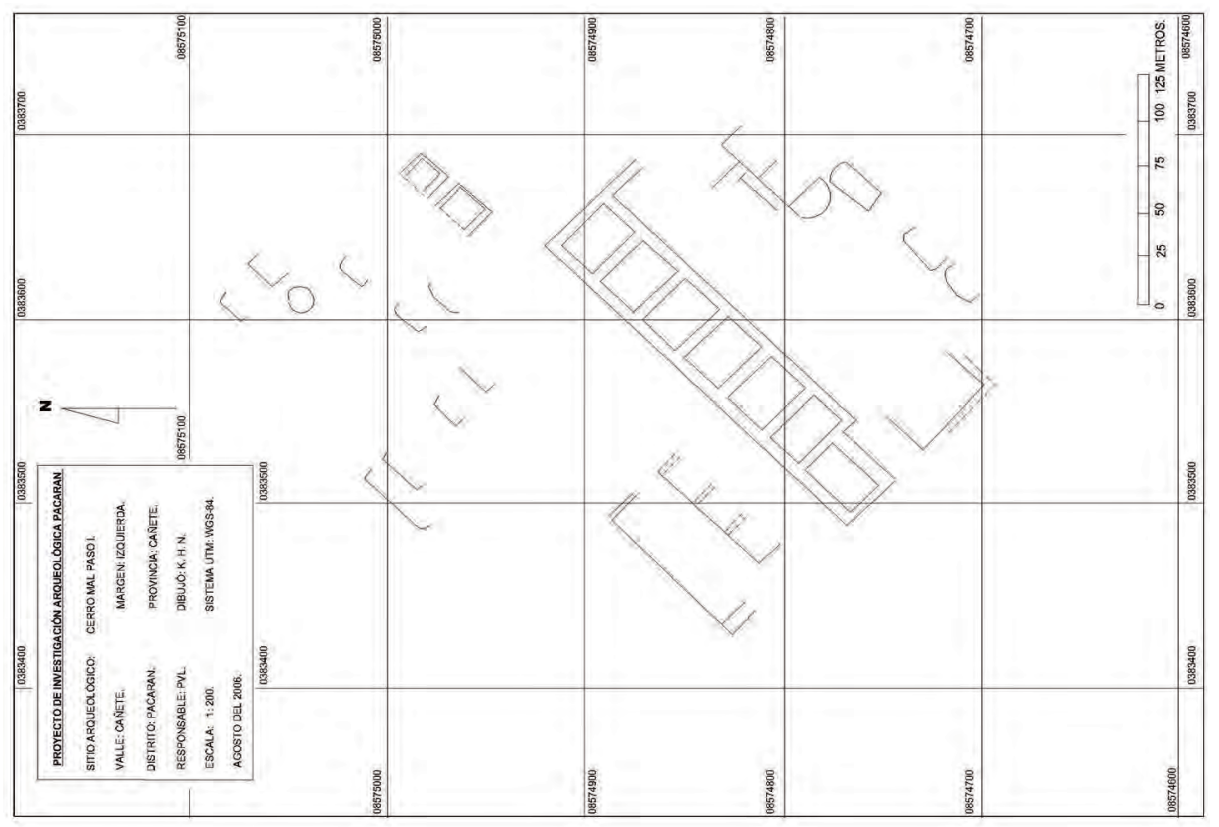

Figura 41: Plano del sitio Cerro Mal Paso I. 


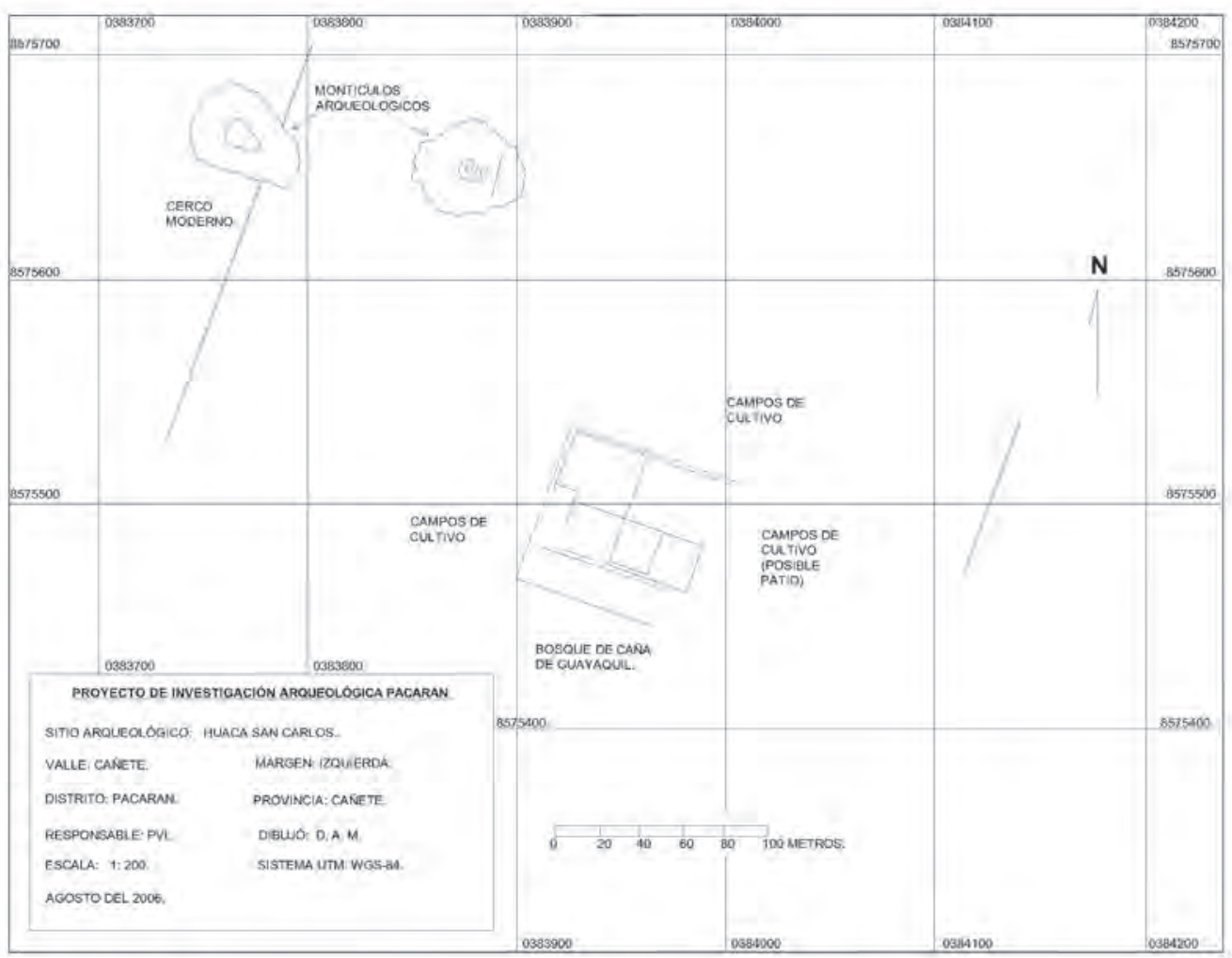

Figura 42: Plano del sitio Huaca San Carlos.

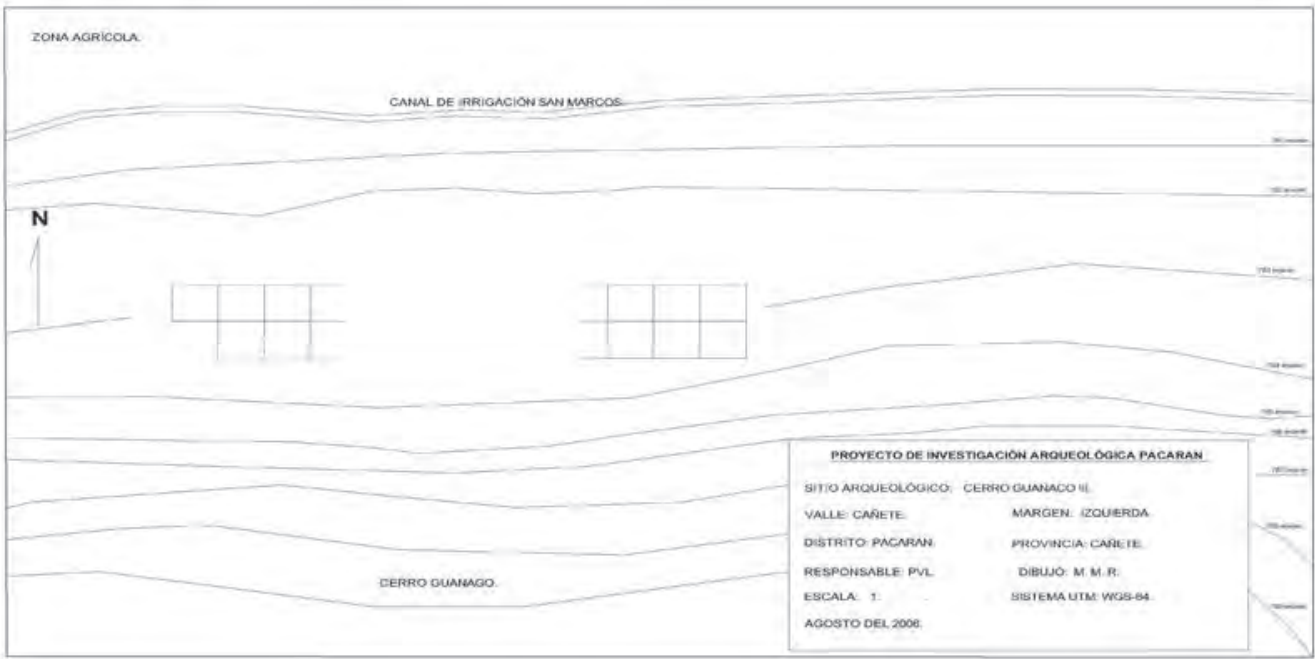

Figura 42: Plano del sitio Cerro Guanaco III. 


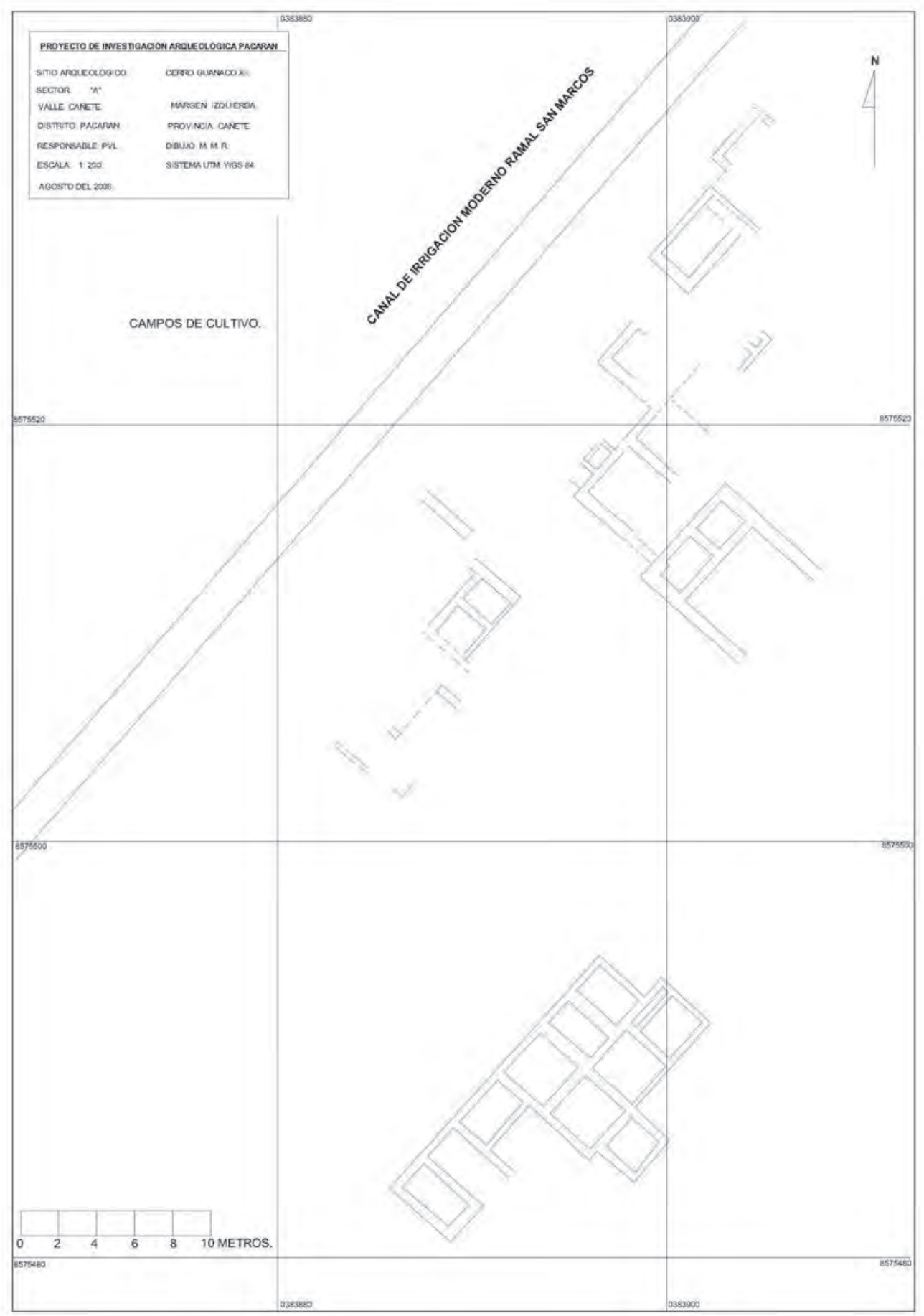

Figura 42: Plano del sitio Cerro Guanaco XII. 


\section{BiBLIOGRAFÍA}

BUENO MENDOZA, Alberto

1982 “Cañete Arqueológico: un futuro provisor". Revista Espacio 12: 64-69. Enero-febrero. Lima.

1992 “Arqueología de Huarochirí”. Huarochirí: ocho mil años de historia. pp. 13-62. Huarochirí: Municipalidad De Santa Eulalia de Acopaya.

2007 “Introducción a la arqueología del distrito de Lunahuaná”. Bitácora de Cañete 2; 5-18. Cañete.

CASAVERDE RÍOS, Guido y Segisfredo LÓPEZ

2011 El camino entre Incawasi de Lunahuaná y la quebrada de Topará. Vía para la conquista Inca del señorío de Guarco. Lima: Ministerio de Cultura.

CIEZA DE LEÓN, Pedro

1943 [1553] El Señorío de los Incas. Buenos Aires.

1986 [1553] Crónica del Perú. Lima: Pontificia Universidad Católica del Perú. Academia Nacional de Historia.

COBO, Bernabé

1964 [1653] Historia del Nuevo Mundo. En: Obras del padre Bernabé Cobo. Biblioteca de autores españoles. XCI-XCII. Madrid.

COELLO RODRÍGUEZ, Antonio

2000 “El camino inca en el distrito de San Damián (Provincia de Huarochirí), Perú." En: L. Herrera y M. Cardale (eds.) Caminos precolombinos. Las vías, los ingenieros y los viajeros, pp. 167-193. Bogotá: Instituto Colombiano de Antropología e Historia.

\section{COLOMA PORCARI, Cesar}

2001 Contribución para un primer inventario general de sitios arqueológicos del Perú. Instituto Nacional de Cultura. Centro Nacional de Información Cultural. Lima, Marzo. 123 p.

DAVILA BRIZEÑO, DIEGO

1586 Descripción y relación de la provincia de los Yauyos toda, Anan Yauyos y Lorin Yauyos, hecha por Diego Davila Brizeño, corregidor de Guarocheri. En: Marcos Jiménez de La Espada. Relaciones Geográficas de Indias.

ECHEVARRÍA, Gori y Enrique RUIZ

2007 "Datos sobre la ocupación Inca en el valle medio de Cañete". Bitácora de Cañete. 2: 49-56. Cañete.

ECHEVARRÍA, Isaak, Gori ECHEVARRÍA LÓPEZ y Enrique RUIZ

2010 “Las quillcas de Pacarán, yunga del río Lunahuaná Cañete. La piedra de los monos". Boletín de la Asociación Peruana de Arte Rupestre (APAR). 4: 58-62. Lima.

FARFAN LOBATON, Carlos

1999 "Investigaciones Arqueológicas en la cordillera de Pariacaca". Actas del XII Congreso Nacional del hombre y la cultura andina, realizado en la ciudad de Huamanga. Universidad Nacional San Cristóbal de Huamanga. pp. 102-107.

HART TERRE, Emilio

1933 “Las ruinas de Incahuasi”. Revista del Museo Nacional. II(1): 101-125. Lima.

HISLOP, John

1986 Incahuasi: el nuevo Cuzco. 76 p.

KAULICKE, Peter

1974-1975 "Reflexiones sobre la arqueología de la Sierra de Lima." En: Boletín de arqueología PUCP 96: 2936. Lima: Instituto Riva-Agüero, PUCP.

MILLA VILLENA, Carlos

1974-1975 "Evidencia de una cultura local la Sierra de Lima” En: Boletín de arqueología PUCP. 96: 53-60. Lima: Instituto Riva-Agüero, PUCP.

RAMIREZ MUÑOZ, Favio

2013 "Sistema de almacenamiento en el valle medio de Cañete y su importancia para el mantenimiento del estado Inka". Arqueología y sociedad 26: 265-288. Lima: UNMSM.

RAMIREZ MUÑOZ, Favio; Guido CASAVERDE RÍOS y Gori ECHEVARRÍA LÓPEZ

2011 "Proyecto de investigación arqueológica Pacarán 01. Valle medio del río Cañete, Lima". Haucaypata. Investigaciones arqueológicas del Tahuantinsuyo 3: 66-68. Lima. 
REY y BASADRE, Ricardo

1898 "Informe presentado por el ingeniero señor Ricardo Rey y Basadre, a la H. Junta Departamental de Lima, sobre los caminos de esta provincia de Yauyos" Boletín de la sociedad geográfica de Lima, Tomo VIII, Jueves 30 de Junio de 1898, № 1, 2 y 3.. Lima. pp. 62-81.

REYES RAMOS, Winston

2002 Historia de los pueblos de Yauyos. Lima. Ediciones R\&R.

ROSTWOROWSKI DE DIEZ CANSECO, María

2004 "Guarco y Lunahuaná: dos señoríos prehispánicos de la costa sur central del Perú". En: Costa Peruana Prehispánica. Obras Completas III. Lima: Instituto de Estudios Peruanos, pp. 83-139.

RUIZ ALBA, Enrique y Gori ECHEVARRÍA LÓPEZ

2003 “Algunos datos sobre la ocupación Inca en el valle de Cañete". Boletín del Museo de Arqueología y Antropología de San Marcos 5(2): 50-55. Lima. UNMSM.

SANTISTEBAN TELLO, Oscar

1958 Ensayo de clasificación de los restos arqueológicos de los Hurin Yauyos. Enero, 7 p.

VAN DALEN LUNA, Pieter

2004 "Los valles de Chancay y Huaura dentro del Tahuantinsuyo" En: Boletín de defensa del patrimonio cultural de los valles de Huaura y Ambar 16, 8 p.

2006 Informe del proyecto de investigación arqueológica de catastro e inventario de sitios arqueológicos en el distrito de Pacarán, provincia de cañete. Municipalidad Distrital de Pacarán. 215 p.

2011 "El Tawantinsuyu en la costa norcentral peruana: valles de Chancay y Huaura". Investigaciones Sociales 27: 77-104. Instituto de Investigaciones Histórico Sociales. Facultad de Ciencias Sociales. UNMSM. Diciembre.

2012 “El Tawantinsuyu en el extremo sur del departamento de Lima (Cuenca del río Cañete)". Cuadernos de campo. Revista oficial de la sociedad de investigación Arqueológica Hallazgos. II(4): 19-47. La Paz - Bolivia.

2013 "Análisis de la costa central peruana descrita por Garcilazo De la Vega en los Comentarios Reales de los Incas". Kullpi. Investigaciones culturales en la provincia de Huaral y el Norte Chico. 6: 149-174. Lima.

VEGA-CENTENO ALZAMORA, Milena

2011 “San Marcos, Huagil y Huaca Daris: Tres sitios Inca de la Huaranca de Pacarán”. Haucaypata. Investigaciones arqueológicas del Tahuantinsuyo. $\mathrm{N}^{\circ}$ 3. Lima, Pp. 66-68.

VILLAR CORDOVA, Pedro

1931 "Las ruinas del departamento de Lima: Contribución al estudio de la arqueología del departamento de Lima". Boletín de la sociedad geográfica de Lima, Tomo XLVIII, segundo trimestre de 1931. Lima, Perú. pp. 117 - 127.

1982 [1935] Arqueología del departamento de Lima. Lima: Ed. Atusparia, 425 p.

WILLIAMS, Carlos y Manuel MERINO

1974 Inventario, catastro y delimitación del patrimonio arqueológico del valle de Cañete. Instituto Nacional de Cultura. Lima, 2 tomos, 175 p. y 179 p. 